\title{
Ring-opening polymerization of $\boldsymbol{\gamma}$-lactones and copolymerization with other cyclic monomers
}

Qilei Song, ${ }^{\dagger, \dagger}$ Chloé Pascouau, ${ }^{\ddagger}$ Junpeng Zhao, ${ }^{\dagger}$ Guangzhao Zhang, ${ }^{\dagger}$ Frédéric Peruch, ${ }^{* *}$ Stéphane Carlotti*

$\dagger$ Faculty of Materials Science and Engineering, South China University of Technology, Guangzhou 510640, People's Republic of China

$\$$ Univ. Bordeaux, CNRS, Bordeaux INP, LCPO, UMR 5629, F-33600, Pessac, France

\begin{abstract}
Triggered by raised environmental awareness and the rising requirements for sustainable polymers such as degradable or recyclable polymers, studies on ring-opening (co)polymerization (ROP/ROCP) of (bio-based) cyclic monomers (e.g., cyclic esters, lactides, epoxides etc.) have been booming in recent years. Renewable five-membered $\gamma$-butyrolactone $(\gamma \mathrm{BL})$ and derivatives would thus be a desirable feedstock to produce poly $(\gamma$-butyrolactone) (P $\gamma \mathrm{BL})$ and different (bio-based) functional polyesters. Their copolymerization with other cyclic monomers could also afford an alternative to tune the properties of the resulting materials. Although $\gamma \mathrm{BL}$ was traditionally regarded "non-polymerizable", some progresses were made recently concerning the ROP/ROCP of $\gamma \mathrm{BL}$ and derivatives. More importantly, some polyesters could be totally depolymerized back to their monomers by thermal or chemical treatment. This review is specially focused on ROP of $\gamma$-lactones and their copolymerization with other cyclic monomers by different catalytic/initiating systems, including Lewis/Brønsted acids, organic bases and alkali metal compounds, organometallic compounds, and cooperative bicomponent catalytic systems. The depolymerization process of some obtained polyesters is also discussed.
\end{abstract}

Keywords: $\quad \gamma$-lactones, polyester, ring-opening (co)polymerization, sustainable polymer

*Corresponding authors: peruch@enscbp.fr, carlotti@enscbp.f 


\section{Contents}

1. Introduction

2. General aspects of ROP of $\gamma$-lactones

$2.1 \gamma$-lactones and comonomers

2.2 Catalytic systems

3. Lewis acid-catalyzed ROP/ROCP of $\gamma$-lactones

4. Brønsted acid-catalyzed ROP/ROCP of $\gamma$-lactones

5. Organic base-catalyzed ROP/ROCP of $\gamma$-lactones

6. Alkali metal compound-catalyzed ROP/ROCP of $\gamma$-lactones

7. Organometallic compound-catalyzed ROP/ROCP of $\gamma$-lactones

8. Dual catalytic system-catalyzed ROP/ROCP of $\gamma$-lactones

9. Other polymerization methodologies for $\gamma$-lactones

10. Thermal or chemical recycling of $\mathrm{P} \gamma \mathrm{BL}$ and other derivatives

11. Conclusion

Acknowledgement

References 


\section{Abbreviations}

\section{$\gamma$-Lactones}

$\begin{array}{ll}\alpha \mathrm{Ac} \gamma \mathrm{BL} & \alpha \text {-Acetyl- } \gamma \text {-butyrolactone } \\ \alpha \mathrm{AL} & \alpha \text {-Angelica lactone (or 5-methyl-2(3H)-furanone) } \\ \beta \mathrm{AL} & \beta \text {-Angelica lactone (or 5-methylfuran-2(5H)-one) } \\ \gamma \mathrm{AMMBL} & \gamma \text {-Allyl- } \gamma \text {-methyl- } \alpha \text {-methylene- } \gamma \text {-butyrolactone } \\ \alpha \mathrm{Br} \gamma \mathrm{BL} & \alpha \text {-Bromo- } \gamma \text {-butyrolactone } \\ \gamma \mathrm{BL} & \gamma \text {-Butyrolactone } \\ \mathrm{BBL} & \text { Bicyclic bis }(\gamma \text {-butyrolactone) } \\ \mathrm{BBL} 8 & 2,8 \text {-Dioxa-1-isopropenylbicyclo[3.3.0]octane- } \\ & 3,7 \text {-dione } \\ \gamma \mathrm{CL} & \gamma \text {-Caprolactone } \\ 4,5-\mathrm{C} 6 \mathrm{~L} & 4,5 \text {-cis Cyclohexyl-ring-fused } \gamma \text {-butyrolactone } \\ \text { rac-CBL } & \text { racemic 3,4-Cyclohexyl-ring-fused } \gamma \text { - } \\ & \text { butyrolactone } \\ \text { DAMBL } & \gamma \text {-Diallyl- } \alpha \text {-methylene- } \gamma \text {-butyrolactone } \\ \text { FO } & 2 \text { (5H)-Furanone } \\ \beta \mathrm{HMBL} & \text { Tulipalin B or } \beta \text {-hydroxy- } \alpha \text {-methylene- } \gamma \text { - } \\ & \text { butyrolactone } \\ 3 \text {-HMFO } & 3 \text {-(Hydroxymethyl) furan-2(5H)-one } \\ 3 \text {-MFO } & \text { 3-Methylfuran-2(5H)-one } \\ \alpha \mathrm{MBL} & \text { Tulipalin A or } \alpha \text {-methylene- } \gamma \text {-butyrolactone }\end{array}$

$\beta \mathrm{MMBL}$

$\gamma \mathrm{MBL}$

$\gamma \mathrm{MMBL}$

$\gamma \mathrm{Me}_{2} \mathrm{MBL}$

$\alpha \mathrm{OH} \gamma \mathrm{BL}$

$\alpha \mathrm{OH} \beta \mathrm{Me}_{2} \gamma \mathrm{BL}$

(R)- $\gamma \mathrm{VL}$

S-BBL

SBL

SBBL

3,4-T6L

4,5-T6L

$\gamma \mathrm{VL}$

VMBL

$\gamma$ VMMBL

VMMBL

\section{Comonomers}

$\begin{array}{ll}\text { AOMEC } & \text { 2-Allyloxymethyl-2-ethyltrimethylene carbonate } \\ \beta \text { BL } & \beta \text {-Butyrolactone } \\ t \text {-BuGE } & \text { tert-Butyl glycidyl ether } \\ \text { BCMO } & \text { 3,3-Bis(chloromethyl)oxetane } \\ \text { DGEBA } & \text { Diglycidyl ether bisphenol A } \\ \text { DGEBS } & \text { Diglycidyl ether bisphenol S } \\ \varepsilon C L & \varepsilon \text {-Caprolactone } \\ \mathrm{CHO} & \text { Cyclohexene oxide } \\ \mathrm{CO}_{2} & \text { Carbon dioxide } \\ \mathrm{EC} & \text { Ethylene carbonate } \\ \mathrm{GP} & \text { Glycidyl pivalate } \\ \mathrm{GPE} & \text { Glycidyl phenyl ether }\end{array}$

$\begin{array}{ll}\text { GME } & \text { Glycidyl methyl ether } \\ \text { HO } & \text { 1-Hexene oxide } \\ \text { LLA } & \text { L-Lactide } \\ \text { MMA } & \text { Methyl methacrylate } \\ \text { PO } & \text { Propylene oxide } \\ \text { PC } & \text { Propylene carbonate } \\ \beta \text { PL } & \beta \text {-Propiolactone } \\ \omega \text { PDL } & \omega \text {-Pentadecalactone } \\ \text { SO } & \text { Styrene oxide } \\ \text { TMC } & \text { Trimethylene carbonate } \\ \text { TeU } & \text { Tetramethylene urea } \\ \delta \text { VL } & \delta \text {-Valerolactone }\end{array}$

\begin{tabular}{|c|c|}
\hline Polymers & \\
\hline $\mathrm{P} \alpha \mathrm{AL}$ & $\operatorname{Poly}(\alpha$-angelica lactone $)$ \\
\hline $\mathrm{P}(\alpha \mathrm{Ac} \gamma \mathrm{BL})$ & $\operatorname{Poly}(\alpha$-acetyl- $\gamma$-butyrolactone $)$ \\
\hline $\mathrm{P} \gamma \mathrm{BL}$ & $\operatorname{Poly}(\gamma$-butyrolactone $)$ \\
\hline $\mathrm{P} \gamma \mathrm{BLL} 1$ & $\begin{array}{l}\text { Linear poly( } \gamma \text {-butyrolactone) with acylated lactone } / \mathrm{H} \\
\text { chain ends }\end{array}$ \\
\hline $\mathrm{P} \gamma \mathrm{BLL2}$ & $\begin{array}{l}\text { Linear poly }(\gamma \text {-butyrolactone }) \text { with } \mathrm{BnO} / \mathrm{H} \text { chain } \\
\text { ends }\end{array}$ \\
\hline $\mathrm{P} \gamma \mathrm{BLL} 3$ & $\begin{array}{l}\text { Linear poly }(\gamma \text {-butyrolactone }) \text { with } \mathrm{MeO} / \mathrm{H} \text { chain } \\
\text { ends }\end{array}$ \\
\hline $\mathrm{P} \gamma \mathrm{BL}$ & Cyclic poly( $\gamma$-butyrolactone $)$ \\
\hline PCL & $\operatorname{Poly}(\varepsilon$-caprolactone $)$ \\
\hline$h t$-PCBL & $\begin{array}{l}\text { heterotactic Poly(3,4-cyclohexyl-ring-fused } \gamma \text { - } \\
\text { butyrolactone) }\end{array}$ \\
\hline it-PCBL & $\begin{array}{l}\text { isotactic Poly }(3,4 \text {-cyclohexyl-ring-fused } \gamma \text { - } \\
\text { butyrolactone) }\end{array}$ \\
\hline PFO & Poly(2(5H)-furanone) \\
\hline
\end{tabular}

PGA

PGM

PGMS

P4HB

$\mathrm{P}(\alpha \mathrm{MBL})_{\mathrm{VAP}}$

$\mathrm{P}(\alpha \mathrm{MBL}) \mathrm{CLP}$

$\mathrm{P}(\alpha \mathrm{MBL})$ ROP

$\mathrm{P}(3,4-\mathrm{T} 6 \mathrm{~L})$

$\mathrm{P}(4,5-\mathrm{T} 6 \mathrm{~L})$

PVL
$\beta$-Methyl- $\alpha$-methylene- $\gamma$-butyrolactone $\alpha$-Methyl- $\gamma$-butyrolactone $\gamma$-Methyl- $\alpha$-methylene- $\gamma$-butyrolactone $\alpha$-Methylene- $\gamma, \gamma$-dimethyl- $\gamma$-butyrolactone $\alpha$-Hydroxy- $\gamma$-butyrolactone

$\alpha$-Hydroxy- $\beta, \beta$-dimethyl- $\gamma$-butyrolactone

(R)- $\gamma$-Valerolactone

Bicyclic bis $(\gamma$-butyrolactone $)$ derivatives bearing sulfide moieties

Spirocyclic ( $\gamma$-butyrolactone)

Spirocyclic bis $(\gamma$-butyrolactone $)$

3,4-trans Cyclohexyl-ring-fused $\gamma$-butyrolactone 4,5-trans Cyclohexyl-ring-fused $\gamma$-butyrolactone (or trans-hexahydro-2(3H)-benzofuranone)

$\gamma$-Valerolactone

$\gamma$-Vinyl- $\alpha$-methylene- $\gamma$-butyrolactone $\gamma$-Vinyl- $\gamma$-methyl- $\alpha$-methylene- $\gamma$-butyrolactone $\gamma$-Vinyl- $\beta$-methyl- $\alpha$-methylene- $\gamma$-butyrolactone 


\section{Catalysts/Initiators}

\begin{tabular}{|c|c|c|c|}
\hline $\mathrm{AlEt}_{3}-\mathrm{H}_{2} \mathrm{O}$ & Triethylaluminium-water & $\mathrm{I}^{t} \mathrm{Bu}$ & 1,3-Di-tert-butylimidazol-2-ylidene \\
\hline $\mathrm{Al}\left(\mathrm{O}^{i} \mathrm{Pr}\right)_{3}$ & Aluminium isopropoxide & IMes & 1,3-Bis-(2,4,6-trimethylphenyl)imidazol-2-ylidene \\
\hline $\mathrm{BDM}$ & 1,4-Benzenedimethanol & $I^{i} \operatorname{Pr}$ & 1,3-Bis(isopropyl)-4,5(dimethyl)imidazol-2-ylidene \\
\hline \multirow[t]{2}{*}{ BEMP } & 2-tert-Butylimino-2-diethylamino-1,3- & $\mathrm{K}_{2} \mathrm{CO}_{3}$ & Potassium carbonate \\
\hline & dimethylperhydro-1,3,2-diazaphosphorine & $\mathrm{KH}$ & Potassium hydride \\
\hline $\mathrm{BF}_{3} \cdot \mathrm{Et}_{2} \mathrm{O}$ & Trifluoride diethyl etherate & $\mathrm{KOH}$ & Potassium hydroxide \\
\hline $\mathrm{BF}_{3} \cdot \mathrm{EtNH}_{2}$ & Boron trifluoride ethylamine complex & $\mathrm{LaCl}_{3}$ & Lanthanum(III) chloride \\
\hline $\mathrm{BF}_{3} \bullet 4 \mathrm{MA}$ & Boron trifluoride $p$-methoxyaniline complex & $\mathrm{La}\left[\mathrm{N}\left(\mathrm{SiMe}_{3}\right)_{2}\right]_{3}$ & 3 (or La) $\operatorname{Tri}[N, N$-bis(trimethylsilyl)amide $]$ \\
\hline \multirow[t]{2}{*}{$\mathrm{Bi}(\mathrm{OTf})_{3}$} & Bismuth(III) trifluoro & & lanthanum(Ш) \\
\hline & methanesulfonate & {$\left[\mathrm{La}(\mathrm{OBn})_{3}\right]_{x}$} & Obtained by the stoichiometric reaction of $\mathrm{La}$ and \\
\hline${ }^{n} \mathrm{Bu} 4 \mathrm{NBr}$ & Tetrabutylammonium bromide & & $\mathrm{BnOH}$ \\
\hline$t$-BuOK & Potassium tert-butoxide & $\mathrm{La}(\mathrm{OTf})_{3}$ & Lanthanum(III) trifluoromethanesulfonate \\
\hline$n$-BuLi & $n$-Butyl lithium & LDA & Diisopropylamide \\
\hline$n-\mathrm{Bu}_{2} \mathrm{Mg}$ & Di- $n$-butylmagnesium & $\mathrm{LiCl}$ & Lithium chloride \\
\hline$n$-BuEtMg & $n$-Butylethylmagnesium & LiX & Lithium halides \\
\hline$n$-BuONa & Sodium $n$-butoxide & $\mathrm{Ln}\left[\mathrm{N}\left(\mathrm{SiMe}_{3}\right)_{2}\right]_{3}$ & 3 Lanthanide analogues $(\mathrm{Ln}=\mathrm{Y}, \mathrm{Sm})$ \\
\hline$t-\mathrm{BuP}_{1}$ & tert-Butylimino-tris(dimethylamino)phosphorane & $\mathrm{MeLi}$ & Methyllithium \\
\hline \multirow[t]{2}{*}{$t-\mathrm{BuP}_{2}$} & 1-tert-Butyl-2,2,4,4,4-pentakis(dimethylamino)- & $\mathrm{Me}_{6}$ TREN & Tris[2-(dimethylamino) \\
\hline & $2 \lambda^{5}, 4 \lambda^{5}$-catenadi(phosphazene) & & ethyl]amine \\
\hline \multirow[t]{3}{*}{$t-\mathrm{BuP}_{4}$} & 1-tert-Butyl-4,4,4-tris(dimethylamino)-2,2-bis- & $\mathrm{MgCl}_{2}$ & Magnesium chloride \\
\hline & [tris(dimethylamino)phosphoranylidenamino]- & 1-MI & 1-Methylimidazole \\
\hline & $2 \lambda^{5}, 4 \lambda^{5}$-catenadi(phosphazene) & MSA & Methanesulfonic acid \\
\hline$n-\mathrm{Bu}_{2} \mathrm{Sn}(\mathrm{OMe})_{2} \mathrm{I}$ & Dibutyldimethoxytin & $\mathrm{MtOMe}$ & Sodium or potassium methoxides \\
\hline \multirow{2}{*}{ Cyclic tin alkoxid } & de $1,1,6,6$-Tetra- $n$-butyl-1,6-distanna-2,5,7,10- & $\mathrm{MtX}$ & Metal halides \\
\hline & tetraoxacyclo-decane & $\mathrm{NaH}$ & Sodium hydride \\
\hline СТРВ & Cyclic trimeric phosphazene base & $\mathrm{NaOH}$ & Sodium hydroxide \\
\hline DABCO & 1,4-Diazabicyclo[2.2.2] octane & NEMO & Non-eutectic mixture of organocatalysts \\
\hline \multirow[t]{2}{*}{ DBU } & 1,8-Diazabicyclo[5.4.0] & & $(\mathrm{MSA} / \mathrm{TBD}=3 / 1)$ \\
\hline & undec-7-ene & $\mathrm{NHC}$ & $N$-Heterocyclic carbene \\
\hline DMAP & $N, N$-Dimethyl-4-aminopyridine & NHO & $N$-Heterocyclic olefin \\
\hline DPP & Diphenyl phosphate & $\mathrm{NHO} 3$ & 1,3-Dimethyl-2-(1- \\
\hline $\mathrm{Et}_{2} \mathrm{AlCl}$ & Diethylaluminum chloride & & methylethylidene)tetrahydropyrimidine \\
\hline $\mathrm{Et}_{3} \mathrm{Al}_{2} \mathrm{Cl}_{3}$ & Ethylaluminum sesquichloride & $\mathrm{NHO} 4$ & 2-Isopropylidene-1,3,4,5-tetramethylimidazoline \\
\hline $\mathrm{Et}_{3} \mathrm{~N}$ & Triethylamine & NHO6 & 1,3-Dimesityl-2-methylidene-tetrahydropyrimidine \\
\hline $\mathrm{Et}_{3} \mathrm{O}\left(\mathrm{BF}_{4}\right)$ & Triethyloxonium tetrafluoroborate & NHO7 & 1,3,4,5-Tetramethyl-2-methyleneimidazoline \\
\hline $\mathrm{FeCl}_{3}$ & Iron(III) chloride & PBM & Polymer supported bimetallic complexes in the form of \\
\hline $\mathrm{FSO}_{3} \mathrm{H}$ & Fluorosulfonic acid & & $\mathrm{P}-\mathrm{Zn}[\mathrm{Fe}(\mathrm{CN}) 6]_{a} \mathrm{Cl}_{2-3 a}\left(\mathrm{H}_{2} \mathrm{O}\right)_{b}$, where $\mathrm{P}$ is a polyether \\
\hline HAPENAIO $^{i} \operatorname{Pr}$ & Aluminum Schiff's base complex & & chelating agent, $a \approx 0.5$ and $b \approx 0.76$ \\
\hline $\mathrm{HBF}_{4} \cdot \mathrm{Et}_{2} \mathrm{O}$ & Tetrafluoroboric acid diethyl ether complex & $\mathrm{P}^{n} \mathrm{Bu} 3$ & Tri- $n$-butylphosphine \\
\hline $\mathrm{HCl} \cdot \mathrm{Et}_{2} \mathrm{O}$ & Hydrochloric acid in diethyl ether & $\mathrm{PCy}_{3}$ & Tricyclohexylphosphine \\
\hline HO-PEG-OH & Dihydroxy-terminated poly(ethylene glycol) & $\mathrm{PPh}_{3}$ & Triphenylphosphine \\
\hline $\mathrm{H}_{3} \mathrm{PO}_{4}$ & Phosphoric acid & PEG-OH & Monohydroxy-terminated poly(ethylene glycol) \\
\hline
\end{tabular}


$\mathrm{Ph}_{2} \mathrm{CHCH}_{2} \mathrm{OH}$ 2,2-Diphenylethanol

$\mathrm{PhCH}_{2} \mathrm{OH}$ (or BnOH) Benzyl alcohol

$\mathrm{Ph}_{2} \mathrm{CHOH}$ Diphenylmethanol

$n$-PrONa Sodium $n$-propoxide

$i$-PrONa Sodium isopropoxide

$i$-PrOH Isopropanol

$\mathrm{Ph}_{4} \mathrm{Sn} \quad$ Tetraphenyl tin

$\mathrm{R}_{3} \mathrm{~N} \quad \mathrm{~N}, \mathrm{~N}$-Dimethylcyclohexylamine

SalenCo ${ }^{I I I} \mathrm{X} \quad$ Salen $=N, N$-bis(3,5-di-tert-butylsalicylidene)ethylenediimine, $X=2$,4-dinitrophenoxide

$\mathrm{SbF}_{3}$

Antimony(III) fluoride

$\mathrm{Sc}(\mathrm{OTf})_{3} \quad$ Scandium(III) trifluoromethanesulfonate

$\mathrm{SmI}_{2} / \mathrm{Sm} \quad$ Samarium(II) iodide-based complex

$\mathrm{Sm}(\mathrm{OAr})_{2}(\mathrm{THF})_{3} \quad$ Samarium(II) aryloxide complex

$\mathrm{SnCl}_{4} \quad$ Tin(IV) chloride

$\mathrm{SnCl}_{2} \cdot 2 \mathrm{H}_{2} \mathrm{O} \quad$ Tin(II) chloride dihydrate

$\mathrm{Sn}(\mathrm{Oct})_{2} \quad \operatorname{Tin}($ II $)$ 2-ethylhexanoate

TBD 1,5,7-Triazabicyclo[4.4.0]dec-5-ene

TfOH Trifluoromethanesulfonic acid

$p$-TfOH $\quad p$-Toluenesulfonic acid

TfOMe Methyl trifluoromethanesulfonate

TPT
$\mathrm{YCl}_{3}$

$\mathrm{Y}-\mathrm{O}^{i} \mathrm{Pr}$ ylidene
Thiourea

1,3-Diisopropyl-2-thiourea

1-[3,5-Bis(trifluoromethyl) phenyl]-3-cyclohexylthiourea

1-Cyclohexyl-3-phenyl-urea

1-Cyclohexyl-3-(4-methoxyphenyl)-urea

1,3-Diphenylurea

1-[3,5-Bis(trifluoromethyl) phenyl]-3-phenyl-urea

1-Cyclohexyl-3-(4-(trifluoromethyl)phenyl)-urea

1-(4-Chlorophenyl)-3-cyclohexyl-urea

1,3-Bis(3,5-bis(trifluoromethyl)phenyl)-urea

Discrete single-site yttrium complex

Tetradentate amino-bisphenolate yttrium alkyl

complex

Bisphenolate yttrium amido complex with $*-\mathrm{CMePh}_{2}$ substituents

Bisphenolate yttrium amido complex with trityl substituents

Bisphenolate yttrium amido complex

Ytterbium(III) trifluoromethanesulfonate

Yttrium(III) chloride

Obtained by the stoichiometric reaction of either Y1a or Y2 with 2-propanol

Zn1 2,6-Diisopropylphenylsubstituted $\beta$-diiminate zinc isopropoxide complex (or $(\mathrm{BDI}) \mathrm{ZnO}^{i} \mathrm{Pr}$ )

$\mathrm{ZnCl}_{2} \quad$ Zinc chloride

$\mathrm{ZnEt}_{2}-\mathrm{H}_{2} \mathrm{O} \quad$ Diethylzinc associated with water

$\mathrm{ZnI}_{2} \quad$ Zinc iodide 


\section{Introduction}

Aliphatic (co)polyesters with biodegradability and biocompatibility, due to their widespread applications, have been the subject of increasing interest [1-3]. There are two pathways to produce such polymers. First, the polycondensation of diols with diacids or diesters or of hydroxyesters or hydroxyacids. This usually needs high energyconsumption and is also not atom-efficient as side-products are released (water, alcohols, etc.). Second, ring-opening polymerization (ROP) of the corresponding cyclic esters provides an interesting alternative. The latter was demonstrated to be a powerful strategy to synthesize (co)polyesters containing different macromolecular architectures in a controlled/living manner [4-7]. Among the manifold lactones used, the fivemembered $\gamma$-butyrolactone $(\gamma \mathrm{BL})$ is a renewable monomer derived from succinic acid, which was ranked as a top biomass-derived compound $[8,9]$. The ROP of $\gamma \mathrm{BL}$ offers a feasible method to produce poly $(\gamma$-butyrolactone) $(\mathrm{P} \gamma \mathrm{BL})$, a structural equivalent of poly(4-hydroxybutyrate) (P4HB), which can be obtained from a bacterial fermentation process [10].

Different from the commonly employed lactones with high ring strain, $\gamma \mathrm{BL}$ was traditionally regarded as "non-polymerizable", resulting from the low strain energy of five-membered ring, so that the negative change of enthalpy $\left(\Delta H_{\mathrm{p}}\right)$ on ring-opening is too small to overcome a large negative entropic change $\left(\Delta S_{\mathrm{p}}\right)$ in a ROP [11-15]. Thus, the ceiling temperature and concentration of each $\gamma$-lactone should be considered to obtain a thermodynamically-favored polymerization. Tracing back to the $1930 \mathrm{~s}-1950 \mathrm{~s}$, the first attempts to polymerize $\gamma \mathrm{BL}$ were unsuccessful $[16,17]$. Later $(1960 \mathrm{~s})$, only 
oligomers of $\mathrm{P} \gamma \mathrm{BL}$ were synthesized under extreme reaction conditions (e.g., 20,000 atm, $160{ }^{\circ} \mathrm{C}$ ) [18]. Therefore, synthesis of $\mathrm{P} \gamma \mathrm{BL}$ with high molar mass under mild conditions remained a challenge in polymer synthesis for several decades. In comparison, the ROP of $\gamma \mathrm{BL}$ derivatives such as $\alpha$-methylene- $\gamma$-butyrolactones (or tulipalin $\mathrm{A}, \alpha \mathrm{MBL}), \alpha$-angelica lactone ( $\alpha \mathrm{AL})$ and $\beta$-angelica lactone $(\beta \mathrm{AL})$ affords the formation of unsaturated polyesters, which could undergo post-functionalization [19]. However, the investigation of such process was limited due to the presence of additional functional groups (i.e., endocyclic or exocyclic $\mathrm{C}=\mathrm{C}$ ) that may also be polymerized by vinyl-addition route [20]. Ring-opening copolymerization (ROCP) of $\gamma$-lactones or its derivatives with other cyclic monomers provides a bypass to circumvent the difficulties in their homopolymerization. The comonomers may be lactones, cyclic carbonates, and epoxides as well as some polymers. Examples of successful applications of this process will be discussed in this review.

Noticeably, a breakthrough was made in the ROP of $\gamma \mathrm{BL}$ in recent years. The polymerization was carried out at low temperatures (below the ceiling temperature, $T_{\mathrm{c}}$ ) and high monomer concentrations, yielding linear/cyclic $\mathrm{P} \gamma \mathrm{BLs}$ with high molar masses [21-26]. The recent development of powerful catalytic/initiating systems also allowed the ROP of $\gamma \mathrm{BL}$ derivatives as well as their copolymerization. The thermal or chemical depolymerization of some resultant polyesters back to the corresponding monomer was also achieved, which not only highlights the advantage of these materials, but also satisfies the rising demand of sustainable/recyclable polymers [27-36].

Up until now, several reviews were published focusing on the ROP of $\gamma \mathrm{BL}$ or its 
derivatives $[10,37-40]$. In this review, we intend to summarize and comment on the previous and recent studies on ROP/ROCP of $\gamma \mathrm{BL}$ and derivatives by different polymerization mechanisms including cationic, anionic, coordination-insertion mechanisms and related ones. The various catalytic systems described in the literatures will be presented, and the recent progresses will be emphasized. Noticeably, only the polymerization of $\gamma \mathrm{BL}$ and derivatives via ring-opening is involved here, and other polymerization methods such as group-transfer polymerization (GTP), ring-opening olefin metathesis polymerization (ROMP), radical polymerization, vinyl-addition polymerization (VAP) or frustrated Lewis pair polymerization (FLP) through the $\mathrm{C}=\mathrm{C}$ of $\gamma \mathrm{BL}$ derivatives are not discussed [41-43]. In addition, only the derivatives containing $\gamma \mathrm{BL}$ ring will be discussed. Other five-membered lactone derivatives such as $\gamma$-thiobutyrolactone [44, 45], $\gamma$-thionobutyrolactone [46], and $\gamma$-selenobutyrolactone $[47,48]$ are also excluded herein because of their different polymerizability, due to the variant hetero atoms contained in the ring.

2. General aspects of ROP of $\gamma$-lactones

\section{$2.1 \gamma$-lactones and comonomers}

Figure 1 lists $\gamma \mathrm{BL}$ and representative derivatives that were studied for ROP/ROCP (except for the blue ones which are still unsuccessful in this chemistry). Functional $\gamma \mathrm{BL}$ derivatives such as $\alpha \mathrm{MBL}, \alpha \mathrm{AL}$ and $\beta \mathrm{AL}$ can be produced from renewable resources. For instance, $\alpha \mathrm{MBL}$ can be isolated from the tulips, while $\alpha \mathrm{AL}, \beta \mathrm{AL}$ can be derived from levulinic acid [49]. The ROP/ROCP of these exocyclic/endocyclic $\mathrm{C}=\mathrm{C}$ contained 
$\gamma \mathrm{BL}$ derivatives can afford the formation of unsaturated (co)polyesters. On the other hand, the polymerizability of $\gamma \mathrm{BL}$ could be highly improved by the presence of proper substitutes at suitable positions. Therefore, the polymerization of spirocyclic $(\gamma$ butyrolactone) or cyclohexyl-ring-fused $\gamma \mathrm{BL}$ was achieved under mild conditions.

In addition, copolymerization of $\gamma \mathrm{BL}$ or its derivatives with other cyclic monomers enriches the diversity of obtained polymer structures. Figure 2 lists the comonomers used in copolymerization with $\gamma \mathrm{BL} /$ its derivatives.

$\gamma$-Butvrolactones

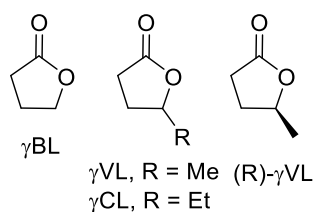

$\underline{\alpha-M e t h v l e n e-\gamma-\text { butvrolactones }}$

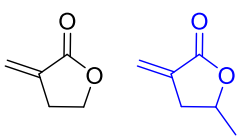

$\alpha \mathrm{MBL}$<smiles>C=C1C(=O)OCC1C</smiles>

BMMBL<smiles>C=C1CC(C)(C)OC1=O</smiles>

$\gamma \mathrm{Me}_{2} \mathrm{MBL}$

\section{$\underline{\alpha-S u b s t i t u e n t-\gamma \text {-butyrolactones }}$}

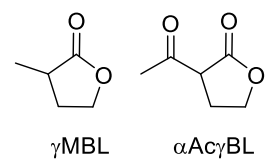<smiles>O=C1OCC(Br)C1OCCO</smiles><smiles>CCCC1(C)COC(=O)C1O</smiles><smiles>C=CC1CC(=C)C(=O)O1</smiles>

Bicvclobis ( $\gamma$-butvrolactone)s

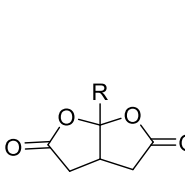

BBL

$$
\begin{aligned}
& \text { BBL1, } \mathrm{R}=\mathrm{Me} \\
& \text { BBL2, } \mathrm{R}=\mathrm{Et} \\
& \text { BBL3, } \mathrm{R}=\mathrm{Pr} \\
& \text { BBL4, } \mathrm{R}={ }^{i} \mathrm{Pr} \\
& \text { BBL5, } \mathrm{R}=\mathrm{Ph} \\
& \text { BBL6, } \mathrm{R}=\mathrm{C}_{6} \mathrm{H}_{2}(\mathrm{OMe})_{3} \\
& \text { BBL7, } \mathrm{R}=\mathrm{CH}_{2} \mathrm{OPh} \\
& \text { BBL8, } \mathrm{R}=\mathrm{CH}_{2} \mathrm{Cl} \\
& \text { BBL9, } \mathrm{R}=\mathrm{CH}\left(\mathrm{CH}_{3}\right)=\mathrm{CH}_{2}
\end{aligned}
$$

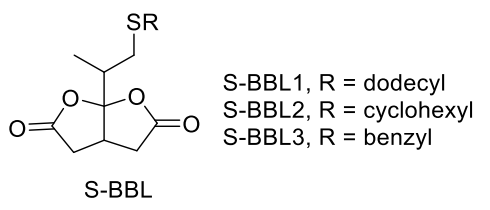

\section{Unsaturated $y$-lactones}

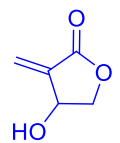

$\beta \mathrm{HMBL}$

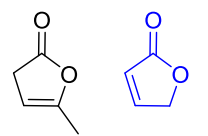

$\alpha A L \quad F O$

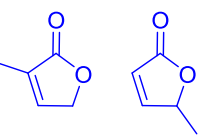

3-MFO

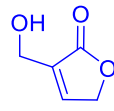

3-HMFO

Crclohexvl-fused $x$-butvrolactones
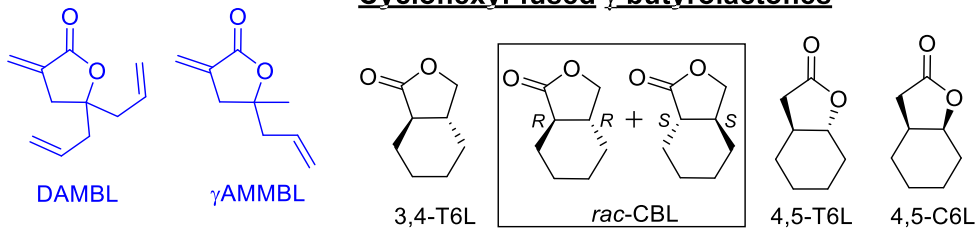

Spirocvclic bis $(\gamma$-butvrolactone)s

Spirocyclic $\gamma$-butyrolactone

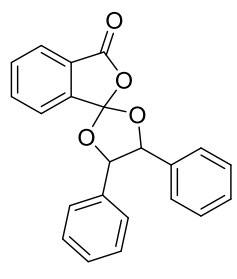

SBL

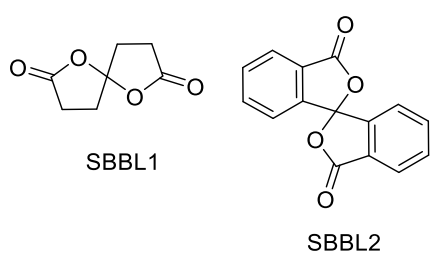


Fig. 1. $\gamma$-lactones (those in blue were not polymerized in ring-opening pathway).

\section{Cyclic esters}<smiles>O=C1CC(CC2CC2)C1</smiles>
$\beta P L \quad \beta B L$<smiles>O=C1COC(=O)CO1</smiles>

GA<smiles>CC1OC(=O)C(C)OC1=O</smiles>
LLA<smiles>O=C1CCCCO1</smiles>

$\delta \mathrm{VL}$<smiles>O=C1CCCCCO1</smiles>

$\varepsilon \mathrm{CL}$

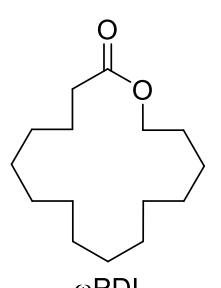

$\omega \mathrm{PDL}$

\section{Cyclic ethers}<smiles>OCCCC1OC1CCCC(=[Se])c1ccccc1</smiles><smiles>C1CC2OC2C1</smiles>
$\mathrm{CHO}$<smiles>COCC1CO1</smiles><smiles>CC(C)(C)OCC1CO1</smiles>

\section{Crclic carbonates}

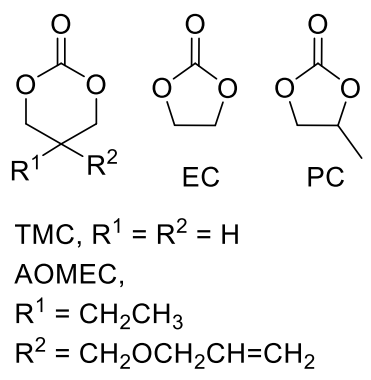<smiles></smiles><smiles>CC(C)(C)C(=O)OCC1CO1</smiles>

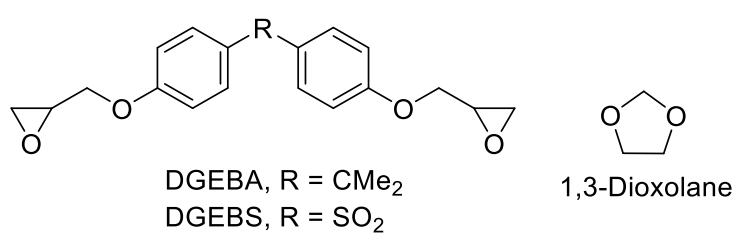

\section{Polvfunctional epoxides}<smiles>CC(C)(C)CC(C(=O)OCC1CO1)C(C)(C)C</smiles>

PGMA<smiles>CC(C)(C)CC(c1ccc(COCC2CO2)cc1)(C(C)(C)C)C(C)(C)C</smiles>

PGMS

\section{Polvesters}<smiles></smiles><smiles>CC(C)(C)CCCCOC(C)(C)C</smiles>
$P V L, x=1 ; P C L, x=2$

\section{Others}<smiles>O=C1CCCCCN1</smiles>

$\mathrm{O}=\mathrm{C}=\mathrm{O}$

$\mathrm{CO}_{2}$

Fig. 2. Representative comonomers used in copolymerization with $\gamma$-lactones.

\subsection{Catalytic systems}

A variety of Lewis/Brønsted acids, metal-based complexes, and organic compounds were employed as catalysts/initiators for $\mathrm{ROP} / \mathrm{ROCP}$ of $\gamma \mathrm{BL}$ and derivatives. These catalytic systems induce mainly ionic and coordination-insertion 
mechanisms. Bicomponent catalytic systems, which usually consist of an acid (or hydrogen-bond donator) and a basic component (hydrogen-bond acceptor), were also employed. Figure 3 shows the representative catalysts/initiators which were used for the ROP/ROCP of $\gamma$-lactones. The chemistries discussed in detail in the following. 


\section{Acids}

\section{Lewis Acids}

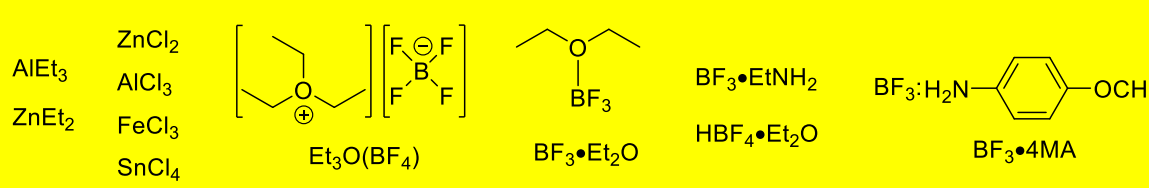

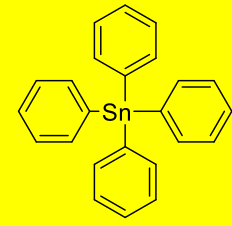

$\mathrm{Ph}_{4} \mathrm{Sn}$

\section{Bronsted Acids}

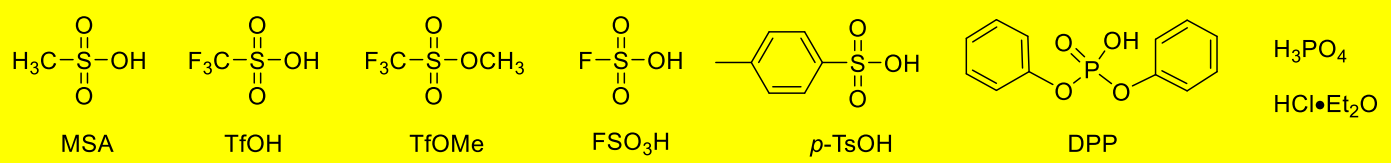

\section{Bases}

\section{Organic bases}
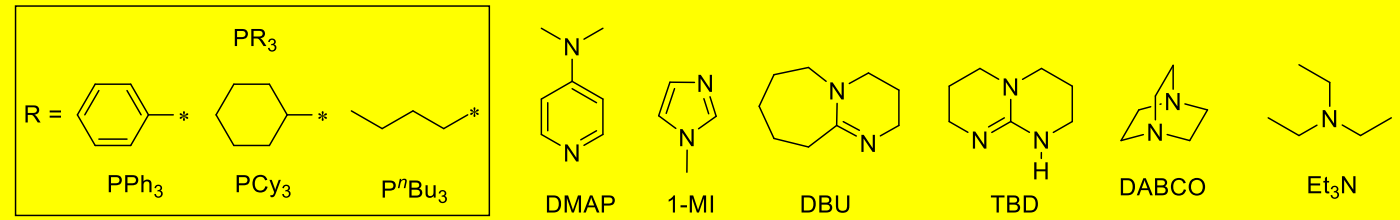

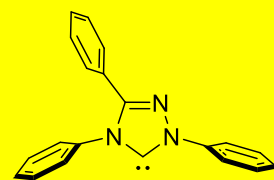

TPT

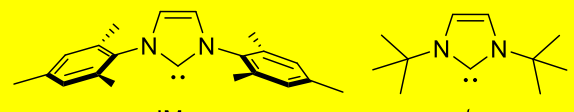

IMes

$\mathrm{I}^{\mathrm{t}} \mathrm{Bu}$
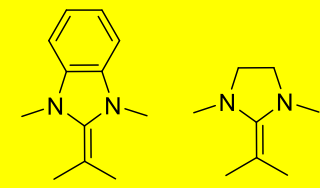

I'P

$\mathrm{NHO} 1 \quad \mathrm{NHO} 2$
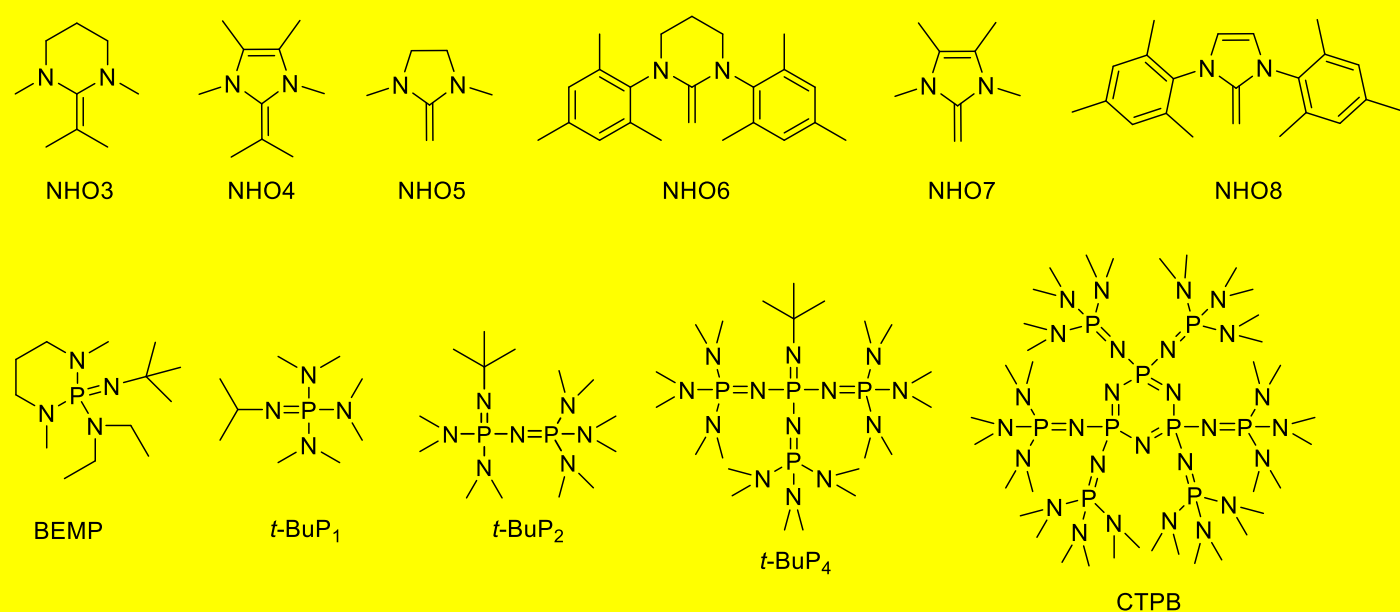

\section{Alkali metal compounds}

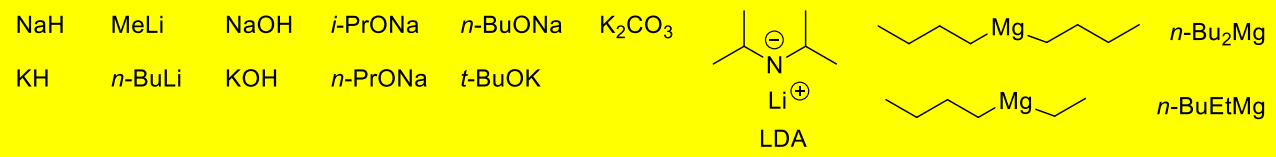




\section{Organometallic compounds}

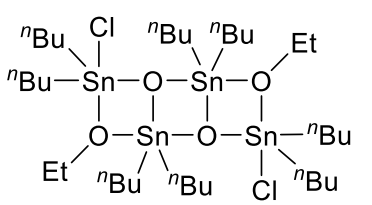

1-Ethoxy-3-chlorotetrabutyldistannoxane<smiles>CCCC[Sn]1(CCCC)OCCO1</smiles>

Cyclic tin alkoxide

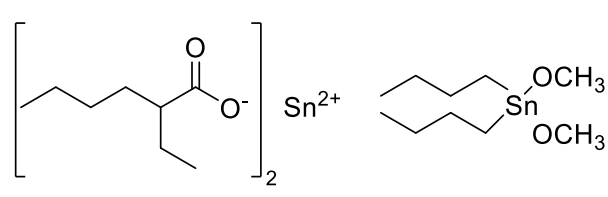

$\mathrm{Sn}(\mathrm{Oct})_{2}$<smiles>CC(C)O[Al](OC(C)C)OC(C)C</smiles>

$\mathrm{Al}\left(\mathrm{O}^{i} \mathrm{Pr}\right)_{3}$<smiles></smiles>

HAPENAIO'Pr

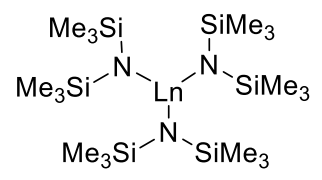

$\operatorname{Ln}\left[\mathrm{N}\left(\mathrm{SiMe}_{3}\right)_{2}\right]_{3}$ $\operatorname{Ln}=\mathrm{La}, \mathrm{Y}, \mathrm{Sm}$<smiles>CC(C)(C)OCc1ccccc1</smiles>

$\left[\mathrm{La}(\mathrm{OBn})_{3}\right]_{x}$

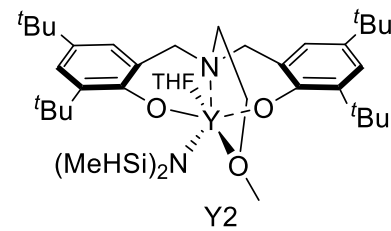

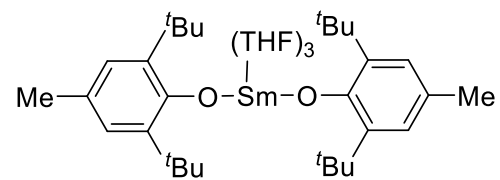
$\mathrm{Sm}(\mathrm{OAr})_{2}(\mathrm{THF})_{3}$
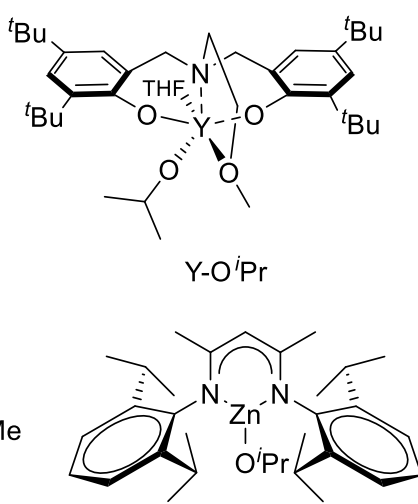

$\mathrm{Zn} 1$

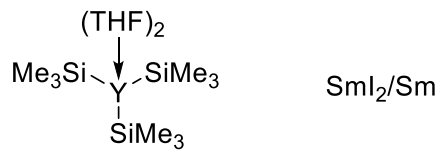

$\mathrm{Y}-\left(\mathrm{CH}_{2} \mathrm{SiMe}_{3}\right)_{3}(\mathrm{THF})_{2}$

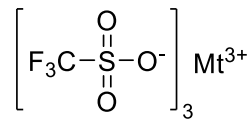

$\mathrm{Bi}(\mathrm{OTf})_{3} \mathrm{Sc}(\mathrm{OTf})_{3}$

$\mathrm{La}(\mathrm{OTf})_{3} \quad \mathrm{Yb}(\mathrm{OTf})_{3}$

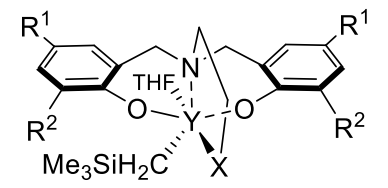

\begin{tabular}{lccc}
\hline & $\mathrm{X}=\mathrm{OMe}$ & $\mathrm{X}=\mathrm{NMe}_{2}$ & $\mathrm{X}=\mathrm{NEt}_{2}$ \\
\hline $\mathrm{R}^{1}=\mathrm{R}^{2}={ }^{t} \mathrm{Bu}$ & $\mathrm{Y} 1 \mathrm{a}$ & $\mathrm{Y} 1 \mathrm{~b}$ & $\mathrm{Y} 1 \mathrm{k}$ \\
$\mathrm{R}^{1}=\mathrm{R}^{2}=\mathrm{Me}$ & $\mathrm{Y} 1 \mathrm{c}$ & - & - \\
$\mathrm{R}^{1}=\mathrm{R}^{2}=\mathrm{Cl}$ & $\mathrm{Y} 1 \mathrm{~d}$ & $\mathrm{Y} 1 \mathrm{e}$ & - \\
$\mathrm{R}^{1}=\mathrm{R}^{2}=-\mathrm{Cumyl}$ & $\mathrm{Y} 1 \mathrm{f}$ & $\mathrm{Y} 1 \mathrm{~g}$ & $\mathrm{Y} 1 \mathrm{~h}$ \\
$\mathrm{R}^{1}=\mathrm{Me}, \mathrm{R}^{2}=-\mathrm{CMePh}_{2}$ & - & $\mathrm{Y} 1 \mathrm{i}$ & - \\
$\mathrm{R}^{1}=\mathrm{Me}, \mathrm{R}^{2}=-\mathrm{CPh}_{3}$ & - & $\mathrm{Y} 1 \mathrm{j}$ & -
\end{tabular}

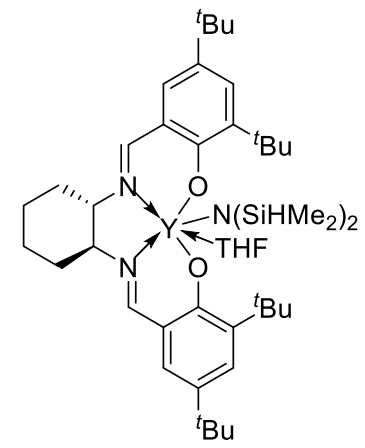

Y3 


\section{Dual catalystic systems}
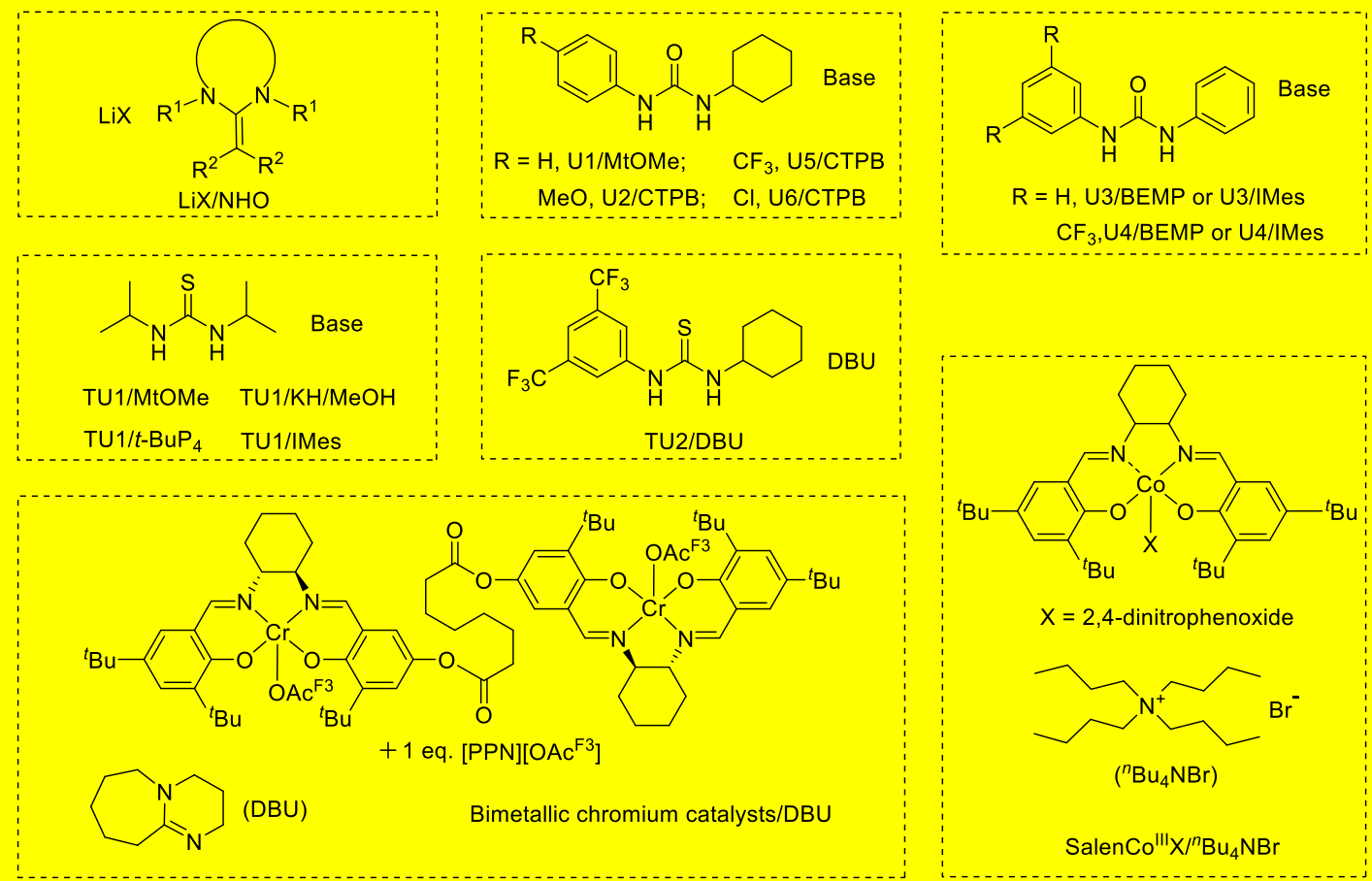

Fig. 3. Representative catalysts/initiators for ROP/ROCP of $\gamma$-lactones.

\section{Lewis acid-catalyzed ROP/ROCP of $\gamma$-lactones}

First attempts to polymerize $\gamma \mathrm{BL}$ by ROP started in the thirties, however, without success. Large sample volumes, high temperature, high pressure, using $\mathrm{ZnCl}_{2}$ or $\mathrm{Et}_{3} \mathrm{O}\left(\mathrm{BF}_{4}\right)$ yielded no polymer or oligomer $[16,18,50]$. The ROP of $\alpha \mathrm{AL}, \beta \mathrm{AL}$, $\alpha \mathrm{OH} \gamma \mathrm{BL}$ and $\alpha \mathrm{Ac} \gamma \mathrm{BL}$ were also studied with very limited success, despite the use of Lewis acids based on Sn, B or Al [51-57].

Considering those difficulties, copolymerization of $\gamma \mathrm{BL}$ with other cyclic monomers (e.g., lactones, epoxides) provides an alternative and is the route to follow with Lewis acids. For instance, $\mathrm{AlEt}_{3} / \mathrm{H}_{2} \mathrm{O}$ was shown to copolymerize $\gamma \mathrm{BL}$ with $\beta$ propiolactone $(\beta \mathrm{PL})$ [58]. The polymerization was performed at $0{ }^{\circ} \mathrm{C}$ in 
dichloromethane (DCM) for 3 days, which yielded copolymers with up to $29 \%$ incorporation of $\gamma \mathrm{BL}$. The reactivity ratios were determined to be $r_{\gamma \mathrm{BL}}=0.36$ and $r_{\mathrm{BPL}}=$ 18 , revealing the low copolymerizability of $\gamma \mathrm{BL}$. Those conditions and results revealed the tricky character of this monomer.

Following that study, copolymerization of $\gamma \mathrm{BL}$ and 3,3-bis(chloromethyl)oxetane (BCMO) was investigated in toluene at RT with tin(IV) chloride $\left(\mathrm{SnCl}_{4}\right)$ and trifluoride diethyl etherate $\left(\mathrm{BF}_{3} \bullet \mathrm{Et}_{2} \mathrm{O}\right)$ [59]. Alternating copolymers were produced in low yields. The $\gamma \mathrm{BL}$ was believed to be coordinated to the Lewis acids, which contributed to its enhanced activity and led to the copolymerization in an alternating way. Glycidyl phenyl ether (GPE) was also used as a comonomer with $\mathrm{BF}_{3}$-based systems, yielding spiroorthoesters and oligomers with low $\gamma \mathrm{BL}$ content $[60,61]$.

In the 1980 s, several Lewis acids such as iron(III) chloride $\left(\mathrm{FeCl}_{3}\right)$, aluminium (III) chloride $\left(\mathrm{AlCl}_{3}\right)$ and $\mathrm{BF}_{3} \cdot \mathrm{Et}_{2} \mathrm{O}$ were utilized for the random copolymerization of $\gamma \mathrm{BL}$ and glycolide at $60{ }^{\circ} \mathrm{C}$ in bulk (Scheme 1a) [62]. $\mathrm{FeCl}_{3}$ showed the best performances, providing copolymers with the highest $\gamma$ BL incorporation (25\%) at a feed ratio of $[\gamma \mathrm{BL}] /[$ glycolide $]=4 / 1$. In addition, $\mathrm{BF}_{3} \bullet \mathrm{Et}_{2} \mathrm{O}$ was employed for this copolymerization under the same conditions with an alcohol (e.g., benzyl alcohol, $\mathrm{BnOH}$ ) as the initiator (Scheme 1a) [63]. The presence of alcohols improved both the polymer yield and $\gamma \mathrm{BL}$ incorporation (up to $34 \%$ ). Random poly $(\gamma \mathrm{BL}-c o-\mathrm{GA}) \mathrm{s}$ with $\overline{M_{n}}$ in the range 5.4-7.3 kg.mol ${ }^{-1}$ and relative low dispersity $(Ð=1.17-1.30)$ were obtained, exhibiting slightly lower degradation temperatures $\left(T_{\mathrm{d}}=241^{\circ} \mathrm{C}\right)$ than poly $($ glycolic acid). 
ROCP of $\gamma \mathrm{BL}$ or $(\mathrm{R})-\gamma$-valerolactone $((\mathrm{R})-\gamma \mathrm{VL})$ with $\beta$-butyrolactone $(\beta \mathrm{BL})$ was performed in bulk at RT for 7 days (Scheme $1 \mathrm{~b}$ ). AlEt 3 and $\mathrm{ZnEt}_{2}$ were able to homopolymerize $\beta \mathrm{BL}$, whereas $\mathrm{BF}_{3} \bullet \mathrm{Et}_{2} \mathrm{O}$ was able to trigger the copolymerization to yield poly $(\gamma \mathrm{BL}-c o-\beta \mathrm{BL}) \mathrm{s}\left(\overline{M_{n}}=1.8-4.4 \mathrm{~kg} \cdot \mathrm{mol}^{-1}, Ð=1.3-1.8\right)$, which were identical to poly(hydroxy alkanoate)s produced by microorganisms $[64,65]$. The $\gamma \mathrm{BL}$ incorporation in the copolymer was enhanced with the increased feed ratio of $[\gamma \mathrm{BL}] /[\beta \mathrm{BL}]$, to reach $56 \%$ at a molar ratio of $90 / 10$. It was inferred that the polymerization was initiated by residual water contained in the reaction medium through the attack of $\mathrm{BF}_{3}$-activated monomer. This suggested the possibility of using alcohols as initiators, and such dihydroxy-telechelic copolymers were prepared as an example.

The copolymerization of $\alpha \mathrm{Ac} \gamma \mathrm{BL}$ and $\beta \mathrm{BL}$ was also performed using $\mathrm{BF}_{3} \cdot \mathrm{Et}_{2} \mathrm{O}$ in bulk at RT for 4 weeks (Scheme 1c) [55]. Yields up to 78\% were observed with 9-74\% of $\alpha \mathrm{Ac} \gamma \mathrm{BL}$ in the copolymer as feed ratios of $[\alpha \mathrm{Ac} \gamma \mathrm{BL}] /[\beta \mathrm{BL}]$ were varied from $20 / 80$ to $80 / 20\left(\overline{M_{n}}=1.6-2.0 \mathrm{~kg} \cdot \mathrm{mol}^{-1}, Ð=1.2-1.4\right)$. Pendant ketone functions were confirmed, opening a way to obtain hydroxyl ones for further functionalization. 
a)<smiles>COC1OC(=O)COC1=O</smiles>

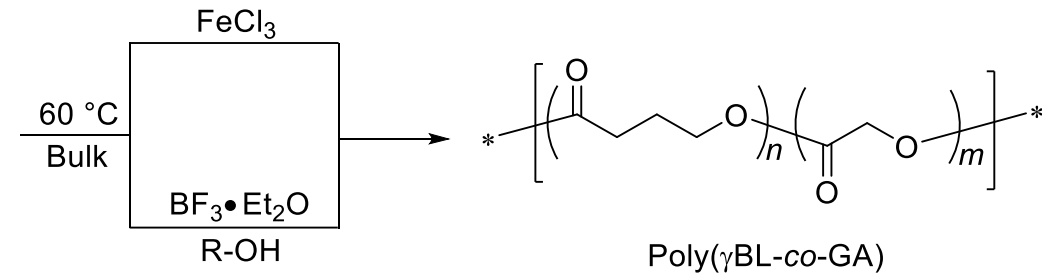

b)

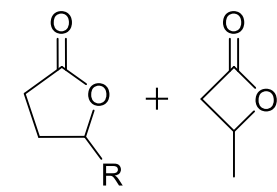
$\gamma \mathrm{BL}, \mathrm{R}=\mathrm{H} \quad \beta \mathrm{BL}$ $(\mathrm{R})-\gamma \mathrm{VL}, \mathrm{R}=\mathrm{Me}$

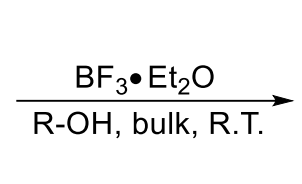<smiles>[R]C(CCC(=O)C(C)(C)C)OC(C)(C)C(=O)CC(C)OC(C)(C)C(C)(C)C</smiles>
Poly $(\gamma B L-c o-\beta B L)$ or poly $((R)-\gamma V L-c o-\beta B L)$

c)

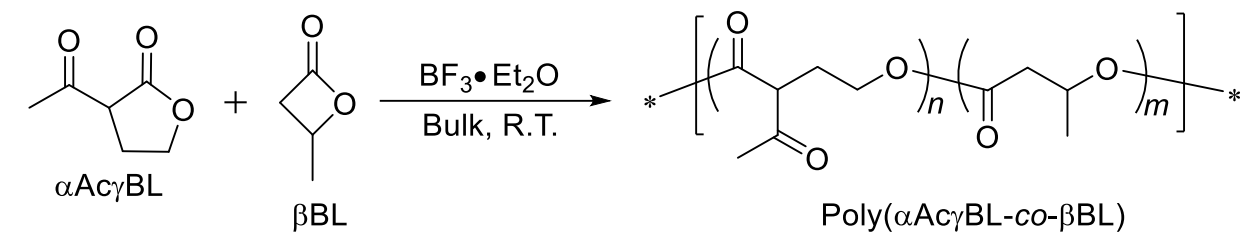

Scheme 1. Examples of Lewis acid-catalyzed ROCP of $\gamma$-lactones with cyclic esters: (a) $\gamma \mathrm{BL} /$ glycolide $[62,63]$, (b) $\gamma \mathrm{BL} /(\mathrm{R})-\gamma \mathrm{VL}$ and $\beta \mathrm{BL}[64,65]$, (c) $\alpha \mathrm{Ac} \gamma \mathrm{BL}$ and $\beta \mathrm{BL}$ $[55]$.

The copolymerization of $\gamma \mathrm{BL}$ and L-lactide (LLA) was achieved in bulk at $120{ }^{\circ} \mathrm{C}$ for 4 days using tetraphenyl tin $\left(\mathrm{Ph}_{4} \mathrm{Sn}\right)$ [66]. Statistical copolyesters poly $(\gamma \mathrm{BL}-c o-$ LLA) were obtained with molar mass as high as $70 \mathrm{~kg} \cdot \mathrm{mol}^{-1}(\nexists=1.3)$. The maximum $\gamma \mathrm{BL}$ incorporation obtained was $c a .17 \%$. The use of $\gamma \mathrm{BL}$ derivatives bearing an alkyl substitute in the $\gamma$-position (i.e., $\gamma$-valerolactone $(\gamma \mathrm{VL}), \gamma$-caprolactone $(\gamma \mathrm{CL})$ ) only produced copolymers with low $\gamma \mathrm{VL}$ or $\gamma \mathrm{CL}$ incorporation $(2 \%)$. The proposed copolymerization mechanism was based on the transesterification between the fastproduced PLLA and $\gamma \mathrm{BL}$. This assumption was supported by the incorporation of $\gamma \mathrm{BL}$ units into PLLA, starting from PLLA in the presence of $\gamma \mathrm{BL}$ under similar conditions 
$\left(\overline{M_{n}}=10.1 \mathrm{~kg} \cdot \mathrm{mol}^{-1}, Ð=1.5\right)$. The degradability of the resulting poly $(\gamma \mathrm{BL}-c o-L L A)$ was confirmed in $\mathrm{H}_{2} \mathrm{O}\left(70{ }^{\circ} \mathrm{C}, 5\right.$ days $)$ or in the presence of lipases from Rhizopus arrhizus and $R$. delemar $\left(37^{\circ} \mathrm{C}, 24 \mathrm{~h}\right)$, which both showed enhanced degradability with the increase of $\gamma \mathrm{BL}$ content in the copolymer.

The $\mathrm{Ph}_{4} \mathrm{Sn}$ catalyst was further used for the ROCP of $\gamma \mathrm{BL}$ with other cyclic esters such as $\beta \mathrm{PL}, \varepsilon$-caprolactone ( $\varepsilon \mathrm{CL}), \delta$-valerolactone $(\delta \mathrm{VL})$ and glycolide [67]. Random copolymers were prepared with various $\gamma \mathrm{BL}$ content $(3-16 \%$ for poly $(\gamma \mathrm{BL}-c o-\varepsilon \mathrm{CL})$ with $\overline{M_{n}}=29.5-145 \mathrm{~kg} \cdot \mathrm{mol}^{-1} ; 3-15 \%$ for $\operatorname{poly}(\gamma \mathrm{BL}-\mathrm{co}-\delta \mathrm{VL})$ with $\overline{M_{n}}=18.6-52.2$ kg.mol $\left.{ }^{-1}\right)$. However, only low-molar-mass copolymers with slightly higher $\gamma$ BL content $\left(4-23 \%, \overline{M_{n}}=1.3-2.2 \mathrm{~kg} \cdot \mathrm{mol}^{-1}\right)$ were produced during the copolymerization of $\gamma \mathrm{BL}$ with $\beta \mathrm{PL}$. The copolymerization of $\gamma \mathrm{BL}$ and glycolide generated a mixture of insoluble parts which were glycolide-rich copolymers and soluble parts which were poly $(\gamma \mathrm{BL}$ co-glycolide) containing 3-26\% of $\gamma \mathrm{BL}$ content. The degradation of the obtained copolymers was investigated in water at $70{ }^{\circ} \mathrm{C}$. The degradation rate of poly $(\gamma \mathrm{BL}-\mathrm{co}$ glycolide) was higher than that of the others, whereas the reverse was observed in the presence of lipases $\left(37^{\circ} \mathrm{C}\right)$.

In summary, the use of Lewis acids as catalysts for the homopolymerization of $\gamma$ lactones has been shown to be inefficient. Copolymerization with other cyclic monomers using boron derivatives appears to be a way to produce biodegradable materials with enhanced degradability. In general, molar masses and $\gamma$-BL incorporation remain low for long polymerization times. 


\section{Brønsted acid-catalyzed ROP/ROCP of $\gamma$-lactones}

Brønsted acids such as methanesulfonic acid (MSA), diphenyl phosphate (DPP) and trifluoromethanesulfonic acid $(\mathrm{TfOH})$ were utilized for ROP/ROCP of lactones and/or cyclic carbonates through activated monomer mechanism (AMM) pathway following a cationic mechanism $[4,5,7,68-70]$. Well-defined polymers (i.e., controlled molar mass, narrow distribution, and targeted macromolecular architecture) could be obtained under mild conditions. Such Brønsted acids were employed for the $\mathrm{ROP} / \mathrm{ROCP}$ of $\gamma \mathrm{BL}$ or its functional derivatives as well.

High pressure (800-1000 MPa) was shown to achieve the ROP of $\gamma \mathrm{BL}$ in bulk at $40{ }^{\circ} \mathrm{C}$, initiated by methanol with $\mathrm{TfOH}$ as an example [71]. The $\overline{M_{n}}$ of the resulting $\mathrm{P} \gamma \mathrm{BLs}$ were in the range $6.4-7.9 \mathrm{~kg} \cdot \mathrm{mol}^{-1}$ with relatively high dispersities $(\nexists=1.49$ 1.57). It was proposed that the polymerization proceeded by the AMM pathway, which was based on the coordination of lactones to the acids to afford the activated cationic complex, followed by the attack of an initiator.

There is a possibility to polymerize $\gamma \mathrm{BL}$ above its ceiling temperature. The polymer stability should be then studied for any polymers obtained.

$\mathrm{TfOH}$ or DPP was also used for the polymerization of a $\gamma \mathrm{BL}$ derivative, transhexahydro-2(3H)-benzofuranone [i.e., 4,5-trans cyclohexyl-ring-fused $\gamma \mathrm{BL}(4,5-\mathrm{T} 6 \mathrm{~L})]$. Only oligomers were produced with a maximum value of $20 \%$ of monomer conversion [72, 73]. The polymerization of $\alpha \mathrm{OH} \gamma \mathrm{BL}$ was carried out at $90{ }^{\circ} \mathrm{C}$ using $\mathrm{TfOH}$, producing oligomers with dehydration [56]. 
The more open copolymerization strategy was also developed with Brønsted acids. Fluorosulfonic acid $\left(\mathrm{FSO}_{3} \mathrm{H}\right)$, TfOMe and $\mathrm{TfOH}$ were quite helpful to copolymerize $\gamma \mathrm{BL}$ (or (R)- $\gamma \mathrm{VL}$ ) with different comonomers such as glycolide, 3,4-trans cyclohexylring-fused $\gamma \mathrm{BL}(3,4-\mathrm{T} 6 \mathrm{~L})$ or $\beta \mathrm{BL}$, allowing up to $30 \%$ of $\gamma \mathrm{BL}$ incorporation into low molar mass copolyester chains $[62-65,73]$. Phosphoric acid $\left(\mathrm{H}_{3} \mathrm{PO}_{4}\right)$ could also achieve the copolymerization of $\gamma \mathrm{BL}, \gamma \mathrm{VL}$ or $\gamma \mathrm{CL}$ with $\varepsilon \mathrm{CL}$ in bulk at $200^{\circ} \mathrm{C}$ [74]. Interestingly, semi-crystalline copolymers were synthesized $\left(\overline{M_{n}}=17.8-41.2 \mathrm{~kg} \cdot \mathrm{mol}^{-1}\right)$ with melting temperature $\left(T_{\mathrm{m}}\right)$ ranging from $48{ }^{\circ} \mathrm{C}$ to $56^{\circ} \mathrm{C}$. The resulting products showed different degradation rates in acidic medium, i.e., $\operatorname{poly}(\gamma \mathrm{BL}-c o-\varepsilon \mathrm{CL})>\operatorname{poly}(\gamma \mathrm{VL}-c o-\varepsilon \mathrm{CL})>$ $\operatorname{poly}(\gamma \mathrm{CL}-c o-\varepsilon \mathrm{CL})$, which may be due to the varying hydrophobicity of the copolymers bearing side chains of different lengths. Either DPP or hydrochloric acid in diethyl ether $\left(\mathrm{HCl} \cdot \mathrm{Et}_{2} \mathrm{O}\right)$ were used in bulk or solution, yielding poly $(\gamma \mathrm{BL}-c o-\varepsilon \mathrm{CL})$ with limited $\gamma \mathrm{BL}$ incorporation [75].

$\alpha$-Bromo- $\gamma$-butyrolactone ( $\alpha \mathrm{Br} \gamma \mathrm{BL})$, a commercial functional $\gamma \mathrm{BL}$ derivative, was copolymerized with other heterocyclic monomers including $\varepsilon \mathrm{CL}$, trimethylene carbonate (TMC), and 2-allyloxymethyl-2-ethyltrimethylene carbonate (AOMEC) [76, 77]. The ROCP proceeded in bulk at RT with DPP or MSA (Scheme 2a) [77]. Copolymers with $4-12 \%$ of $\alpha \mathrm{Br} \gamma \mathrm{BL}$ were obtained $\left(\overline{M_{n}}=17.0-31.2 \mathrm{~kg} \cdot \mathrm{mol}^{-1}, Ð=\right.$ 1.08-1.12). Separated $\alpha \mathrm{Br} \gamma \mathrm{BL}$ units along the copolymer backbone were confirmed by ${ }^{13} \mathrm{C}$ NMR analysis (i.e., no homosequence of $\alpha \mathrm{Br} \gamma \mathrm{BL}$ ). The narrow distribution may originate from the mild reaction temperature and the intrinsic merits of organic acids, which greatly suppressed the transesterification reactions. Therefore, a triblock 
copolymer, $\quad$ poly $[(\alpha \mathrm{Br} \gamma \mathrm{BL}-c o-\varepsilon \mathrm{CL})-b$-AOMEC- $b-(\alpha \mathrm{Br} \gamma \mathrm{BL}-c o-\varepsilon \mathrm{CL})] \quad\left(\overline{M_{n}}=40.8\right.$ kg.mol ${ }^{-1}, Ð=1.12$ ) was synthesized in one-pot two-steps procedure, through the DPPcatalyzed sequential ROP of AOMEC and $\varepsilon \mathrm{CL} / \alpha \mathrm{Br} \gamma \mathrm{BL}$ with 1,6 -hexanediol as the initiator. The selective incorporation of separated $\alpha \mathrm{Br} \gamma \mathrm{BL}$ site into the $\alpha \mathrm{Br} \gamma \mathrm{BL} / \varepsilon \mathrm{CL}$ block was again demonstrated. Both poly(TMC-co- $\alpha \mathrm{Br} \gamma \mathrm{BL})$ and triblock copolymer were used as macroinitiators for single electron transfer living radical polymerization (SET-LRP) of methyl acrylates, the dispersed $\alpha \mathrm{Br} \gamma \mathrm{BL}$ site along the polymer chain being the initiating sites. The "graft from" polymerization proceeded with good control and nearly complete initiation, resulting in well-defined poly(methyl acrylate) graftedcopolymers with degradable polymers based on $\alpha \mathrm{Br} \gamma \mathrm{BL}$ and $\varepsilon \mathrm{CL}$ [76]. In the same vein, amphiphilic triblock copolymers were synthesized starting from HO-PEG-OH.

Functional copolymers of $\alpha \mathrm{MBL}$ and $\varepsilon \mathrm{CL}$ were synthesized in DCM or bulk at RT using TfOH or DPP as a catalyst (Scheme $2 b)$ [78]. Poly $(\alpha \mathrm{MBL}-c o-\varepsilon C L)$ s with $4-11 \%$ $\alpha \mathrm{MBL}$ incorporation $\left(\overline{M_{n}}=3.3-17.9 \mathrm{~kg} \cdot \mathrm{mol}^{-1}\right)$ were obtained by TfOH-catalyzed copolymerization in DCM $([\alpha \mathrm{MBL}] /[\varepsilon \mathrm{CL}]<1)$, while $\mathrm{P}(\alpha \mathrm{MBL})$ vaP via vinyl-addition polymerization of $\alpha \mathrm{MBL}$ or cross-linked polymers $\mathrm{P}(\alpha \mathrm{MBL})$ CLP were observed in other cases (e.g. bulk, $[\alpha \mathrm{MBL}] /[\varepsilon \mathrm{CL}]>1$ ). The desired linear structure of copolyesters containing unsaturated pendant side groups with ${ }^{i} \mathrm{PrO} / \mathrm{H}$ chain ends was confirmed by ${ }^{1} \mathrm{H}$ NMR and MALDI-TOF MS analyses. A random distribution of the two monomers was expected by the authors. However, the less reactive DPP allowed a better control of the copolymerization, resulting in the formation of copolymers with $4-11 \% \alpha \mathrm{MBL}$ content $\left(\overline{M_{n}}=2.9-7.9 \mathrm{~kg} \cdot \mathrm{mol}^{-1}\right)$. Due to the lower acidity of DPP, the copolymerization 
proceeded in bulk without the appearance of $\mathrm{P}(\alpha \mathrm{MBL}) \mathrm{VAP}$. The copolymers obtained showed a reduced $T_{\mathrm{m}}$ due to the presence of non-crystallizable $\alpha \mathrm{MBL}$ component and high thermal stability. The post-polymerization of unsaturated copolyesters poly $(\alpha \mathrm{MBL}-c o-\varepsilon \mathrm{CL})$ was verified by thiol-ene chemistry under thermal initiation $\left(2,2^{\prime}-\right.$ azobis(2-methylpropionitrile), AIBN) or photoinitiation (2,2-dimethoxy-2phenylacetophenone, DMPA). In addition, multihydroxyl copolymers with similar $\alpha \mathrm{MBL}$ content (4-8\%) were synthesized in bulk by employing multifunctional alcohols such as 1,2-ethanediol or di(trimethylolpropane) as the initiator.

a)

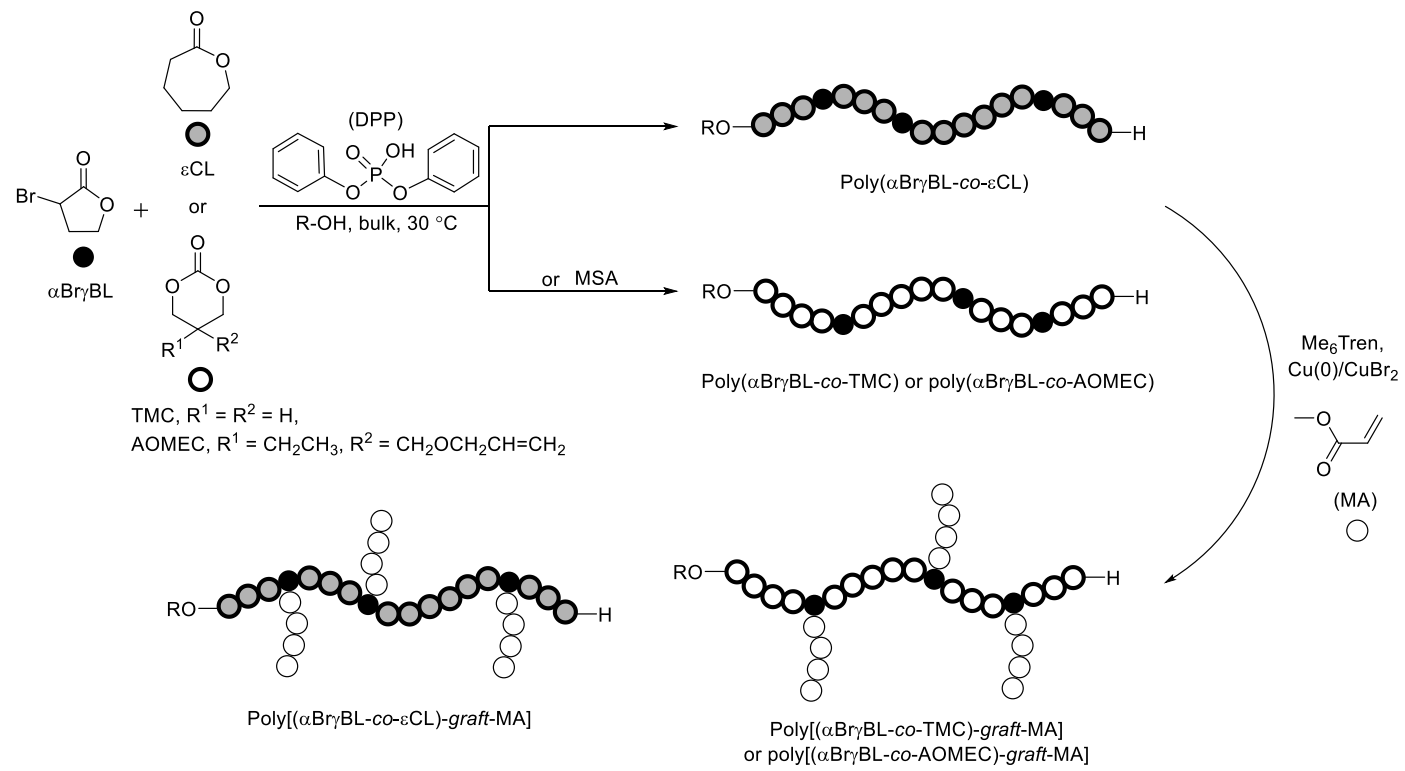

b)

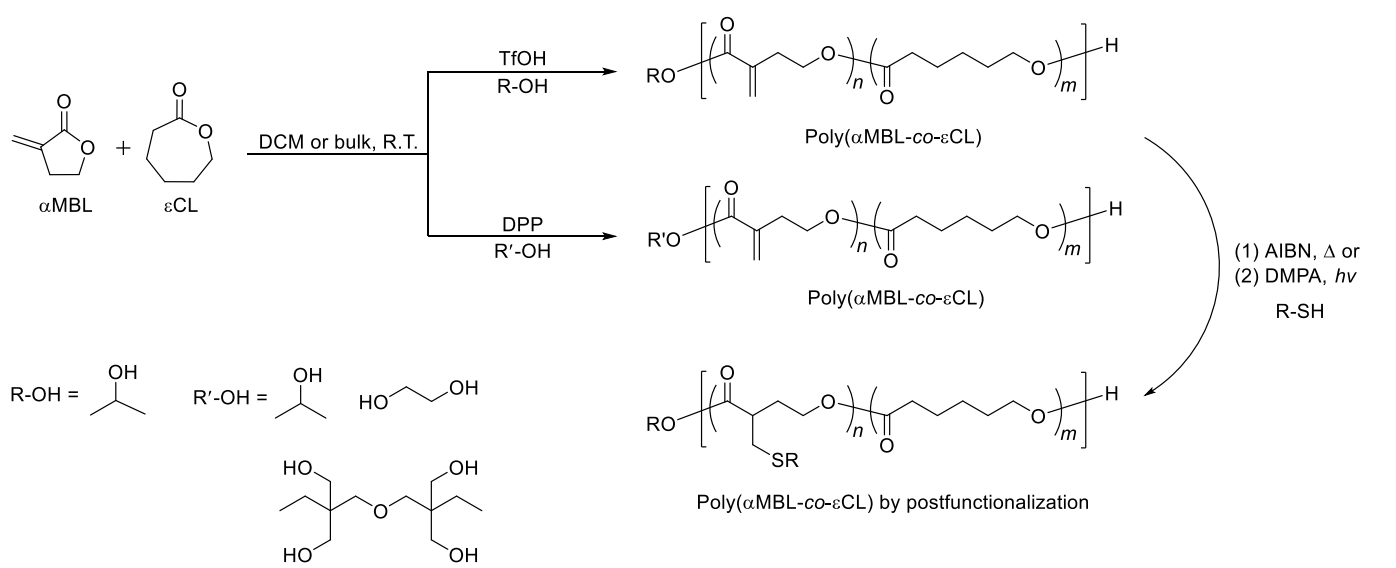

Scheme 2. Brønsted acid-catalyzed ROCP of $\gamma$-lactones with cyclic ester/carbonate: (a) 
$\alpha \mathrm{Br} \gamma \mathrm{BL}$ and $\varepsilon \mathrm{CL}, \mathrm{TMC}, \mathrm{AOMEC}$ [77], (b) $\alpha \mathrm{MBL}$ and $\varepsilon \mathrm{CL}[78]$.

Again, the copolymerization strategy is preferred to ring-open $\gamma$-lactones by Brønsted acids and take benefit of specific molecular structures. Indeed, TfOH or DPP are the most efficient acids to synthesize (co)polyesters bearing reactive functions introduced by the $\gamma$-lactones. Adjusting the acidity of the catalyst seems to be key to minimizing side reactions. Nevertheless, molar masses and $\gamma$-lactones incorporation are still limited, and a controlled copolymerization cannot be achieved by this route.

\section{Organic base-catalyzed ROP/ROCP of $\gamma$-lactones}

Organocatalytic polymerization following a nucleophilic/anionic mechanism is a powerful pathway for the synthesis of metal-free polymers with different macromolecular architectures. Since the first report of nucleophilic organocatalyzed ROP of lactide [79] or cyclic monomers [80], several reviews focusing on this subject have been published $[4,7,69,81-88]$, including on initiating/catalytic systems for the polymerization of $\gamma \mathrm{BL}$ and derivatives.

Different organic bases such as NHCs (e.g. IMes), guanidines (e.g. TBD), and phosphazene bases including $t$ - $\mathrm{BuP}_{2}$ and $t$ - $\mathrm{BuP}_{4}$ were used for the ROP of $\gamma \mathrm{BL}$. The superbase $t$-BuP4 was revealed to be the most efficient catalyst (Scheme 3a) [21, 22]. The polymerization was carried out in tetrahydrofuran (THF) at a high monomer concentration $\left([\gamma \mathrm{BL}]_{0}=10 \mathrm{M}\right)$ and a low reaction temperature $\left(-40^{\circ} \mathrm{C}\right)$ below $T_{\mathrm{c}}$, which is $22{ }^{\circ} \mathrm{C}$ for $\gamma \mathrm{BL}$ in bulk [15]. Two different polymerization mechanisms were proposed, 
depending on the presence of an alcohol as the initiator or not. In absence of an alcohol, $\gamma \mathrm{BL}$ can be directly deprotonated by the superbase to produce a reactive enolate species. This results in a mixture of linear $\mathrm{P} \gamma \mathrm{BL}$ with acylated lactone/H chain ends ( $\mathrm{P} \gamma \mathrm{BLL} 1)$ and cyclic $\mathrm{P} \gamma \mathrm{BL}(\mathrm{P} \gamma \mathrm{BLC})$, the latter was believed to be achieved by a backbiting reaction of the polymer chain $\left(\overline{M_{n}}=9.2-26.4 \mathrm{~kg} \cdot \mathrm{mol}^{-1}, Ð=1.16-1.79\right)$. The addition of an alcohol (e.g., benzyl alcohol, $\left.\mathrm{BnOH} ;\left[t-\mathrm{BuP}_{4}\right] /[\mathrm{BnOH}]=1 / 0.5-1 / 1.5\right)$ was a more rapid and efficient pathway for the formation of relatively high molar mass polymers in high conversion (up to $90 \%$ in $4 \mathrm{~h}, \overline{M_{n}}$ up to $27.1 \mathrm{~kg} \cdot \mathrm{mol}^{-1}, Ð=2.11$ ). In this case, a mixture of $\mathrm{P}_{\gamma} \mathrm{BL}_{\mathrm{L} 1}$ and linear $\mathrm{P} \gamma \mathrm{BL}$ with $\mathrm{BnO} / \mathrm{H}$ chain ends $\left(\mathrm{P}_{\gamma} \mathrm{BLL}_{\mathrm{L} 2}\right)$ was obtained. It was considered that the presence of alcohols led to more stabilized propagating alkoxide chain ends $\left(\left[\mathrm{BnO}^{-} / t-\mathrm{BuP}_{4} \mathrm{H}^{+}\right]\right)$, which also accounted for the more controlled polymerization behaviour. The absence of $\mathrm{P} \gamma \mathrm{BL}_{\mathrm{c}}$ under this condition was not explained. Moreover, the weaker phosphazene base $t$ - $\mathrm{BuP}_{2}$ showed lower activity under the same conditions, whereas the weakest $t$ - $\mathrm{BuP}_{1}$ was inactive.

The ROP of $\gamma \mathrm{BL}$ was also performed in the presence of a cyclic trimeric phosphazene base (CTPB) as the catalyst [23]. The polymerization was conducted in toluene at $-50{ }^{\circ} \mathrm{C}$ with a slightly lower monomer concentration $\left([\gamma \mathrm{BL}]_{0}=6 \mathrm{M}\right)($ Scheme 3a). Compared to the superbase $t$-BuP, CTPB was proved to be inactive in absence of an alcohol. The use of CTPB with $\mathrm{BnOH}$ as the initiator selectively afforded welldefined linear $\mathrm{P} \gamma \mathrm{BL}$ L2 with a high monomer conversion (up to $98 \%$ in $4 \mathrm{~h}, \overline{M_{n}}=10.5-$ $\left.22.9 \mathrm{~kg} \cdot \mathrm{mol}^{-1}, Ð=1.27-1.72\right)$. The polymerization mechanism was similar to that proposed in $t-\mathrm{BuP} 4 / \mathrm{BnOH}$ catalytic system, i.e., the loose ion pair $\left[\mathrm{BnO}^{-} / \mathrm{CTPBH}^{+}\right]$ 
could polymerize $\gamma \mathrm{BL}$. The relative lower basicity of CTPB $\left(\mathrm{p} K_{\mathrm{a}}^{\mathrm{MeCN}}=33.3\right)$ compared to $t-\mathrm{BuP}_{4}\left(\mathrm{p} K_{\mathrm{a}}^{\mathrm{MeCN}}=42.6\right)$ may account for the selective production of linear polymer with $\mathrm{BnO} / \mathrm{H}$ chain ends $\left(\mathrm{P}_{\gamma} \mathrm{BL}_{\mathrm{L} 2}\right)$ in this case.

Recently, $N$-heterocyclic olefins (NHOs) were utilized for the polymerization of $\gamma \mathrm{BL}$ in bulk at $-36{ }^{\circ} \mathrm{C}[24]$. A mixture of linear and cyclic polyesters $(\mathrm{P} \gamma \mathrm{BLL} 2+\mathrm{P} \gamma \mathrm{BLC})$ $\left(\overline{M_{n}}=3.3-7.2 \mathrm{~kg} \cdot \mathrm{mol}^{-1}, Ð=1.5-2.1\right)$ was obtained only when an initiator $(\mathrm{BnOH})$ was initially added. The zwitterionic ROP of $\gamma \mathrm{BL}$ with NHOs alone was completely supressed (Scheme 3a).

Organic bases were also used for the ROP of $\gamma \mathrm{BL}$ derivatives such as $\alpha \mathrm{Br} \gamma \mathrm{BL}$ and 4,5-T6L. DBU, TBD or $t$-BuP2 were ineffective for the ROP of $\alpha \mathrm{Br} \gamma \mathrm{BL}$ in bulk at RT, due to the elimination of the bromine atom under such conditions [77]. Several organic bases were also tested for the polymerization of 4,5-T6L performed in bulk with different temperatures $[72,73]$. For instance, the attempts to utilize DBU or BEMP in presence of alcohols at RT were unsuccessful. Only 5\% of monomer conversion was observed with $t$-BuP 4 after $24 \mathrm{~h}$ under such conditions, while IMes led to $20 \%$ monomer conversion after $96 \mathrm{~h}$. TBD/BnOH could mediate well-controlled polymerization of 4,5-T6L $\left(\overline{M_{n}}=9.1 \mathrm{~kg} \cdot \mathrm{mol}^{-1}, Ð=1.11\right)$. The monomer conversion was limited to $64 \%$ due to the polymerization-depolymerization equilibrium. However, cyclic $\mathrm{P}(4,5-\mathrm{T} 6 \mathrm{~L}) \mathrm{s}$ with $\overline{M_{n}}=40.6-72.1 \mathrm{~kg} \cdot \mathrm{mol}^{-1}$ and $Ð=1.21-1.30$ were synthesized in bulk at RT in the presence of less sterically hindered NHCs alone (e.g. $\mathrm{I}^{t} \mathrm{Bu}$ and $\mathrm{I}^{i} \mathrm{Pr}$ ) (Scheme 3b) [73]. DBU, Et $3 \mathrm{~N}$ or DMAP were inactive for the ROP of 4,5-T6L in bulk at $40{ }^{\circ} \mathrm{C}$ [72]. 


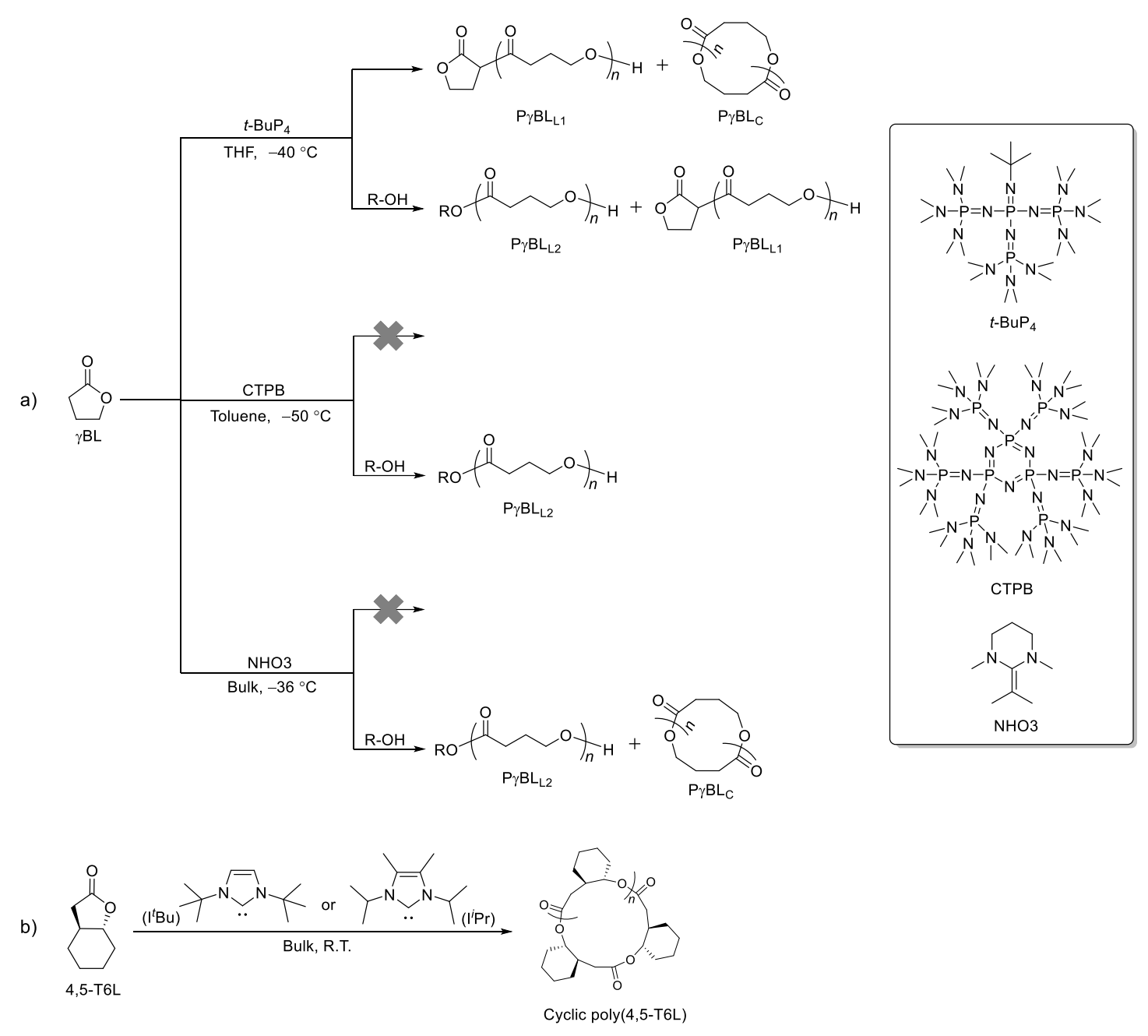

Scheme 3. (a) ROP of $\gamma$-lactones by different organic bases: $t$-BuP 4 [22], CTPB [23] and NHO3 [24] (up to down, respectively), (b) ROP of 4,5-T6L by NHCs [73].

Recently, organic bases such as $\mathrm{I}^{t} \mathrm{Bu}$ and $\mathrm{I}^{i} \mathrm{Pr}, t-\mathrm{BuP}_{4}$ and $\mathrm{DABCO}$ were tested for the polymerization of $\beta \mathrm{AL}, 3$-methylfuran-2(5H)-one (3-MFO), and their parent monomer 2(5H)-furanone (FO) [89]. Only vinyl-addition poly(2(5H)-furanone)s $\left(\overline{M_{n}}\right.$ $=1.57-2.06 \mathrm{~kg} \cdot \mathrm{mol}^{-1}$ ) and compounds with dimer or trimer structures (corresponding to $\beta \mathrm{AL}, 3-\mathrm{MFO}$, respectively) were obtained, no matter the catalyst and the reaction conditions (e.g., solvent, temperature, initiator). Noteworthy, tri-functional monomers 
such as $\beta$-hydroxy- $\alpha$-methylene- $\gamma$-butyrolactone ( $\beta$ HMBL or Tulipalin B) and 3(hydroxymethyl) furan-2(5H)-one (3-HMFO) were also polymerized in solution using organocatalysts such as TPT, $\mathrm{I}^{t} \mathrm{Bu}$ and $t$ - $\mathrm{BuP}_{4}$. The resultant products were considered as branched copolymers with various structures, originating from the multiple types of reactions and the relevant mechanistic crossovers $[89,90]$.

Eventually, some organic bases appear to be efficient catalysts for the homopolymerization of $\gamma \mathrm{BL}$ and derivatives using the ring-opening mechanism, preferably with an alcohol as the initiator. High monomer conversion can be reached in short time with phosphazene bases.

To go further with this approach, the ROCP of $\gamma \mathrm{BL}$ with $\varepsilon \mathrm{CL}$ or $\delta \mathrm{VL}$ was studied in the presence of $t-\mathrm{BuP}_{4} / \mathrm{BnOH}(1 / 1)$ (Scheme 4a) [91]. The copolymerization was carried out in THF at $25^{\circ} \mathrm{C}$ or low reaction temperatures $\left(-40\right.$ or $\left.-20^{\circ} \mathrm{C}\right)$ with a relatively low molar ratio of $[\gamma \mathrm{BL}] /[\varepsilon \mathrm{CL}](3$ or $4 / 1)$ or $[\gamma \mathrm{BL}] /[\delta \mathrm{VL}](1,3$ or $10 / 1)$. The resultant random copolymers showed high $\gamma \mathrm{BL}$ incorporation, $42-80 \%$ for poly $(\gamma \mathrm{BL}-c o-\varepsilon \mathrm{CL})$ $\left(\overline{M_{n}}=5.2-26.0 \mathrm{~kg} \cdot \mathrm{mol}^{-1}, Ð=1.35-1.91\right)$ and $19-75 \%$ for $\operatorname{poly}(\gamma \mathrm{BL}-c o-\delta \mathrm{VL})\left(\overline{M_{n}}=\right.$ 5.3-20.7 kg.mol $\left.{ }^{-1}, Ð=1.49-1.88\right)$.

The use of a comonomer facilitates an increase of the polymerization temperature above the ceiling tempratufe.

The introduction of $\gamma \mathrm{BL}$ influenced the thermal properties and co-crystallization behaviour of the copolyesters. For example, poly $(\gamma \mathrm{BL}-c o-\varepsilon \mathrm{CL}) \mathrm{s}$ showed unique eutectic phase behaviour, with an eutectic temperature of $11{ }^{\circ} \mathrm{C}$ at $66 \% \gamma \mathrm{BL}$ incorporation. Such poly $(\gamma \mathrm{BL}-c o-\varepsilon \mathrm{CL})$ copolyesters (with $\gamma \mathrm{BL}$ content up to $28 \%$ ) were 
also produced with TBD as catalyst in bulk or solution [75]. With the same catalyst, using PEG-OH as a macroinitiator, amphiphilic diblock copolymers with random comonomer distribution of $\gamma \mathrm{BL}$ and $\varepsilon \mathrm{CL}$ in the polyester block were also synthesized.

Furthermore, diblock copolymers of $\gamma \mathrm{BL}$ and LLA were achieved using CTPB via one-pot two-steps sequential ROP of $\gamma$ BL and LLA (Scheme 4b) [92]. The formation of poly $\left(\gamma \mathrm{BL}-b\right.$-LLA)s with high $\gamma \mathrm{BL}$ amount (up to $52 \%$ ) was obtained $\left(\overline{M_{n}}=6.5-20.5\right.$ kg.mol $\left.{ }^{-1}, Ð=1.45-2.09\right)$. All block copolymers displayed two $T_{\mathrm{m}}$, the lower temperature $\left(c a .56^{\circ} \mathrm{C}\right.$ ) was attributed to the $T_{\mathrm{m}}$ of $\mathrm{P} \gamma \mathrm{BL}$ block and the higher one ( $c a$. $165^{\circ} \mathrm{C}$ ) was attributed to the $T_{\mathrm{m}}$ of PLLA block. The block copolymers also showed enhanced thermal stability compared to $\mathrm{P} \gamma \mathrm{BL}\left(T_{\mathrm{d}} \geq 284{ }^{\circ} \mathrm{C} v s 240{ }^{\circ} \mathrm{C}\right)$, which could be further improved with the increase of PLLA block length. Using $\varepsilon \mathrm{CL}$ or $\delta \mathrm{VL}$ as the second monomer only led to the formation of random copolymers, which was also observed in the sequential ROP of $\omega \mathrm{PDL}$ and LLA/ $/ \varepsilon \mathrm{CL} / \delta \mathrm{VL}$ [93]. Amphiphilic block copolymers PEG- $b-\mathrm{P} \gamma \mathrm{BL}$ could also be obtained starting from monohydroxyterminated poly(ethylene glycol) (PEG-OH) and self-assemble to micelles and vesicles in water, indicating their potential for drug delivery carriers [94].

a)

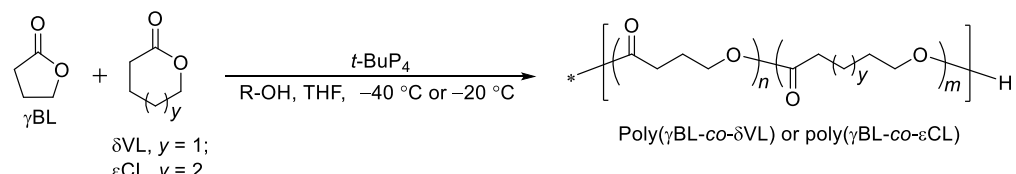

b)

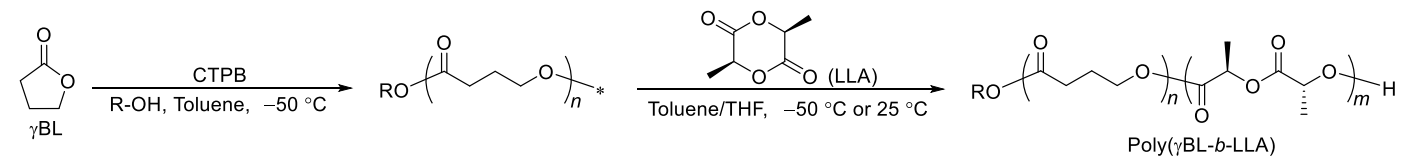

Scheme 4. (a) ROCP of $\gamma \mathrm{BL}$ with $\varepsilon \mathrm{CL}$ or $\delta \mathrm{VL}$ [91], (b) sequential ROP of $\gamma \mathrm{BL}$ and LLA 
Organic phosphines, including $\mathrm{PPh}_{3}, \mathrm{P}^{n} \mathrm{Bu}_{3}$ and $\mathrm{PCy}_{3}$, were employed as initiator/catalysts in the zwitterionic copolymerization of bicyclic bis( $\gamma$-butyrolactone)s (BBLs) and glycidyl phenyl ether (GPE) performed in THF at $120{ }^{\circ} \mathrm{C}$, generating polyesters with alternating sequence structures due to suppression of back-biting reactions. [95-97]. These monomer structures will be discussed further in section 6.

Looking at the possibility to prepare copolymers based on $\gamma$-lactones with mainly other lactones, lactides or epoxides, organic bases and in particular phosphazene bases are efficient systems permitting high molar masses and $\gamma$-BL incorporation under mild conditions. Properties of such copolymers only start to be investigated and will be developed in a near future, in particular, because of the possibility to introduce reactive functions via the $\gamma$-lactones.

\section{Alkali metal compound-catalyzed ROP/ROCP of $\gamma$-lactones}

The early investigation of ROP of $\gamma \mathrm{BL}$ was conducted in bulk at $80{ }^{\circ} \mathrm{C}$ for 12 months in the absence/presence of potassium carbonate $\left(\mathrm{K}_{2} \mathrm{CO}_{3}\right)$. No polymer was produced [16]. When the polymerization of $\gamma \mathrm{BL}$ was performed with $t$-BuOK in bulk at $40{ }^{\circ} \mathrm{C}$ under high pressure $(800 \mathrm{MPa})$, once again no $\mathrm{P} \gamma \mathrm{BL}$ was obtained[71]. However, the bulk ROP of $\gamma \mathrm{BL}$ was shown to proceed at $-40{ }^{\circ} \mathrm{C}$ with sodium or potassium methoxides (MtOMe) following an anionic mechanism to yield $\mathrm{P} \gamma \mathrm{BLs}\left(\overline{M_{n}}\right.$ $=9.2-14.0 \mathrm{~kg} \cdot \mathrm{mol}^{-1}$ and $\left.Ð=1.65-2.17\right)$ with low monomer conversion $(\leq 25 \%)$ after 4 
h. Block copolymers containing $\gamma \mathrm{BL}$ were also synthesized. For example, with potassium methoxide $(\mathrm{KOMe})$ or sodium hydride $(\mathrm{NaH})$ in $\mathrm{DCM} / \mathrm{THF}$ at $-50{ }^{\circ} \mathrm{C}$ $\left([\gamma \mathrm{BL}]_{0}=6 \mathrm{M}\right)$, PEG-OH was used as a macroinitiator to yield amphiphilic block copolymers PEG- $b-\mathrm{P} \gamma \mathrm{BL}$ with $\overline{M_{n}}=5.8-12.8 \mathrm{~kg} \cdot \mathrm{mol}^{-1}[94]$.

Sodium hydroxide $(\mathrm{NaOH})$ or sodium $n$-butoxide $(n$-BuONa) were used for the ROP of $\alpha \mathrm{AL}$, and only oligomers were produced at $\mathrm{RT}$, despite a $\mathrm{T}_{\mathrm{c}}$ estimated at $152^{\circ} \mathrm{C}$ [98-100].

When the five-membered lactone is fused to other cyclic substitutes, the ring strain of this compound changes and thus the monomer may become more polymerizable in some cases. Therefore, the polymerization of substituted $\gamma \mathrm{BL}$ derivatives such as spirocyclic $\gamma$-butyrolactone (SBL), 4,5-T6L and its cis isomer (4,5-C6L) were investigated $[72,101]$.

The ROP of SBL was investigated with $t$-BuOK or methyllithium (MeLi) at RT in THF (Scheme 5a) [101]. Polyesters with moderate molar masses $\left(\overline{M_{n}}=6.5-10.0\right.$ kg.mol $\left.{ }^{-1}, Ð=1.13-1.59\right)$ were obtained, which may be due to the tandem double ringopening reaction that involves an isomerization. The successful ROP of SBL also indicated that the increased ring strain of spirocyclic skeleton would reduce the degree of back-biting.

$t$-BuOK was also used for the homopolymerization of $4,5-\mathrm{T} 6 \mathrm{~L}$ in bulk at $40{ }^{\circ} \mathrm{C}$ (Scheme 5b) [72]. The resultant product showed moderate molar mass and relatively broad distribution $\left(\overline{M_{n}}=5.0 \mathrm{~kg} \cdot \mathrm{mol}^{-1}, Ð=1.62\right)$. Other anionic initiators with a stronger basicity such as $n$-butyllithium ( $n$-BuLi) and lithium diisopropylamide (LDA) were also 
efficient under the same conditions, leading to the synthesis of the corresponding polyesters with similar molar masses as observed with $t$-BuOK [73]. Meanwhile, the polymerization of its cis isomer (4,5-C6L) with the same anionic systems was unsuccessful, highlighting the contribution of the trans-fused cyclohexane for the improved polymerizability of 4,5-T6L [73].

a)
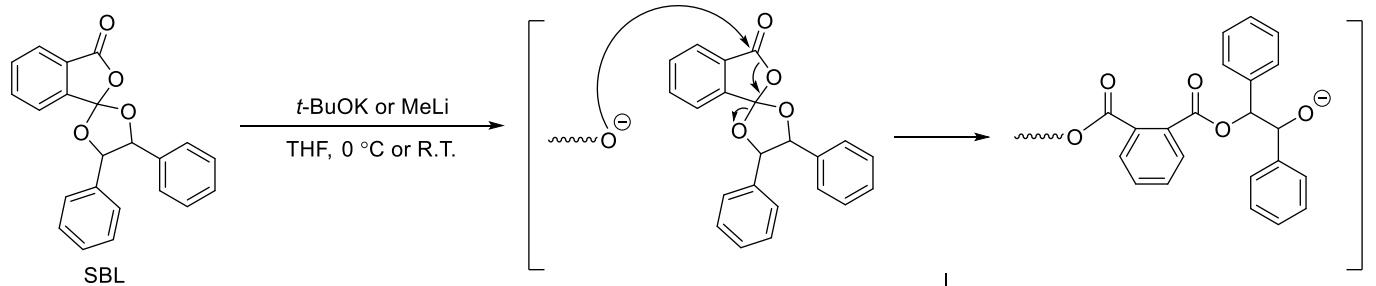

b)

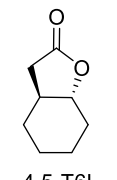

$t$-BuOK, $n$-BuLi or LDA

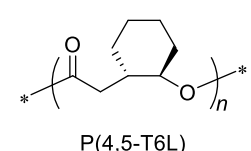

$4,5-\mathrm{T} 6 \mathrm{~L}$ Bulk, $40^{\circ} \mathrm{C}$

$\mathrm{P}(4,5-\mathrm{T} 6 \mathrm{~L})$

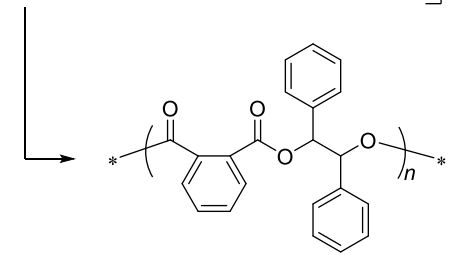

Poly(SBL)

Scheme 5. Alkali metal-catalyzed/initiated polymerization of $\gamma$ BL derivatives: (a) ROP of SBL [101], (b) ROP of 4,5-T6L [72].

The copolymerization strategy was also employed here. The random copolymerization of $\gamma \mathrm{BL}$ and $\varepsilon \mathrm{CL}$ was conducted with LDA in dioxane at $25{ }^{\circ} \mathrm{C}$, producing copolymers with $26 \%$ of $\gamma \mathrm{BL}$ incorporation [102]. While the ROP of bicyclic $\gamma$-butyrolactones was yielding only oligomers [103, 104], the copolymerization of bicyclic or spirocyclic bis( $\gamma$-lactone)s (e.g., BBL1-9, S-BBL1-3 and spirocyclic bis( $\gamma$ butyrolactone)s (SBBL) with GPE was investigated (Scheme 6) [95, 97, 105-109]. More particularly, the copolymerization of bicyclic bis( $\gamma$-lactone) bearing methyl group 
(BBL1) and GPE was conducted in THF at $120^{\circ} \mathrm{C}$ with $t$-BuOK as an initiator/catalyst $[105,106,108]$. The copolymerization was facilitated by the double ring-opening reaction of BBL1 that formed a ketone moiety in the polymer side chain, thus preventing the depolymerization reaction which would induce the reformation of stable five-membered lactones. The resultant copolymers show moderate molar masses $\left(\overline{M_{n}}\right.$ $\left.=4.6-8.2 \mathrm{~kg} \cdot \mathrm{mol}^{-1}\right)$ and relatively low dispersities $(Ð=1.20-1.30)$. Linear alternating copolymers with $\alpha, \omega$-alkoxide/H chain ends, linear copolymers with $\alpha, \omega$-carboxyl chain terminals and cyclic alternating ones were obtained [109].
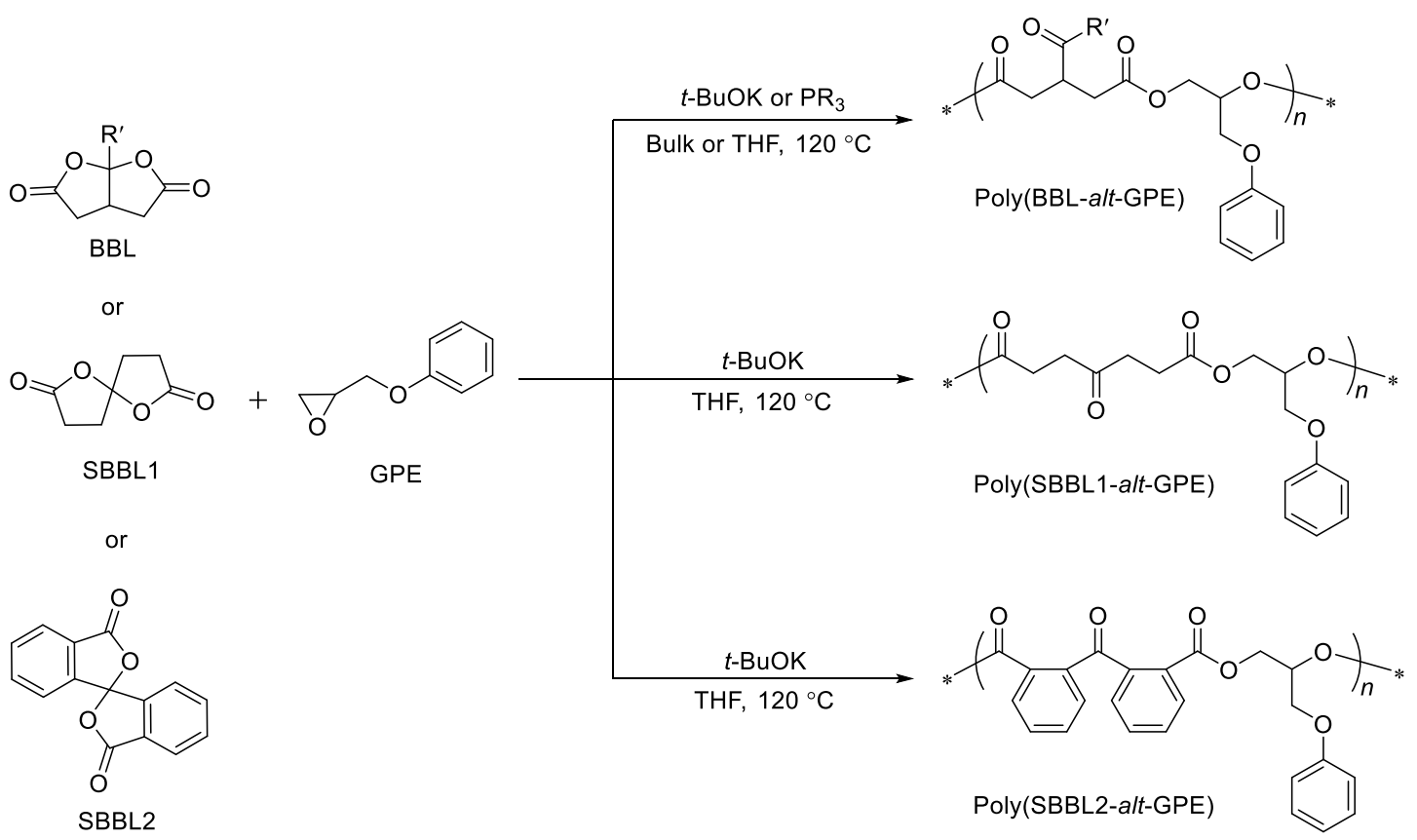

$\mathrm{BBL}, \mathrm{R}^{\prime}=\mathrm{Me}, \mathrm{Et}, \mathrm{Pr},{ }^{i} \mathrm{Pr}, \mathrm{Ph}, \mathrm{C}_{6} \mathrm{H}_{2}(\mathrm{OMe})_{3}$, $\mathrm{CH}_{2} \mathrm{OPh}, \mathrm{CH}\left(\mathrm{CH}_{3}\right)=\mathrm{CH}_{2}, \mathrm{CH}_{2} \mathrm{Cl}$ $\mathrm{PR}_{3}, \mathrm{R}=\mathrm{Ph},{ }^{n} \mathrm{Bu}, \mathrm{Cy}$

Scheme 6. Alkali metal compound-catalyzed/initiated ROCP of BBLs/SBBLs with GPE [105-110].

The scope of this alternating copolymerization system could be expanded to 
various BBL derivatives bearing different substitutes and diverse epoxides, including propylene oxide (PO), styrene oxide (SO) etc. (see cyclic ethers in Figure 3) [107, 108, 110, 111]. All the copolymers obtained showed a strictly alternating monomeric sequence distribution, with $\overline{M_{n}}=1.3-7.6 \mathrm{~kg} \cdot \mathrm{mol}^{-1}, Ð=1.05-1.62$. On the other hand, using SBBL as the comonomer also led to similar results, producing alternating polyesters [108]. In addition, polyfunctional epoxides such as poly(glycidyl methacrylate) (PGM) and poly(4-(glycidyl methyl)styrene) (PGMS) can also be copolymerized with BBLs or SBBLs under the same conditions, producing cross-linked copolymers $[107,111]$. Moreover, it was shown that the volume shrinkage during crosslinking of epoxy groups containing polymers can be considerably suppressed by such alternating copolymerization. Furthermore, the alternating copolymerization of BBLs and bifunctional epoxides such as diglycidyl ether bisphenol A (DGEBA) and diglycidyl ether bisphenol S (DGEBS) showed similar volume shrinkage effect [110].

All research based on alkali metal compound-catalyzed ROP/ROCP of $\gamma$-lactones follow an anionic mechanism and are related to the ones carried out with organic bases. Results follow the same trend but appear less convincing, due to limited efficiencies for some monomers depending on the ring strain. Only monometallic catalysts were used, and a fine tuning of the reactivity of the active centers by using multi-metallic systems might be a way of improvement. Nevertheless, new copolymers were prepared showing the possibilities to copolymerized those $\gamma$-lactones to other cyclic monomers.

7. Organometallic compound-catalyzed ROP/ROCP of $\gamma$-lactones 
Metal-based catalysts are employed for the ROP/ROCP or stereoselective ROP of cyclic esters to obtain corresponding (bio)degradable polyesters [112-116] following a coordination/insertion mechanism. Several metal-based compounds were also used for the ROP/ROCP of $\gamma \mathrm{BL}$ and derivatives. For instance, $\mathrm{P} \gamma \mathrm{BL}$ with $\overline{M_{n}}$ of $3 \mathrm{~kg} \cdot \mathrm{mol}^{-1}$ and slightly high dispersity $(\bigoplus=1.36)$ was produced using scandium(III) trifluoromethanesulfonate $\left(\mathrm{Sc}(\mathrm{OTf})_{3}\right)$ with methanol as the initiator under harsh conditions (800 $\mathrm{MPa}, 40{ }^{\circ} \mathrm{C}$ ) [71]. Oligomers with dehydration of $\alpha \mathrm{OH} \gamma \mathrm{BL}$ was produced in presence of $\mathrm{Sc}(\mathrm{OTf})_{3}$ at $40-80^{\circ} \mathrm{C}[56]$.

More recently, $\mathrm{La}\left[\mathrm{N}\left(\mathrm{SiMe}_{3}\right)_{2}\right]_{3}$ allowed the polymerization of $\gamma \mathrm{BL}$ at high monomer concentration $\left([\gamma \mathrm{BL}]_{0}=10 \mathrm{M}\right)$ and $-40{ }^{\circ} \mathrm{C}($ Scheme $7 \mathrm{a})[21]$. In absence of protic species (i.e., alcohols) as the initiator (sometimes also referred to chain transfer agent (CTA)), $\mathrm{Ln}\left[\mathrm{N}\left(\mathrm{SiMe}_{3}\right)_{2}\right]_{3}$ alone could polymerize $\gamma \mathrm{BL}$ with low yields (up to 3\%) to produce both linear $\mathrm{P} \gamma \mathrm{BL}$ with $\mathrm{MeO} / \mathrm{H}$ as the $\alpha, \omega$-chain ends ( $\mathrm{P} \gamma \mathrm{BLL} 3)$ and cyclic $\mathrm{P} \gamma \mathrm{BL}(\mathrm{P} \gamma \mathrm{BLC})$. The latter was presumably formed by the intramolecular back-biting reaction. Other Ln analogues gave similar results with a small decrease of the activity when the $\mathrm{Ln}$ ionic radius is varied $(\mathrm{La}>\mathrm{Sm}>\mathrm{Y})$. However, the most efficient way was to generate metal alkoxides using the combination of alcohols and $\mathrm{La}\left[\mathrm{N}\left(\mathrm{SiMe}_{3}\right)_{2}\right]_{3}$ by in situ alcoholysis to obtain $\mathrm{P} \gamma \mathrm{BL}$ with high molar mass in high yields. The initial molar ratio of $\mathrm{La} / \mathrm{PhCH}_{2} \mathrm{OH}(\mathrm{BnOH})$ had an obvious effect on the polymer structures. When the feed ratio of $\mathrm{La} / \mathrm{BnOH}=1 / 1$, linear $\mathrm{P} \gamma \mathrm{BL}$ with $\mathrm{BnO} / \mathrm{H}$ chain ends $\left(\mathrm{P}_{\gamma} \mathrm{BLL}_{2}\right)$ was the major product with the presence of minor $\mathrm{P} \gamma \mathrm{BLL} 3$ and $\mathrm{P} \gamma \mathrm{BLC}\left(\overline{M_{n}}=10.2-11.8 \mathrm{~kg} \cdot \mathrm{mol}^{-}\right.$ 1, $Ð=2.17-2.23)$. As the ratio of $\mathrm{La} / \mathrm{BnOH}$ increased to $1 / 3, \mathrm{P} \gamma \mathrm{BL} L 2$ became 
predominant and $\mathrm{P} \gamma \mathrm{BLL} 3 / \mathrm{P} \gamma \mathrm{BLc}$ were negligible $\left(\overline{M_{n}}=5.4-6.5 \mathrm{~kg} \cdot \mathrm{mol}^{-1}, Ð=1.26-\right.$ 1.38), indicating that most of the polymeric chains were obtained through the insertion of monomer into $\mathrm{BnO}-\mathrm{La}$ bond. In general, $\mathrm{P} \gamma \mathrm{BLs}$ displayed two $T_{\mathrm{m}}$, in which the lower one $\left(c a .52^{\circ} \mathrm{C}\right)$ was attributed to the $T_{\mathrm{m}}$ of the $\mathrm{P} \gamma \mathrm{BLC}$ and the higher one $\left(c a .63{ }^{\circ} \mathrm{C}\right)$ was attributed to the $T_{\mathrm{m}}$ of the linear polymer. Moreover, both the $T_{\mathrm{d}}$ and maximum degradation temperature $\left(T_{\max }\right)$ of the $\mathrm{P} \gamma \mathrm{BL}_{\mathrm{C}}\left(273{ }^{\circ} \mathrm{C}, 334{ }^{\circ} \mathrm{C}\right.$, respectively) was about $70{ }^{\circ} \mathrm{C}$ higher than that of the linear ones $\left(202{ }^{\circ} \mathrm{C}, 225^{\circ} \mathrm{C}\right.$, respectively), which was consistent with the hypothesis that the thermal stability of the cyclic polymer without chain ends is generally higher than that of the linear analogue [117]. Linear telechelic P $\gamma$ BLs with different termination chain ends were synthesized by the postpolymerization chain-end capping process [118]. Compared with the uncapped $\mathrm{P} \gamma \mathrm{BL}$, chain-end capped $\mathrm{P} \gamma \mathrm{BL}-\mathrm{OR}$ with similar molar masses significantly enhanced the $T_{\mathrm{d}}$ value by $55,65,78$, and $112^{\circ} \mathrm{C}$ for $\mathrm{R}=*-\mathrm{C}(=\mathrm{O}) \mathrm{Ph}, *-\mathrm{C}(=\mathrm{O}) \mathrm{CH}=\mathrm{CH}_{2}, *-\mathrm{C}(=\mathrm{O}) \mathrm{Me}$, and $*-\mathrm{SiMe}_{2} \mathrm{CMe}_{3}$, respectively. The resultant $\mathrm{P} \gamma \mathrm{BL}-\mathrm{OR}$ also showed enhanced resistance toward hydrolytic degradation, especially in basic medium. On the other hand, the thermal transition temperatures, thermal recyclability, and dynamic mechanical behaviour of the resulting polyesters were hardly influenced by the chainend capping.

Functional $\gamma \mathrm{BL}$ derivatives such as tulipalin $\mathrm{A}(\alpha \mathrm{MBL})$ which contains a highly reactive exocyclic $\mathrm{C}=\mathrm{C}$ bond, was also polymerized in a ring-opening pathway for the synthesis of unsaturated and degradable polyesters (Scheme 7b) [119]. The combination of $\mathrm{La}\left[\mathrm{N}\left(\mathrm{SiMe}_{3}\right)_{2}\right]_{3}$ and alcohols $(\mathrm{La} / \mathrm{ROH}=1 / 3)$ or $\mathrm{Y} 1 \mathrm{a}, \mathrm{Y} 1 \mathrm{k}$ alone proved to be the 
best catalytic systems for the ROP of $\alpha \mathrm{MBL}$ performed in THF at $-60{ }^{\circ} \mathrm{C}\left([\alpha \mathrm{MBL}]_{0}=\right.$ $5 \mathrm{M})$. La alone led to the formation of vinyl-addition polymerization product $\mathrm{P}(\alpha \mathrm{MBL})$ vaP, while lower amount of alcohols $($ e.g., $\mathrm{La} / \mathrm{ROH}=1 / 1)$ produced crosslinked polymers $\mathrm{P}(\alpha \mathrm{MBL})$ CLP. Interestingly, it was shown by density functional theory (DFT) calculation that the observed chemoselectivity was due to the steric bulkiness of the $*-\mathrm{N}\left(\mathrm{SiMe}_{3}\right)_{2}$ groups that would lead to the VAP process, while the La-OR group favoured the ROP one. Unsaturated $\mathrm{P}(\alpha \mathrm{MBL})$ ROP with $\overline{M_{n}}=4.6-10.4 \mathrm{~kg} \cdot \mathrm{mol}^{-1}$ and $Ð=$ $1.15-1.45$ were obtained with a ratio $\mathrm{La} / \mathrm{ROH}=1 / 3$ for various alcohols.

$\mathrm{La}\left[\mathrm{N}\left(\mathrm{SiMe}_{3}\right)_{2}\right]_{3}, \mathrm{Y} 1 \mathrm{a}$ or $(\mathrm{BDI}) \mathrm{ZnO}{ }^{i} \mathrm{Pr}(\mathrm{Zn} 1)$ complexes were employed for the polymerization of 3,4-T6L in bulk at RT [120]. Different macromolecular structures with various and high molar masses were obtained depending on the conditions used (Scheme 7c). One can note that a zinc catalyst (i.e. Zn1) showed good performances in terms of polymerization activity and polymer dispersity $\left(\overline{M_{n}}=27.1-588 \mathrm{~kg} \cdot \mathrm{mol}^{-1}, Ð=\right.$ 1.01-1.02). The $T_{\mathrm{d}}$ and $T_{\max }$ of the resulting linear polyesters $\left(316{ }^{\circ} \mathrm{C}, 390{ }^{\circ} \mathrm{C}\right.$, respectively) obtained by $\mathrm{La} / \mathrm{ROH}$ catalytic system were much higher than that of $\mathrm{P} \gamma \mathrm{BL}$ $\left(202{ }^{\circ} \mathrm{C}, 225^{\circ} \mathrm{C}\right.$, respectively), which demonstrated the positive effect of substitutes on the thermal properties of the corresponding polymer. In addition, the formation of nanocrystalline stereocomplexes of the two enantiomeric isotactic polymers (1:1) was observed and showed increased crystallinity, crystallization rate and solvent resistance as compared to the parent enantiomers.

Recently, commercial and simple organomagnesium compounds such as dialkylmagnesium $\left(n-\mathrm{Bu}_{2} \mathrm{Mg}, n\right.$-BuEtMg etc.) were used as catalysts for the 
polymerization of 3,4-T6L and its enantiomers, forming linear polyesters with welldefined moderate molar masses in bulk at RT [121].

Similarly, and taking benefit of this coordination-insertion mechanism, stereoselective ROP of racemic-3,4-cyclohexyl-ring fused $\gamma$-butyrolactone ( $r a c$-CBL) [122] using achiral yttrium complexes bearing $N, O$ tetradentate ligands (Y1a, Y1i, Y1j, Y3 etc.) could be achieved. The tethered donor sidearm of Y catalysts induced a switch from heteroselectivity to isoselectivity via a chain-end control mechanism. The ROP of rac-CBL by Y1a with the $\beta$-OMe side group alone or combined with alcohols produced heterotactic PCBL (ht-PCBL) $\left(\overline{M_{n}}=18.6-102 \mathrm{~kg} \cdot \mathrm{mol}^{-1}, Ð=1.02-1.34\right)$. The coordination-insertion polymerization by more sterically hindered Y $1 \mathrm{i}$ and $\mathrm{Y} 1 \mathrm{j}$ with the $\beta-\mathrm{NMe}_{2}$ side group afforded crystalline isotactic it $\mathrm{PCBL}\left(\overline{M_{n}}=2.83 \mathrm{~kg} \cdot \mathrm{mol}^{-1}, Ð=\right.$ 1.04, probability of meso enchainment $\left.\left(P_{\mathrm{m}}\right)=0.95\right)$, with a $T_{\mathrm{m}}$ up to $171^{\circ} \mathrm{C}$. Meanwhile, the ROP of 4,5-T6L, a constitutional isomer of 3,4-T6L, was also investigated (Scheme 7d) [123]. Similar results were observed and poly(4,5-T6L- $b-\varepsilon C L)$ block copolymers were prepared.

This approach confirmed the expected possible stereoregulation for such $\gamma$ lactones, permitting control of the polymer tacticity and therefore the related properties. 
a)

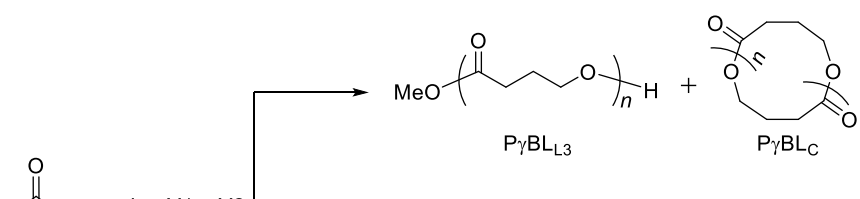

$\sum_{\gamma B L} \frac{\operatorname{Ln}, Y 1 a, Y 2}{T H F,-40{ }^{\circ} \mathrm{C}}$

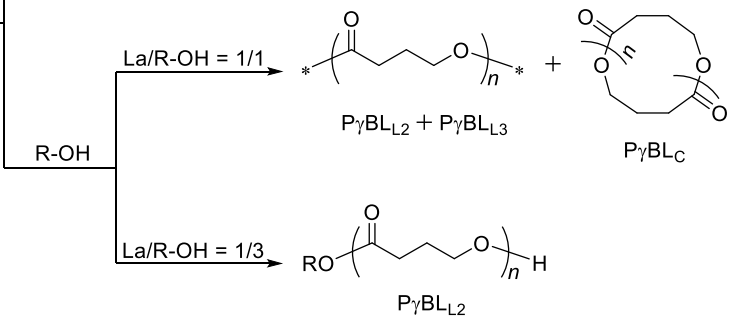

b)

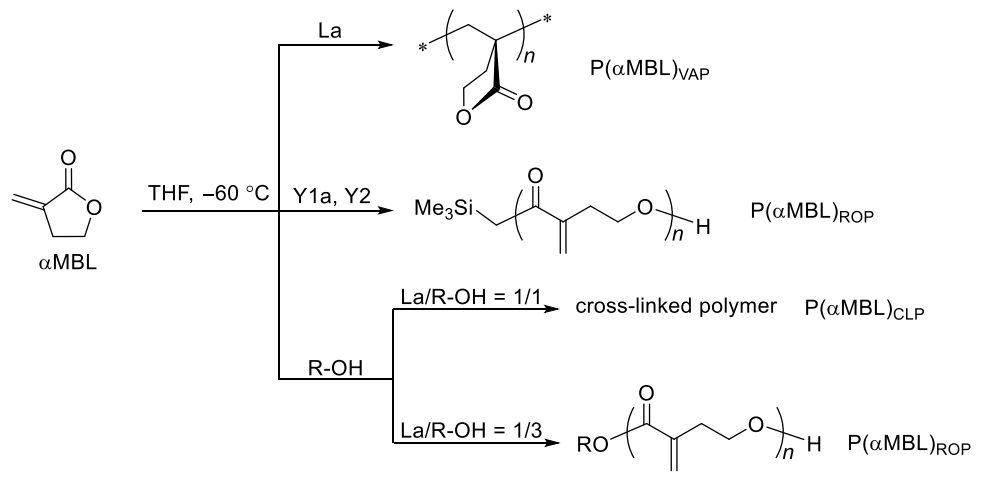

c)
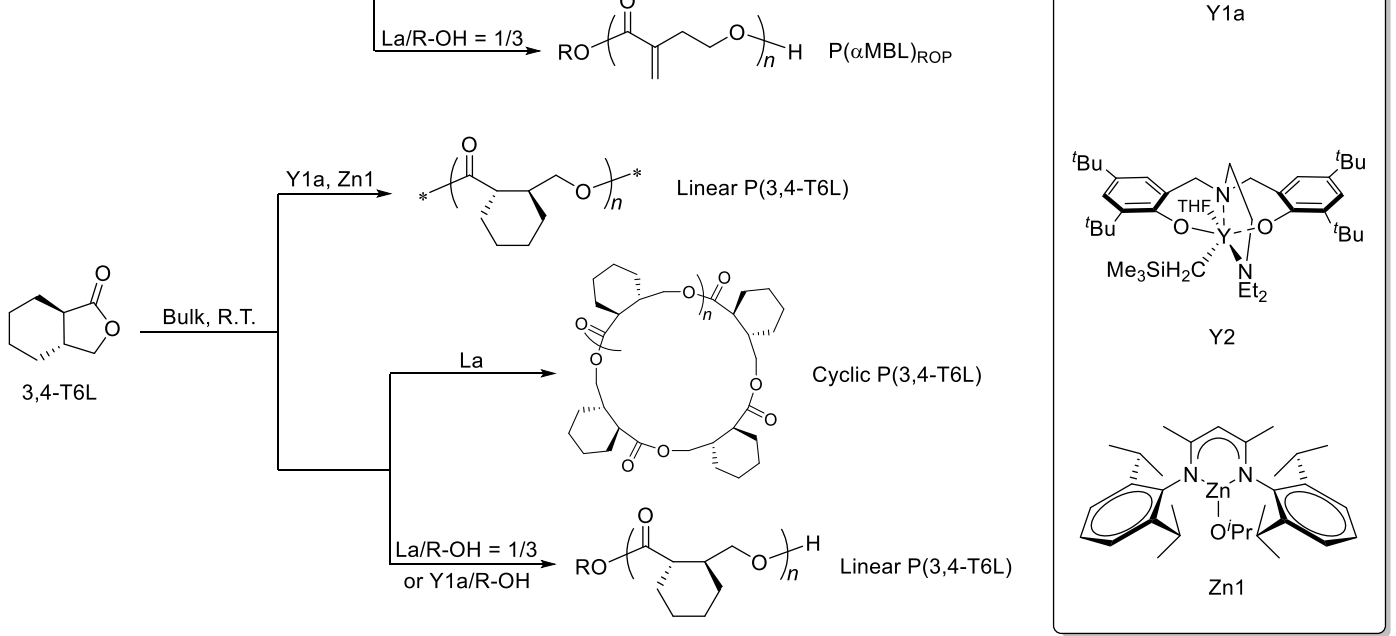

Y2

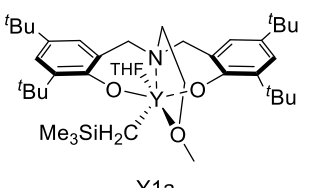

Y1a

$\operatorname{Ln}\left[\mathrm{N}\left(\mathrm{SiMe}_{3}\right)_{2}\right]_{3}$

$\mathrm{Ln}=\mathrm{La}, \mathrm{Y}, \mathrm{Sm}$
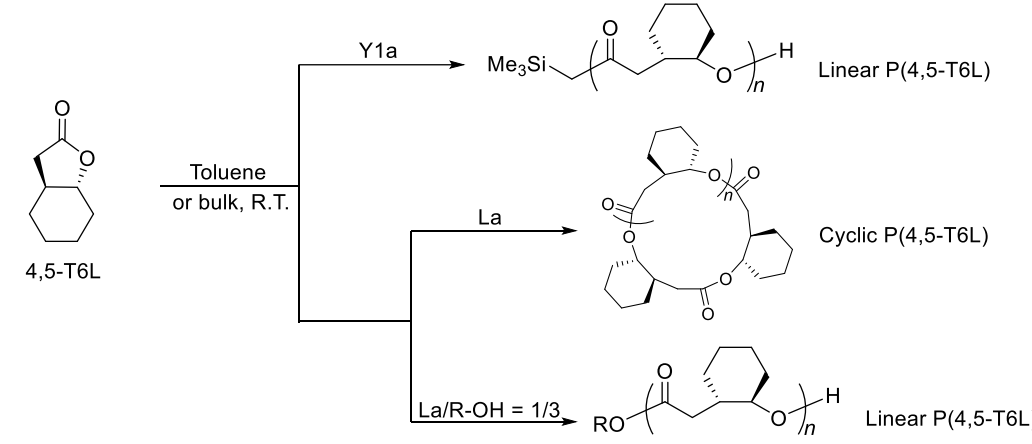

Scheme 7. Examples of ROP of $\gamma$-lactones by coordination-insertion mechanism: (a) $\gamma \mathrm{BL}$ [21], (b) $\alpha \mathrm{MBL}$ [119], (c) 3,4-T6L [120], (d) 4,5-T6L [123]. 
As already mentioned, ROCP of $\gamma \mathrm{BL}$ or its derivatives and other cyclic monomers with high ring-strain energy (e.g., lactones, cyclic ether) is a different way to circumvent the "non-polymerizability" of $\gamma \mathrm{BL}$ and to tune the properties of polymers.

Many catalytic systems (e.g. $\mathrm{Sc}(\mathrm{OTf})_{3}, \mathrm{Al}\left(\mathrm{O}^{i} \mathrm{Pr}\right)_{3}, \mathrm{La}\left[\mathrm{N}\left(\mathrm{SiMe}_{3}\right)_{2}\right]_{3}$, Sn complexes, $\mathrm{Sm}(\mathrm{OAr})_{2}(\mathrm{THF})_{3}$ or aluminum Schiff's bases) and comonomers (BCMO, $\left.\beta \mathrm{BL}, \varepsilon \mathrm{CL}\right)$ added to $\gamma \mathrm{BL}$ were investigated, enabling the synthesis of various polymer structures and $\gamma \mathrm{BL}$ fraction (Scheme 8a) [78, 91, 102, 124-130].

As an example, poly $(\gamma \mathrm{BL}-c o-\varepsilon \mathrm{CL}) \mathrm{s}$ with $84 \%$ of $\gamma \mathrm{BL}$ content revealed a higher degradation rate than PCL, following the degradation order $\left[\mathrm{OH}^{-} / \mathrm{H}_{2} \mathrm{O}\right]>\left[\mathrm{H}^{+} / \mathrm{H}_{2} \mathrm{O}\right]>$ $\left[\mathrm{H}_{2} \mathrm{O}\right]$. The incorporation of $\gamma \mathrm{BL}$ into PCL is a way to regulate its degradation rate.

Interestingly, alternated poly(amine urethane)s were synthesized by the copolymerization of tetramethylene urea (TeU) and $\gamma \mathrm{BL}$ [131]. Di- $n$-butylmagnesium $\left(n\right.$-Bu $\mathrm{Bu}_{2} \mathrm{Mg}$ ) was employed as the catalyst in bulk at $100{ }^{\circ} \mathrm{C}$ (Scheme $8 \mathrm{~b}$ ). Terpolymers of $\mathrm{TeU}, \gamma \mathrm{BL}$, and ethylene carbonate (EC) or propylene carbonate (PC) were also synthesized in the same reaction conditions.

$\mathrm{CO}_{2}$ was also proposed to be part of the copolymerization of $\mathrm{PO}$ with $\gamma \mathrm{BL}$ in benzene at $60{ }^{\circ} \mathrm{C}$ with polymer supported bimetallic complexes (PBM, P$\mathrm{Zn}[\mathrm{Fe}(\mathrm{CN}) 6]_{a} \mathrm{Cl}_{2-3 a}\left(\mathrm{H}_{2} \mathrm{O}\right)_{b}$, where $\mathrm{P}$ is a polyether type chelating agent) $[132,133]$. With the increased $\gamma \mathrm{BL}$ incorporation, the resultant copolymers exhibited varied $\overline{M_{v}}$ from 59.8 to $123 \mathrm{~kg} \cdot \mathrm{mol}^{-1}$, as well as enhanced degradability.

Amphiphilic block copolymers of PEG- $b$-poly $(\gamma \mathrm{VL}-c o-\varepsilon \mathrm{CL})$ were synthesized 
using PEG-OH as a macroinitiator with $\mathrm{Sn}(\mathrm{Oct})_{2}$ at elevated temperatures $\left(120-160^{\circ} \mathrm{C}\right)$ $[134,135]$. The lower temperature was beneficial to the copolymerization, providing more controlled copolymers with relatively narrow distribution $\left(\overline{M_{n}}=8.6-10.6 \mathrm{~kg} \cdot \mathrm{mol}^{-}\right.$ $\left.{ }^{1}, Ð=1.18-1.25\right)$. When the incorporation of $\gamma \mathrm{VL}$ was increased $(9-16 \%)$, the copolymers showed higher surface hydrophilicity, decreased crystallization, and consequently higher biodegradation rates.

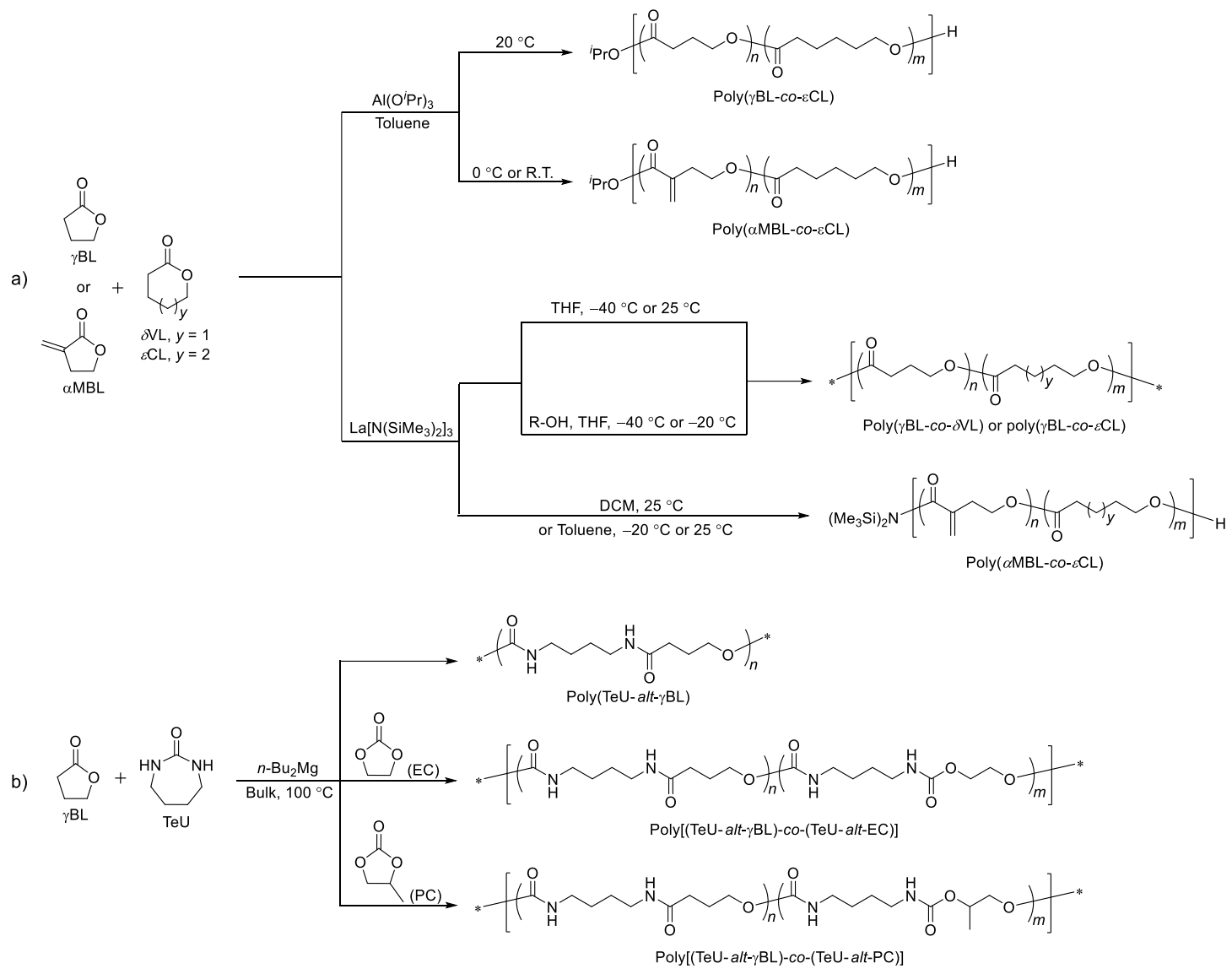

Scheme 8. Examples of ROCP of $\gamma$-lactones by coordination-insertion mechanism: (a) $\gamma \mathrm{BL}$ and $\varepsilon \mathrm{CL} / \delta \mathrm{VL}[91,125], \alpha \mathrm{MBL}$ and $\varepsilon \mathrm{CL}[78,136],(b) \gamma \mathrm{BL}, \mathrm{TeU}$ and/or EC, PC [131]. 
Following a similar approach, the copolymerization of $\alpha \mathrm{MBL}$ and $\varepsilon \mathrm{CL}$ was first carried out in bulk at $130{ }^{\circ} \mathrm{C}$ using bismuth(III) trifluoromethanesulfonate (Bi(OTf) $\left.)_{3}\right)$ as the catalyst, which actually led to a mixture of ring-opening copolyester, poly $(\alpha \mathrm{MBL}-c o-\varepsilon \mathrm{CL})$, and undesired homopolymer, $\mathrm{P}(\alpha \mathrm{MBL}) \mathrm{VAP}$, originating from the vinyl-addition polymerization of $\alpha \mathrm{MBL}$ [136, 137]. More recently, unsaturated copolyesters poly $(\alpha \mathrm{MBL}-c o-\varepsilon \mathrm{CL})$ without contamination of $\mathrm{P}(\alpha \mathrm{MBL}) \mathrm{VAP}$ were obtained with lanthanide compounds $\left(\operatorname{Ln}\left[\mathrm{N}\left(\mathrm{SiMe}_{3}\right)_{2}\right]_{3}\right)$ [136]. The $T_{\mathrm{m}}$ of the obtained poly $(\alpha \mathrm{MBL}-c o-\varepsilon \mathrm{CL})$ decreased linearly with the increase of the amount of $\alpha \mathrm{MBL}$ incorporated, as $\alpha \mathrm{MBL}$ units prevented the crystallization of PCL segments.

The ROP of $\alpha \mathrm{AL}$ was successfully carried out in toluene at $110-130{ }^{\circ} \mathrm{C}$ using $\mathrm{Sn}(\mathrm{Oct})_{2}$ as the catalyst/initiator (Scheme 9a) $[138,139]$. Aliphatic unsaturated poly $(\alpha-$ angelica lactone)s ( $\mathrm{P} \alpha \mathrm{AL})$ with carboxylic and hydroxyl groups as the chain-ends were obtained $\left(\overline{M_{n}}=8.9-29.4 \mathrm{~kg} \cdot \mathrm{mol}^{-1}, Ð=1.12-1.57\right)$, corresponding to a coordinationinsertion mechanism. The degradability of these synthesized P $\alpha \mathrm{AL}$ was tested in different conditions, and the degradation rate follows the order of basic $(\mathrm{pH}=10.0)>$ acidic $(\mathrm{pH}=2.5)>$ neutral $(\mathrm{pH}=7.0)$. Through DFT analysis, it was inferred that the presence of endocyclic $\mathrm{C}=\mathrm{C}$ significantly increased the strain energy of the corresponding five-membered ring, leading to the ROP of $\alpha \mathrm{AL}$ under moderate conditions. This catalytic system was also applied for the copolymerization of $\alpha \mathrm{AL}$ and $\varepsilon \mathrm{CL}$ to produce poly $(\alpha \mathrm{AL}-c o-\varepsilon \mathrm{CL})$ s with $30-47 \%$ of $\alpha \mathrm{AL}$ incorporation $\left(\overline{M_{n}}=5.8-7.4\right.$ kg.mol ${ }^{-1}, Ð=1.19-1.33$ ) (Scheme 9a) [140]. The incorporation of $\alpha$ AL significantly decreased the crystallization of PCL and showed an enhanced degradability compared 
to PCL.

Graft copolymers with a degradable polyester backbone were obtained through the copolymerization of $\alpha$-bromo- $\gamma$-butyrolactone $(\alpha \mathrm{Br} \gamma \mathrm{BL})$ and $\varepsilon \mathrm{CL}$ or LLA. The ROCP was conducted in bulk at $110^{\circ} \mathrm{C}$ using $\mathrm{Sn}(\mathrm{Oct})_{2}$ as the catalyst (Scheme 9b) [141]. The non-homopolymerizability of $\alpha \mathrm{Br} \gamma \mathrm{BL}$ under such conditions was confirmed, and only separated $\alpha \mathrm{Br} \gamma \mathrm{BL}$ units were detected. The $\alpha \mathrm{Br} \gamma \mathrm{BL}$ incorporation was always below $12 \%$. This was consistent with their reactivity ratios, i.e., $r_{\mathrm{LLA}}=18.48, r_{\varepsilon \mathrm{CL}}=4.43$ and $r_{\alpha \mathrm{Br} \gamma \mathrm{BL}}$ close to 0 for both ( 0.32 and 0.01 , respectively). These copolymers were used for SET-LRP, with separated $\alpha \mathrm{Br} \gamma \mathrm{BL}$ units as active grafting sites. Several acrylic monomers such as methyl methacrylate (MMA), 2-hydroxyethyl methacrylate, and butyl acrylate were successfully grafted onto the poly $(\alpha \operatorname{Br} \gamma \mathrm{BL}-c o-\varepsilon \mathrm{CL})$ backbone in a controlled manner.

The ROCP of $\gamma \mathrm{BL}$ and 3,4-T6L was investigated in order to produce a new class of biorenewable and degradable materials (Scheme 9c) $[142,143] . \mathrm{La}\left[\mathrm{N}\left(\mathrm{SiMe}_{3}\right)_{2}\right]_{3}$, $\mathrm{Zn} 1$ and Y1a complexes proved to be suitable for the copolymerization. The obtained polymers showed ductility and barrier properties that are suitable for packaging applications and could be readily modified by adjusting the copolymer composition to obtain materials suitable for specific purposes.

The $\alpha \mathrm{OH} \gamma \mathrm{BL}$ was chosen as the inimer to be copolymerized with $\varepsilon \mathrm{CL}$ [144]. The copolymerization was performed in toluene or bulk at $110^{\circ} \mathrm{C}$ using $\operatorname{Sn}(\mathrm{Oct})_{2}$. Branched copolyesters with various degree of branching were synthesized. The higher amount of branching led to the decrease of $T_{\mathrm{m}}$. Interestingly, $\alpha$-hydroxy- $\beta, \beta$-dimethyl- $\gamma$ - 
butyrolactone ( $\left.\alpha \mathrm{OH} \beta \mathrm{Me}_{2} \gamma \mathrm{BL}\right)$ could only serve as an initiator in such copolymerization due to the steric hindrance of the substitutes. Copolymerization of $\gamma \mathrm{BL}$ and glycidol was also an alternative to produce such branched structures [145].

a)

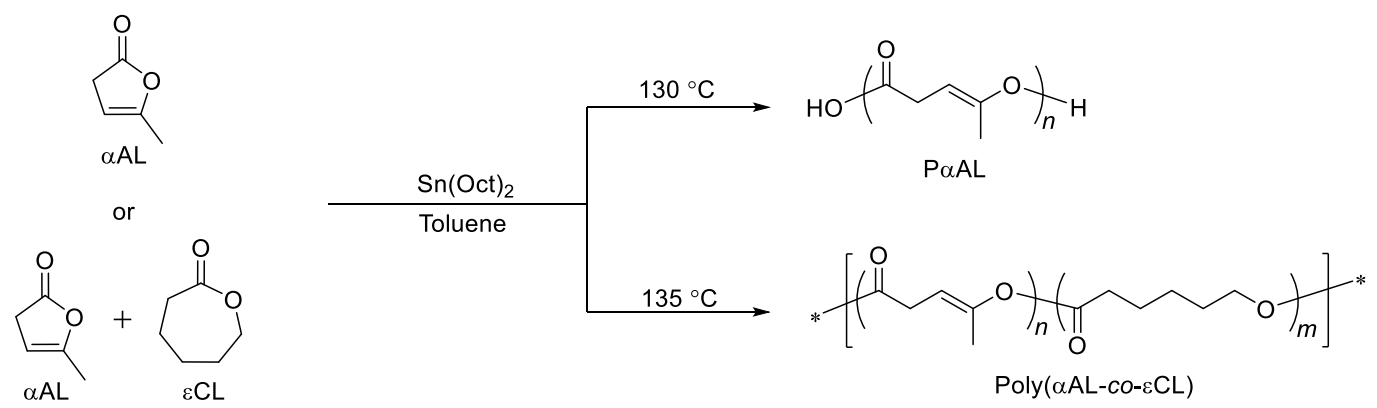

b)
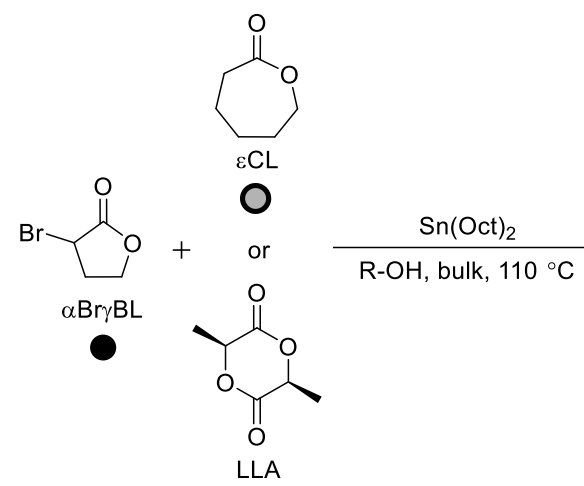

O

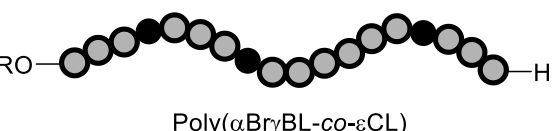

c)

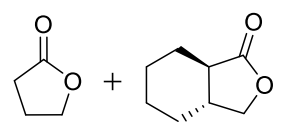

$\gamma \mathrm{BL}$

$3,4-\mathrm{T} 6 \mathrm{~L}$

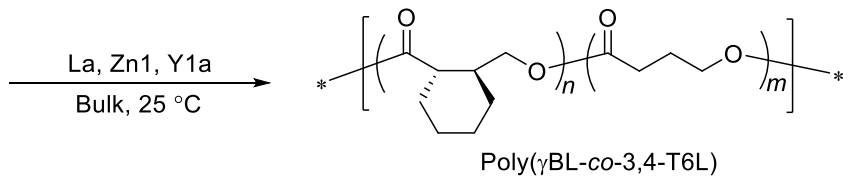

Scheme 9. Examples of ROCP of $\gamma$-lactones by coordination-insertion mechanism: (a) $\alpha \mathrm{AL}$ and $\varepsilon \mathrm{CL}[138,140]$, (b) $\alpha \mathrm{Br} \gamma \mathrm{BL}$ and $\varepsilon \mathrm{CL} / \mathrm{LLA}[141]$, (c) $\gamma \mathrm{BL}$ and 3,4-T6L [143].

Organo-metallic systems permitting a coordination-insertion mechanism also appear to be efficient catalysts for the homopolymerization of $\gamma$-lactones and their copolymerization with other cyclic monomers, yielding polyesters with enhanced 
degradability. High molar masses can be reached by this route. A few works are dealing with stereoselectivity, which make this route unique to produce specific materials.

8. Dual catalytic system-catalyzed ROP/ROCP of $\gamma$-lactones

Bifunctional catalytic systems (also termed as cooperative catalysts) including bicomponent catalysts (Lewis acid-base pairs) and bifunctional unimolecular catalysts like the cyclic guanidine TBD were widely investigated and utilized for the polymerization of polar monomers (e.g., polar vinyl monomers, cyclic esters and others). Several reviews focusing on this subject were already published [42, 43, 146152]. The advantage of such systems originates from the cooperative dual activation of both the monomer and the initiator/chain end. Such bifunctional dual activation is the result of the combination of an electrophile (e.g., weak Brønsted acids) activating the monomer (activated monomer mechanism, AMM) and a general base activating the initiator/chain end (activated chain-end mechanism, ACEM) (Scheme 10), which provides an effective means to trigger/promote the ROP and improves the selectivity of the polymerization over side reactions.

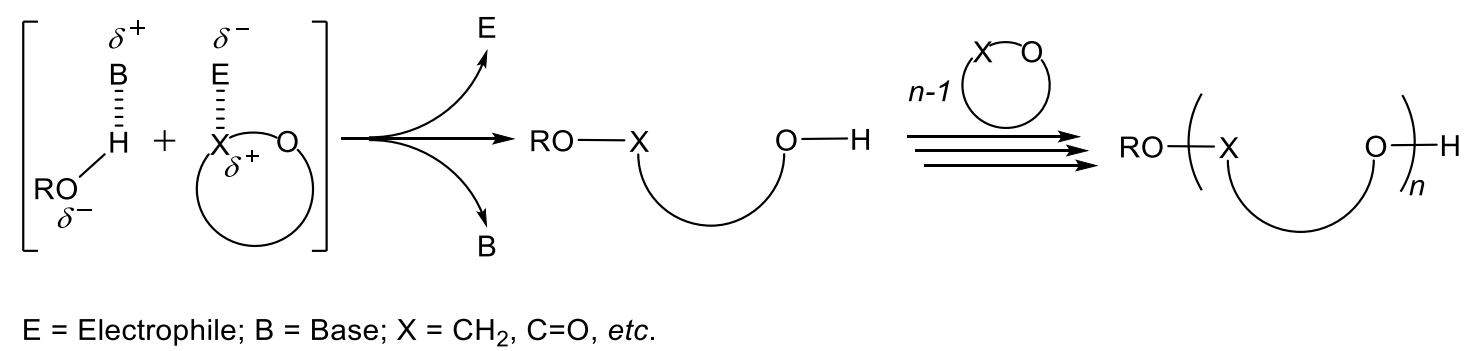

Scheme 10. Bifunctional activation mechanism for ROP of cyclic monomers. 
Generally, (thio)ureas are a class of representative hydrogen-bonding donors which were widely utilized in organic base-catalyzed cyclic monomers (e.g., lactones, lactides, cyclic carbonates etc.) [153-155]. The presence of (thio)ureas is usually considered to play dual roles during the polymerization, i.e., activating the monomer as well as associating with the chain end. The latter character sometimes can also be regarded as modifying the basicity/nucleophilicity of the active species. This hypothesis was proven through the synthesis of polyether-based block copolymers via a "catalyst switch" strategy $[156,157]$. The addition of thiourea (TU) was shown to attenuate the basicity of the active center. This allowed the controlled polymerization of the subsequently added monomers, and prevented side reactions that are usually caused by the strong basicity of alkoxides. Such retarded active species strategy was also applied to the ROP of $\gamma \mathrm{BL}$ and derivatives.

Linear $\mathrm{P} \gamma \mathrm{BLs}$ with high molar masses were synthesized in toluene at low temperatures $\left(<-40{ }^{\circ} \mathrm{C}\right)$ through the combination of $t-\mathrm{BuP}_{4}$ and symmetrical thioureas bearing electron-donating groups (Scheme 11a) [25]. In absence of alcohol as the initiator, the ROP of $\mathrm{P} \gamma \mathrm{BL}$ could be directly initiated/catalyzed by the dual organocatalyst 1,3-diisopropyl-2-thiourea (TU1) TU1/t-BuP 4 . Depending on the feed ratios of TU1/t-BuP4, a mixture of $\mathrm{P}_{\mathrm{BLL} 1}$ and $\mathrm{P} \gamma \mathrm{BLc}$ or only $\mathrm{P} \gamma \mathrm{BLL} 1\left(\mathrm{TU} 1 / t-\mathrm{BuP}_{4}=1\right.$ or 1.5) was obtained. Using the latter feed ratio, $\mathrm{P} \gamma \mathrm{BLL1}$ with higher molar mass $\left(\overline{M_{n}}=\right.$ $64.3 \mathrm{~kg} \cdot \mathrm{mol}^{-1}, Ð=2.35$ ) was produced when the polymerization was performed at $55^{\circ} \mathrm{C}$. On the other hand, the addition of an alcohol $(\mathrm{BnOH})$ could greatly decrease the 
formation of $\mathrm{P} \gamma \mathrm{BLL} 1$ and cyclic polymer. Fully BnO-initiated polyester ( $\mathrm{P} \gamma \mathrm{BLL} 2)$ was obtained. The combination of DBU and TU2 (1-[3,5-bis(trifluoromethyl) phenyl]-3cyclohexyl-thiourea) was also effective to polymerize $\gamma \mathrm{BL}$ in bulk [75].

Similarly, a binary catalytic system composed of ureas and CTPB was also studied for the polymerization of $\gamma \mathrm{BL}$ conducted in THF at $-50^{\circ} \mathrm{C}$ (Scheme $11 \mathrm{~b}$ ) [158]. In the absence of the initiator $(\mathrm{BnOH})$, 1-cyclohexyl-3-(4-methoxyphenyl)-urea (U2; $\mathrm{U} 2 / \mathrm{CTPB}=3 / 1$ ), a urea bearing unsymmetrical and electron-donating substituents, yielded a mixture of high molar mass $\mathrm{P}_{\gamma} \mathrm{BLL}_{\mathrm{L} 1}$ and $\mathrm{P} \gamma \mathrm{BL}_{\mathrm{C}}$ with $c a .50 \%$ monomer conversion $\left(\overline{M_{n}}=28-35 \mathrm{~kg} \cdot \mathrm{mol}^{-1}, Ð=1.90-2.06\right)$. However, keeping U2/CTPB at 3/1 and adding $\mathrm{BnOH}$ as the initiator favoured the formation of mainly $\mathrm{P} \gamma \mathrm{BLL} 2\left(\overline{M_{n}}=9.1-\right.$ $\left.23.3 \mathrm{~kg} \cdot \mathrm{mol}^{-1}, Ð=1.38-2.13\right)$. Noticeably, the thermal stability and mechanical properties of the resultant $\mathrm{P} \gamma \mathrm{BLs}$ were improved with increasing molar mass.

Adding (thio)ureas to phosphazene bases for the polymerization of $\gamma \mathrm{BL}$ appeared to be efficient. Initiation was more selective, and defined (linear) structures were produced. 


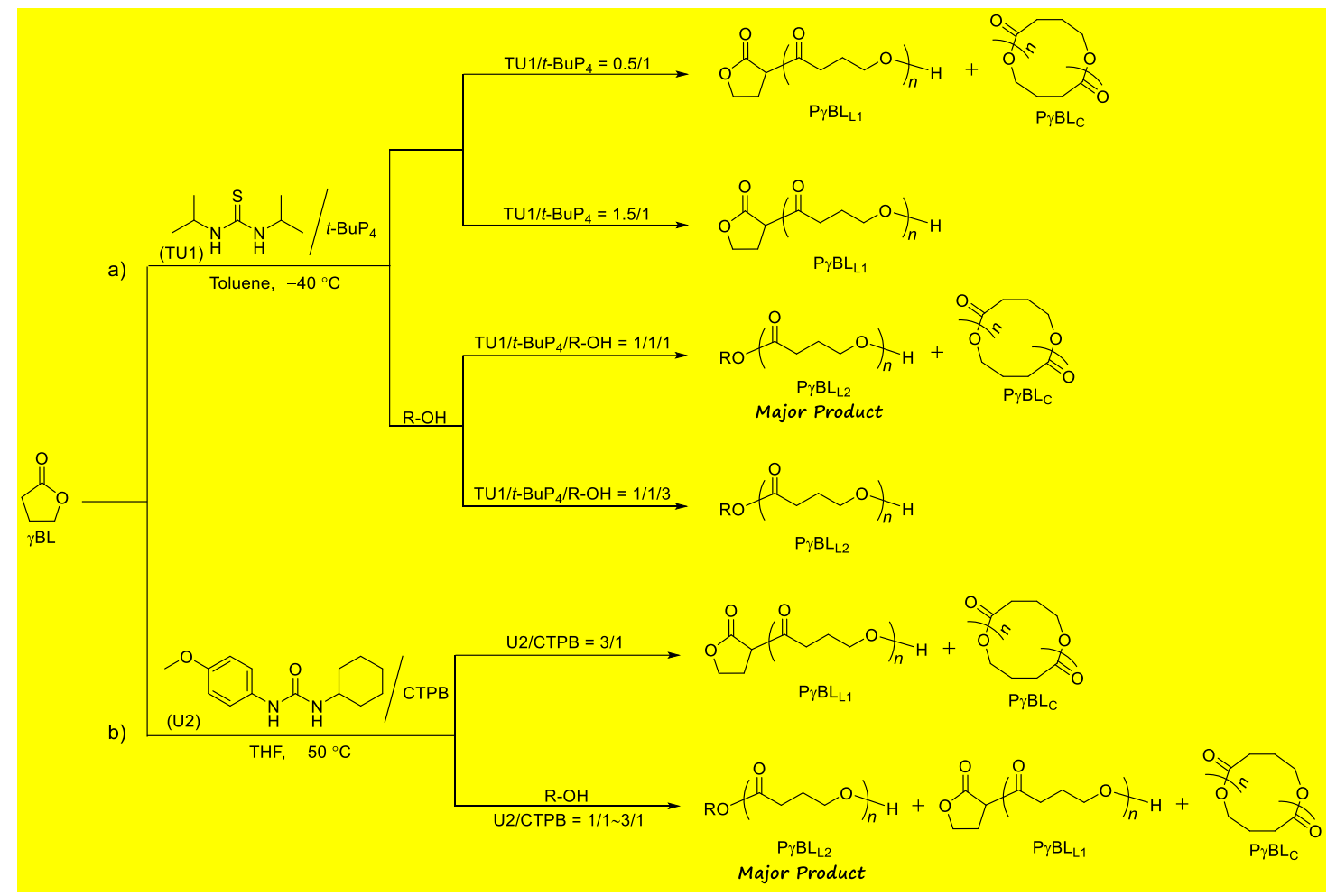

Scheme 11. ROP of $\gamma \mathrm{BL}$ by different dual catalytic systems: (a) TU1/t-BuP4 [25], (b) $\mathrm{U} 2 / \mathrm{CTPB}[158]$.

Bicomponent catalysts composed of NHOs and lithium halides (LiX) were used for the ROP of $\gamma \mathrm{BL}$ in bulk at $-36{ }^{\circ} \mathrm{C}$ (Scheme 12) [24]. With $\mathrm{BnOH}$ as the initiator, NHO3 and LiX $(\mathrm{NHO} 3 / \mathrm{LiX}=1 / 5)$ provided a mixture of $\mathrm{P} \gamma \mathrm{BLL} 2$ and $\mathrm{P} \gamma \mathrm{BLC}$ with a monomer conversion similar to the one obtained with NHOs alone $\left(\overline{M_{n}}=4.7-7.8\right.$ kg.mol $\left.{ }^{-1}, Ð=1.4-1.8\right)$. Interestingly, NHOs/LiX could also trigger the polymerization without any alcohol. The topological structures of the obtained $\mathrm{P} \gamma \mathrm{BLs}$ depended on the nucleophilicity and steric hindrance of involved NHOs. For example, the combination of $\mathrm{LiCl}$ and $\mathrm{NHO} 4$, which is highly basic and sterically hindered, led to the formation of linear P $\gamma$ BLL1 $\left(\overline{M_{n}}=5.8 \mathrm{~kg} \cdot \mathrm{mol}^{-1}, Ð=1.6\right)$ based on an anionic ROP mechanism. On 
the contrary, the association of $\mathrm{LiCl}$ and $\mathrm{NHO}$, which is highly nucleophilic and sterically non-hindered, provided NHO-terminated $\mathrm{P} \gamma \mathrm{BL}$ based on a zwitterionic ROP mechanism $\left(\overline{M_{n}}=3 \mathrm{~kg} \cdot \mathrm{mol}^{-1}, Ð=1.9\right)$. The association of LiX and NHO6, which is mildly polarized and sterically hindered, delivered exclusively the macrocyclic $\mathrm{P} \gamma \mathrm{BLC}$ in short reaction time, whereas increasing amounts of enolate-terminated $\mathrm{P} \gamma \mathrm{BL}$ 1 appear with time $\left(\overline{M_{n}}=1.6-9 \mathrm{~kg} \cdot \mathrm{mol}^{-1}, Ð=1.4-2.4\right)$. In addition, and irrespective of the pathway, low monomer conversion was observed $(<20 \%)$.

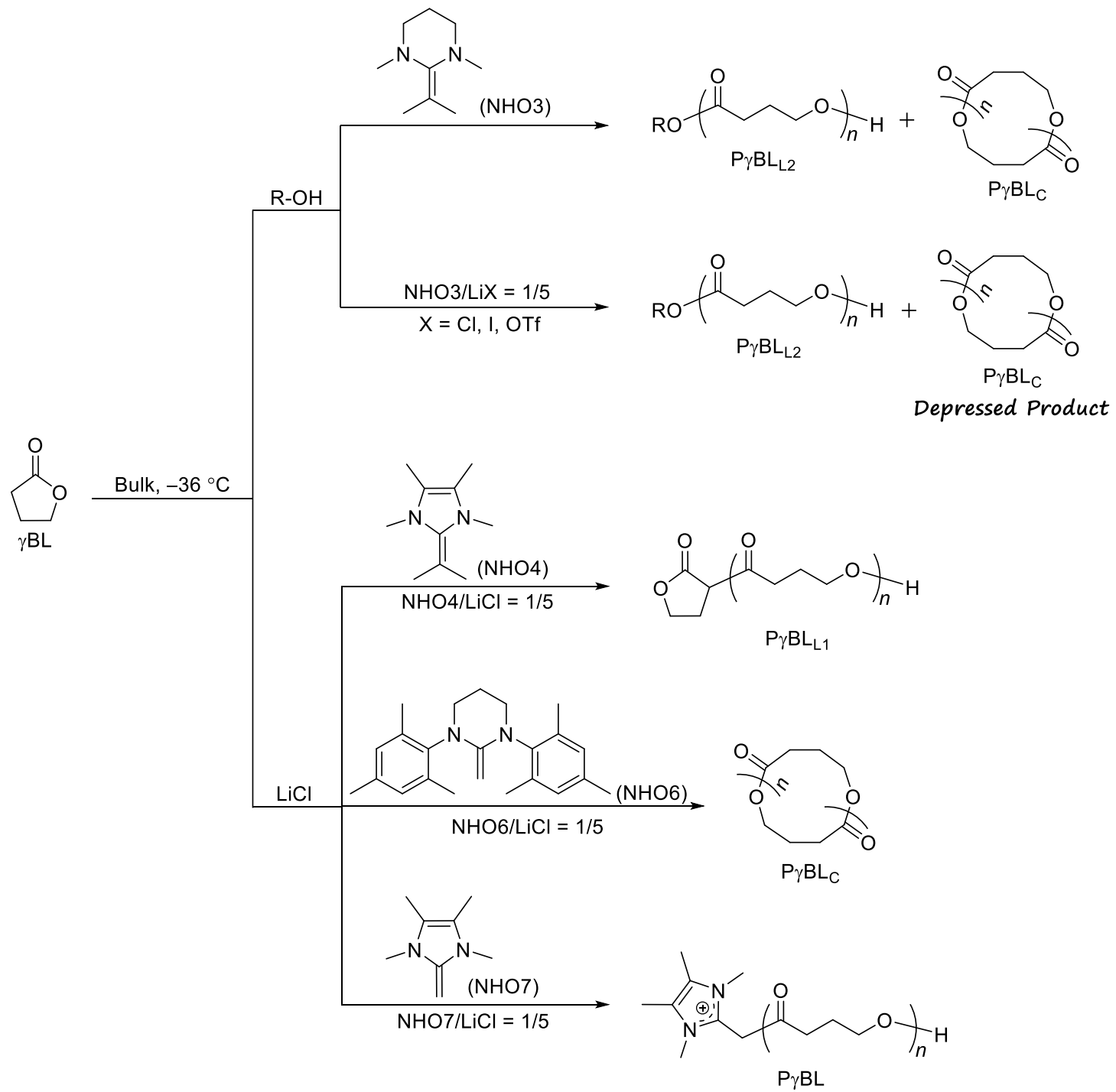

Scheme 12. ROP of $\gamma \mathrm{BL}$ by LiX/NHOs dual catalytic system [24]. 
Commercial alkoxides such as sodium or potassium methoxides (MtOMe) were also combined with ureas to polymerize $\gamma \mathrm{BL}$ (Scheme 13a) [26]. Its bulk polymerization was shown to procced at $-40{ }^{\circ} \mathrm{C}$ using $\mathrm{MtOMe}$ alone with limited monomer conversion $(\leq 25 \%)$. Combination of 1-cyclohexyl-3-phenyl-urea (U1) and MtOMe (U1/MtOMe $=1 / 1$ to $3 / 1$ ) enhanced the reactivity of the active species, allowing for the ROP of $\gamma \mathrm{BL}$ in bulk at low temperatures $\left(-40\right.$ to $\left.-20^{\circ} \mathrm{C}\right)$, and a monomer conversion with up to $86 \%$ was achieved in a few hours. The obtained P $\gamma$ BLs showed two different chain ends, i.e., $\mathrm{MeO} / \mathrm{H}$ and acylated lactone $/ \mathrm{H}\left(\overline{M_{n}}=7.0-68.2 \mathrm{~kg} \cdot \mathrm{mol}^{-1}, Ð=1.33-2.08\right)$ [158].

The ROP of substituted $\gamma \mathrm{BL}, 4,5-\mathrm{T} 6 \mathrm{~L}$, was also investigated with binary catalytic system (Scheme 13b) [73]. Initially, various bicomponent catalysts with balanced acidity of (thio)ureas and basicity of co-catalysts ((thio)ureas/base $=1 / 1)$ were studied. Among them, the combination of 1,3-diphenylurea (U3) and BEMP or IMes (U3/BEMP or IMes), 1-[3,5-bis(trifluoromethyl) phenyl]-3-cyclohexyl-urea (U4) and BEMP or IMes (U4/BEMP or IMes), and TU1/IMes afforded the best results. The monomer conversion was higher than $50 \%$ in a few minutes with the polymerization performed at RT in bulk. Linear $\mathrm{P}(4,5-\mathrm{T} 6 \mathrm{~L})$ s with various molar masses were obtained using TU1/IMes under the same conditions $\left(\overline{M_{n}}=21.1-106 \mathrm{~kg} \cdot \mathrm{mol}^{-1}, Ð=1.02-1.04\right)$. Block copolymers poly(4,5-T6L- $b$-LLA) were obtained, verifying the living character of the polymerization. Linear $\mathrm{P}(4,5-\mathrm{T} 6 \mathrm{~L})$ produced by this binary organocatalyst showed a higher $T_{\mathrm{d}}\left(\right.$ by $13{ }^{\circ} \mathrm{C}$ ) than that of the polymer synthesized with a metal catalyst, which highlights the advantages of organocatalysis $\mathrm{c}$ due to better selectivity of the active 
centers.

a)

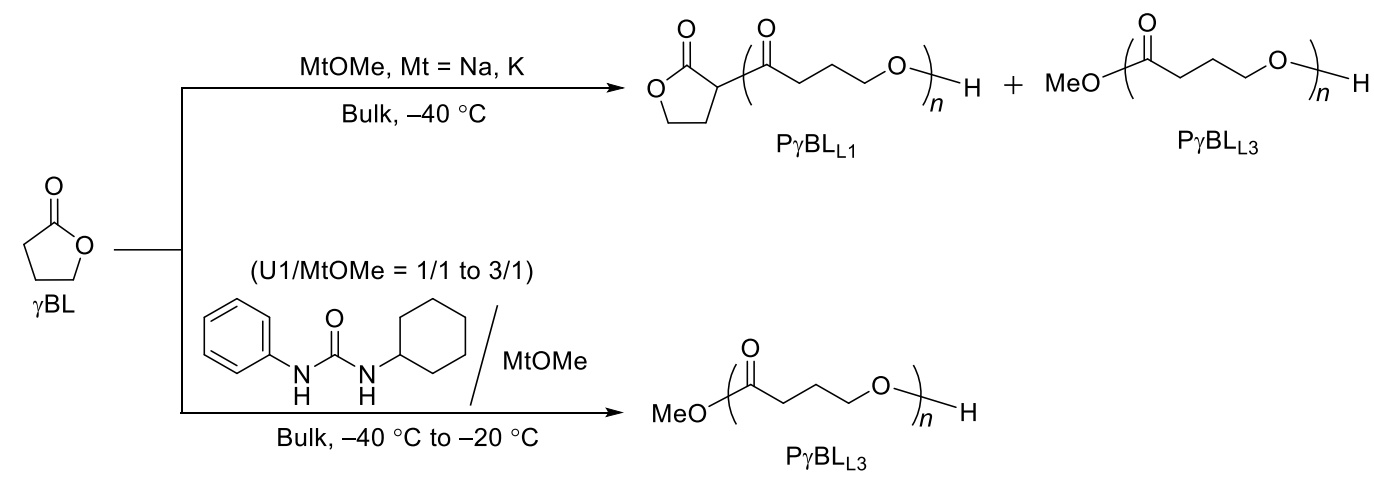

b)

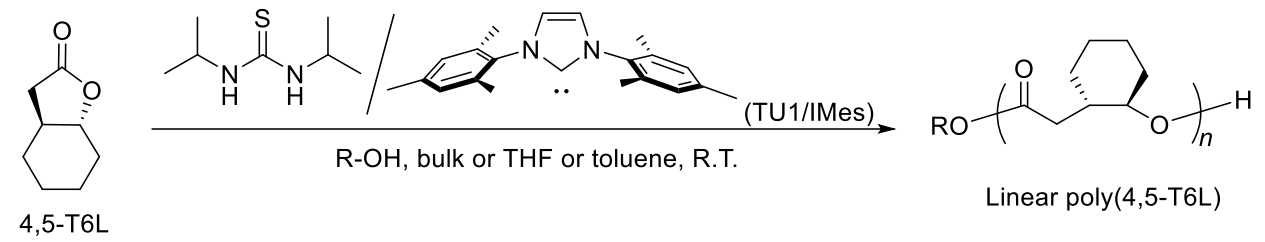

Scheme 13. ROP of $\gamma \mathrm{BL}$ or 4,5-T6L by different dual catalytic systems: (a) U1/MtOMe [26], (b) TU1/IMes [73].

Recently, the chemoselective ROP of biorenewable $\alpha \mathrm{MBL}$ was achieved in THF at $-50{ }^{\circ} \mathrm{C}$ through the cooperative catalysis of 1-cyclohexyl-3-(4(trifluoromethyl)phenyl)-urea (U5) and CTPB (U5/CTPB = 3/1) [159]. Low reaction temperature and the choice of urea were critical to produce these unsaturated polyesters $\left(\overline{M_{n}}\right.$ up to $\left.6.7 \mathrm{~kg} \cdot \mathrm{mol}^{-1}\right)$. Moreover, high monomer concentration $\left([\alpha \mathrm{MBL}]_{0}=8 \mathrm{M}\right)$ improved yields. DFT calculation results also indicated that the ROP pathway was more kinetically favored, whereas the competing VAP pathway was thermodynamically favored. The resultant polyesters could be recycled back to $\alpha \mathrm{MBL}$ with the dual catalysis of CTPB and a urea with more electron-withdrawing substituents (1,3-bis(3,5- 
bis(trifluoromethyl)phenyl)-urea, U7).

Selective ring-opening copolymerization of $\alpha \mathrm{MBL}$ and $\varepsilon \mathrm{CL}$ or $\delta \mathrm{VL}$ was also achieved at low temperatures with similar bicomponent catalyst based on CTPB [160].

The ROCP of $\gamma \mathrm{BL}$ and $\delta \mathrm{VL}, \varepsilon \mathrm{CL}$ or $\omega$-pentadecalactone ( $\omega \mathrm{PDL})$ was performed in the presence of $\mathrm{NHO} / \mathrm{BnOH}$ associated with several metal halides (MtX) such as $\mathrm{LiCl}$, magnesium chloride $\left(\mathrm{MgCl}_{2}\right)$, yttrium(III) chloride $\left(\mathrm{YCl}_{3}\right)$, and zinc iodide $\left(\mathrm{ZnI}_{2}\right)$ $(\mathrm{NHO} / \mathrm{MtX}=1 / 5)($ Scheme 14a) [161]. Copolymers with moderate $\gamma \mathrm{BL}$ content (up to $22 \%$ ) were generally obtained.

Another dual catalytic system based on the combination of bimetallic chromium catalyst which could mediate enantioselective polymerization of racemic propylene oxide (racPO) and DBU (1/5) was used to copolymerize $\gamma \mathrm{BL}$ and racPO. The copolymerization was performed in bulk at $23{ }^{\circ} \mathrm{C}$ with 1,6 -hexanediol as the CTA (Scheme 14b) [162]. Both the monomer conversion of $\gamma \mathrm{BL}$ and PO were limited $(\leq$ $13 \%$, ), generating statistical poly $(\gamma \mathrm{BL}-\mathrm{co}-\mathrm{PO}) \mathrm{s}$ with isotactic polyether sequences $\left(\overline{M_{n}}\right.$ $\left.=2.7-10.5 \mathrm{~kg} \cdot \mathrm{mol}^{-1}, Ð=1.07-1.14\right)$. The poly(ether-ester) copolymers obtained showed adjustable ester content and crystallinity, the latter decreasing with increasing $\gamma \mathrm{BL}$ and CTA loadings.

The terpolymerization of $\mathrm{PO}, \mathrm{CO}_{2}$ and $\gamma \mathrm{BL}$ was also investigated in bulk at $50{ }^{\circ} \mathrm{C}$ using the combination of salen $\mathrm{Co}^{\mathrm{III}} \mathrm{X}(\mathrm{X}=2$,4-dinitrophenoxide $)$ and a bulky ionic salt tetrabutylammonium bromide $\left({ }^{n} \mathrm{Bu} 4 \mathrm{NBr}\right)[163]$. The $\overline{M_{n}}$ of terpolymers obtained was affected by several reaction parameters, such as the feed ratio of monomer, temperature, and reaction time (74-102.1 kg.mol $\left.{ }^{-1}\right)$. Compared with the copolymers of $\mathrm{PO}$ and $\mathrm{CO}_{2}$, 
these terpolymers revealed improved thermal properties with the introduction of $\gamma \mathrm{BL}$.

a)

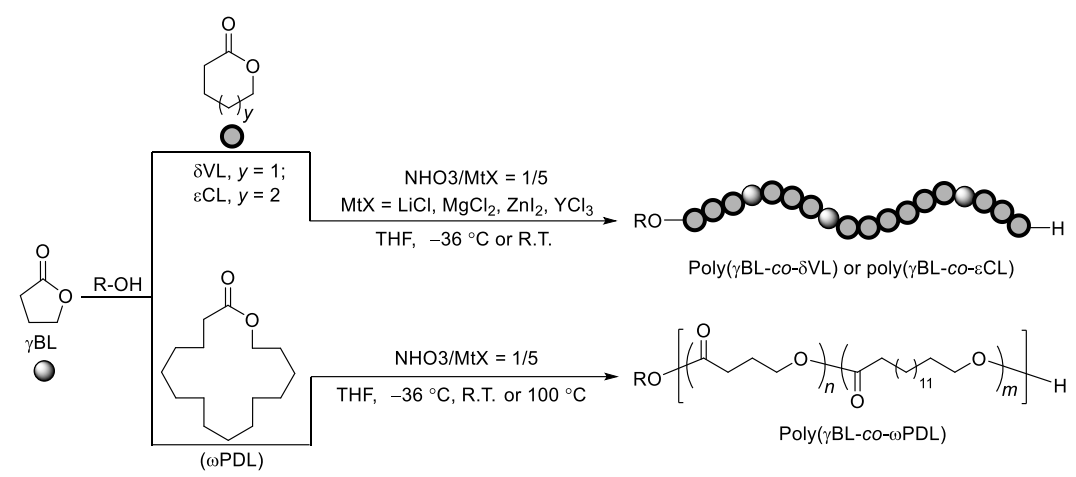

b)

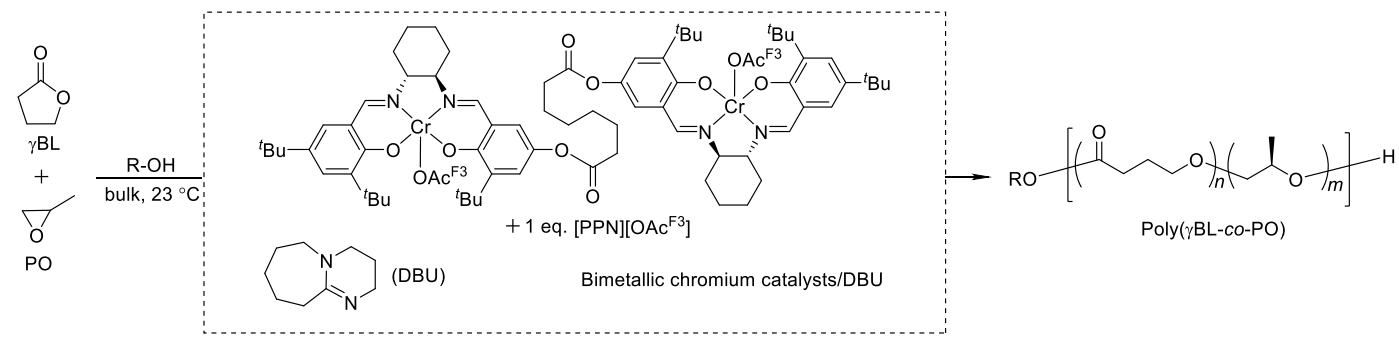

Scheme 14. ROCP of $\gamma \mathrm{BL}$ with cyclic monomers by dual catalysts in the presence of an alcohol: (a) $\gamma \mathrm{BL}$ and $\delta \mathrm{VL}, \varepsilon \mathrm{CL}$ or $\omega \mathrm{PDL}$ [161], (b) $\gamma \mathrm{BL}$ and racemic $\mathrm{PO}$ [162].

Comparing this dual catalysis approach to the mono-component organic one discussed previously (section 5), a better control seems to be achieved and can be attributed to a finely tuned reactivity of the active centers and monomers. Combining a urea to a metal alkoxide allows, for example, the ROP of $\gamma \mathrm{BL}$ with a monomer conversion higher than $80 \%$ in short times. Thus, the utilizzation of bicomponent catalysts, such as Lewis acids and bases, or bifunctional unimolecular catalysts, permits the modulation of the basic and nucleophilic character as well as steric hindrance of the chain ends. This enables control of reactivities and selectivities and, is definitely a route 
to follow in order to progress in the polymerization control of such lactones.

9. Other polymerization methodologies for $\gamma$-lactones

In this section, several approaches used for polymerization of $\gamma \mathrm{BL}$ and its derivatives are summarized. The related mechanism depends on the specific catalytic system used, such as polycondensation, enzymatic catalysis, transesterification, or ringopening..

The copolymerization of $\gamma \mathrm{BL}$ and L-Lactic acid or glycolic acid was conducted without catalysts in bulk at $200{ }^{\circ} \mathrm{C}$ [164-166]. Copolymers with relatively low molar masses and $\gamma \mathrm{BL}$ content $\left(1.1-5.2 \mathrm{~kg} \cdot \mathrm{mol}^{-1}, 10-20 \%\right)$ were synthesized, containing single $\gamma \mathrm{BL}$ units in the polymeric chain. The proposed mechanism was a direct polycondensation between the linear acids and the $\omega$-hydroxy acid produced by the hydrolysis of $\gamma \mathrm{BL}$ in presence of water.

Enzymatic ROP (eROP) of lactones has been studied since 1993 [167-170]. A few studies described the use of lipases for the ROP/ROCP of $\gamma \mathrm{BL}$. For instance, $\mathrm{P} \gamma \mathrm{BL}$ with $\overline{D P}$ around 10 was produced by the use of lipases from Porcine Pancreatic or from Pseudomonas cepacia in $n$-hexane at $60{ }^{\circ} \mathrm{C}$ after 20 days [171]. A poly $(\gamma \mathrm{BL}-c o-\varepsilon \mathrm{CL})$ copolymer was also synthesized under similar conditions with $3 \%$ of $\gamma \mathrm{BL}$ conversion $\left(\overline{M_{n}}=2.9 \mathrm{~kg} \cdot \mathrm{mol}^{-1}, Ð=2.16\right)$ [172]. Besides, the use of immobilized Candida antarctica lipase $\mathrm{B}$ in ionic liquids led to the oligomerization of $\gamma \mathrm{BL}(\overline{D P}=5)[173]$.

The ROP of $\gamma \mathrm{BL}$ was also studied at RT using tin(IV) ion-exchanged montmorillonite, mainly producing dimers and trimers, while its copolymerization with 
$\delta$ VL led to the formation of copolyester with a limited $\gamma \mathrm{BL}$ incorporation $(\overline{D P}$ around 4-6) [174]. Activated clay could also promote the copolymerization of $\gamma \mathrm{BL}$ and 1,2ethanediol in xylene at reflux to produce oligomeric polyether-polyester with single $\gamma \mathrm{BL}$ units in the polymeric chain. They were used as precursors for polyurethane synthesis [175].

The curing reaction of DGEBA and $\gamma \mathrm{VL}$ or $\gamma \mathrm{MBL}$ was performed in the presence of boron trifluoride ethylamine complex $\left(\mathrm{BF}_{3} \bullet \mathrm{EtNH}_{2}\right)$ or rare earth triflates such as $\mathrm{Sc}(\mathrm{OTf})_{3}$ and lanthanum(III), ytterbium(III) trifluoromethanesulfonate (La(OTf) 3 , and $\mathrm{Yb}(\mathrm{OTf})_{3}$, respectively) (Scheme 15) [176-178]. Four different reactions were observed during the curing process, that is, (1) spiroorthoester intermediates formation by the reaction of DGEBA and $\gamma \mathrm{VL}$ (or $\gamma \mathrm{MBL}$ ), (2) homopolymerization of DGEBA, (3) copolymerization of DGEBA with the spiroorthoester intermediate, and (4) homopolymerization of the spiroorthoester [179]. Compared with the conventional epoxy resin, the obtained thermosets were more thermally degradable, due to the introduction of ester group in the polymer chain [180]. In addition, DMAP, DBU, and 1-methylimidazole (1-MI) were applied for the copolymerization of DGEBA and BBLs (BBL1, BBL5). The stoichiometric proportion of DGEBA/BBL led to the desirable alternating poly(ether-ester-ketone) structure [181]. 
a)

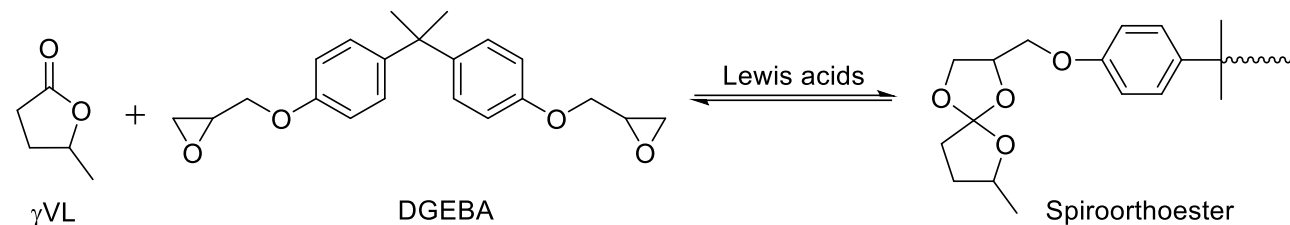

b)
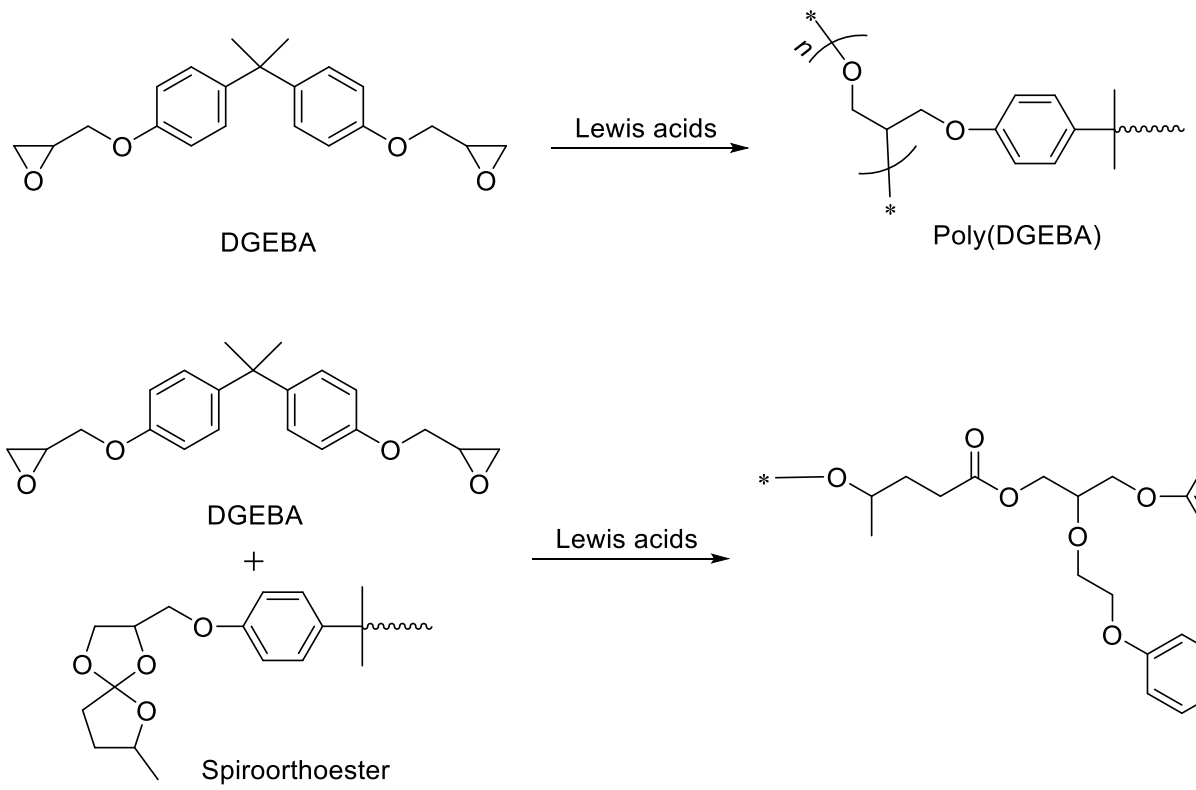

Lewis acids

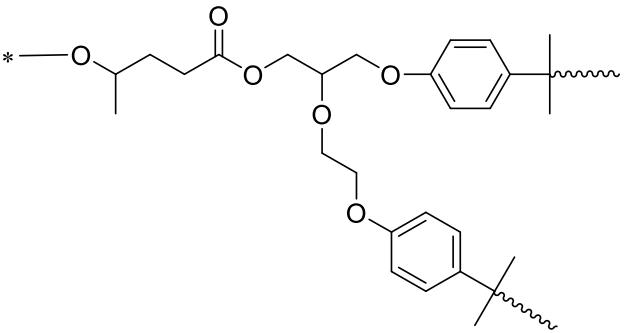

d)
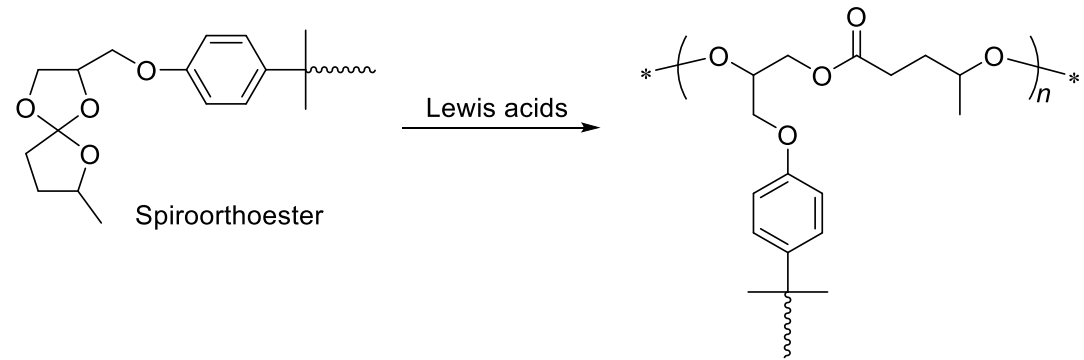

Scheme 15. Curing procedure between DGEBA and $\gamma \mathrm{VL}$ : (a) spiroorthoester intermediates formation, (b) homopolymerization of DGEBA, (c) copolymerization of DGEBA with the spiroorthoester, (d) homopolymerization of the spiroorthoester [179].

The polycondensation of BBLs (BBL1, 8, 9) and 1,4-benzenedimethanol (BDM) was promoted by $p$-toluenesulfonic acid $(p-\mathrm{TsOH})$ under ambient or reduced pressure at $80-120^{\circ} \mathrm{C}$, generating corresponding polyesters with a ketone group in the side chain $\left(\overline{M_{n}}=3.0-5.0 \mathrm{~kg} \cdot \mathrm{mol}^{-1}, Ð=1.6-8.9\right)$ [182]. On the other hand, $\gamma \mathrm{BL}$ was shown able to 
end-functionalize oligoethylene glycol (HO-PEG-OH, $\left.\overline{M_{w}}=0.8 \mathrm{~kg} \cdot \mathrm{mol}^{-1}\right)$ [183]. The process was performed at $130{ }^{\circ} \mathrm{C}$ with non-eutectic mixture of organocatalysts (NEMO), composed of a non-stoichiometric complex of MSA and TBD $(\mathrm{MSA} / \mathrm{TBD}=$ 3/1). $52 \%$ of the oligo-PEG hydroxyl end-groups were functionalized by about 1.5 units of $\gamma \mathrm{BL}$, and polyethers were subsequently produced by the thermal/vacuum polycondensation of these functionalized oligomers. The resulting polycondensate PEG $\left(\overline{M_{p}}=17.0 \mathrm{~kg} \cdot \mathrm{mol}^{-1}, Ð=1.7\right)$ was completely degradable in a $0.5 \mathrm{M} \mathrm{NaOH}$ solution.

Transesterification, which is normally regarded as a detrimental side reaction for the synthesis of polyester, could nevertheless be utilized to modify the polyesters. The original strategy was to employ an organic superbase that acted as the promoter for both ROP of epoxides and transesterification reactions with hydroxyl-terminated polyester, to provide a random poly(ester-ether) [184]. This approach was employed for the upcycling of polyesters with ROP of $\gamma \mathrm{BL}$ (Scheme 16a). Poly(glycolic acid) (PGA) was chosen as the first candidate for the transesterification, combined with ROP of $\gamma \mathrm{BL}$, which served as both a solvent and a comonomer [63]. The reaction was performed in the presence of $\mathrm{BnOH}$ as the initiator at $160{ }^{\circ} \mathrm{C}$ using $\mathrm{La}\left[\mathrm{N}\left(\mathrm{SiMe}_{3}\right)_{2}\right]_{3}$ or TBD. The $\gamma \mathrm{BL}$ incorporation in the poly(GA-co- $\gamma \mathrm{BL}) \mathrm{s}$ varied from 12 to $20 \%$ and improved the solubility of the copolymer $\left(\overline{M_{n}}=4.7-7.2 \mathrm{~kg} \cdot \mathrm{mol}^{-1}, Ð=1.15-1.30\right)$. The resulting poly(GA-co- $\gamma \mathrm{BL}) \mathrm{s}$ also showed enhanced thermal properties compared to PGA.

The transesterification on poly $(\delta$-valerolactone) (PVL) - or PCL in the process of ROP of $\gamma \mathrm{BL}$ - was also investigated (Scheme 16b) [185]. Dual organocatalyst based on U3/TBD (1/1 to 10/1) was employed for the reaction of PVL and $\gamma \mathrm{BL}$ performed at 
$25{ }^{\circ} \mathrm{C}$. TBD alone could catalyze the transesterification of PVL and $\gamma \mathrm{BL}$, whereas its association to $\mathrm{U} 3(\mathrm{U} 3 / \mathrm{TBD}=1 / 1)$ improved the $\gamma \mathrm{BL}$ incorporation without deteriorating the $\overline{M_{n}}$ of obtained copolyesters. The enhanced $\gamma \mathrm{BL}$ incorporation in U3/TBD-mediated transesterification was proposed to be due to the preferential activation of $\gamma \mathrm{BL}$ monomer over the polymer chain. $\operatorname{Poly}(\delta \mathrm{VL}-c o-\gamma \mathrm{BL})$ with higher $\gamma \mathrm{BL}$ incorporation (up to $38 \%$ ) could be synthesized by increasing the feed ratio of U3/TBD from $1 / 1$ to $10 / 1\left(\overline{M_{n}}=10.5-20.5 \mathrm{~kg} \cdot \mathrm{mol}^{-1}, Ð=1.56-1.63\right)$. The reaction could also be performed in the absence of alcohols, and high molar mass copolymers with various $\gamma \mathrm{BL}$ incorporation $\left(7-28 \% ; \overline{M_{n}}=21.0-40.6 \mathrm{~kg} \cdot \mathrm{mol}^{-1}, Ð=1.72-1.89\right)$ were obtained. When switching to PCL, the reaction was more efficient if conducted at $80{ }^{\circ} \mathrm{C}$, producing poly $(\varepsilon \mathrm{CL}-c o-\gamma \mathrm{BL})$ with moderate $\gamma \mathrm{BL}$ incorporation $\left(5-13 \% ; \overline{M_{n}}=9.6-26.7\right.$ $\left.\mathrm{kg} \cdot \mathrm{mol}^{-1}, Ð=1.33-1.77\right)$. Noticeably, both reactions could be carried out under air to give similar copolymers, highlighting the air/moisture tolerance of such binary catalytic system.

a)

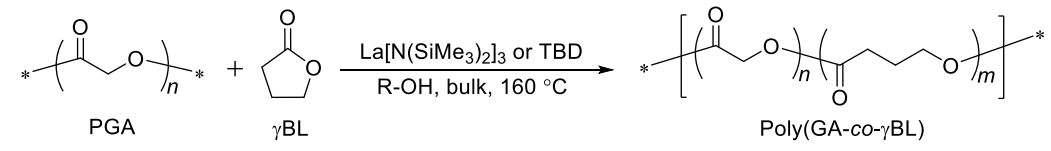

b)

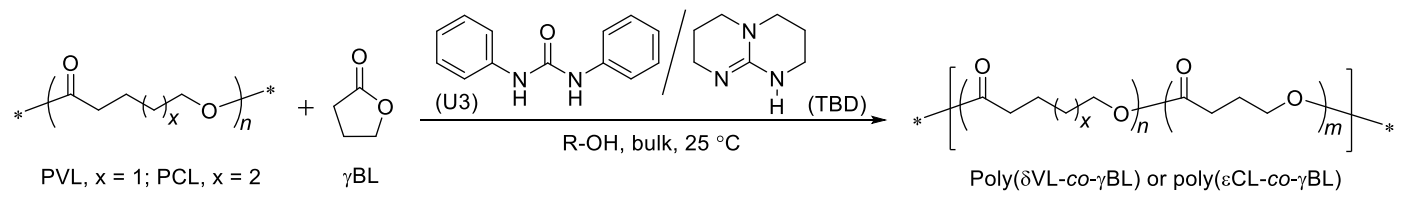

Scheme 16. Copolyesters produced by transesterification and ring-opening of $\gamma \mathrm{BL}$ : (a) PGA with $\gamma$ BL [63], (b) PVL or PCL with $\gamma$ BL [185]

Polycondensation and enzymatic catalysis remain limited both in their use and 
efficiency. The transesterification route combined to ring-opening polymerization of $\gamma$ $\mathrm{BL}$, which is following the organometallic or dual catalysis methodologies and results, offers another way to get copolyesters.

10. Thermal or chemical recycling of $\mathrm{P} \gamma \mathrm{BL}$ and other derivatives

Table 1 summarizes the methods to recycle the $\mathrm{P} \gamma \mathrm{BL}$ and other derivatives back to the corresponding monomer, based on thermal or chemical procedures. In most cases, the use of a catalyst allowed to depolymerize the product in a more energy-efficient way. For example, the depolymerization of $\mathrm{P} \gamma \mathrm{BL}$ in the absence of a catalyst needed to be carried out at $220^{\circ} \mathrm{C}$ or $300^{\circ} \mathrm{C}$ in bulk (linear or cyclic product, respectively), while the employment of $\mathrm{TBD}$ or $\mathrm{La}\left[\mathrm{N}\left(\mathrm{SiMe}_{3}\right)_{2}\right]_{3}$ allowed it to proceed at $25^{\circ} \mathrm{C}$ in solution [21]. The linear $\mathrm{P} \gamma \mathrm{BL}$ with different termination chain ends showed also similar depolymerization behaviours [118].

The recycling process of $\mathrm{P}(\alpha \mathrm{MBL})$ ROP was slightly different from other derivatives [119]. Due to the appearance of unsaturated $\mathrm{C}=\mathrm{C}$ in polyester, insoluble cross-linked products would be formed when the depolymerization was performed in bulk at high temperatures. In the presence of $\mathrm{La}\left[\mathrm{N}\left(\mathrm{SiMe}_{3}\right)_{2}\right]_{3}, \mathrm{P}(\alpha \mathrm{MBL})_{\text {ROP }}$ could be recycled back to $\alpha \mathrm{MBL}$ in a dilute dimethyl sulfoxide (DMSO) solution $\left(\mathrm{H}_{2} \mathrm{O}\right.$ is added to inhibit polymerization) at relatively low temperatures. Moreover, the depolymerization of $\mathrm{P}(\alpha \mathrm{MBL})$ Rop could also be achieved in DMSO using simple metal halides such as lanthanum(III) chloride $\left(\mathrm{LaCl}_{3}\right)$, which was incapable to reinitiate the VAP of $\alpha \mathrm{MBL}$ generated from depolymerization. 
The depolymerization of other derivatives such as $\mathrm{P}(3,4-\mathrm{T} 6 \mathrm{~L}), \mathrm{P}(4,5-\mathrm{T} 6 \mathrm{~L})$ and $i t-$ PCBL, $h t$-PCBL also showed similar behaviours [73, 120, 122, 123]. Compared with thermal recycling of related polymers in bulk at high temperatures, the depolymerization process was more favourable using catalysts in toluene. In addition, the copolyester poly $(\gamma \mathrm{BL}-c o-3,4-\mathrm{T} 6 \mathrm{~L})$ could also be chemically recycled back to its building monomers ( $\gamma \mathrm{BL}, 3,4-\mathrm{T} 6 \mathrm{~L}$, respectively) [143], while the recycling of poly(GA-co- $\gamma \mathrm{BL})$ was achieved in a hydrolysis pathway [63]. 
Table 1 Summary of methods used for depolymerizing $\mathrm{P} \gamma \mathrm{BL}$ and derivatives

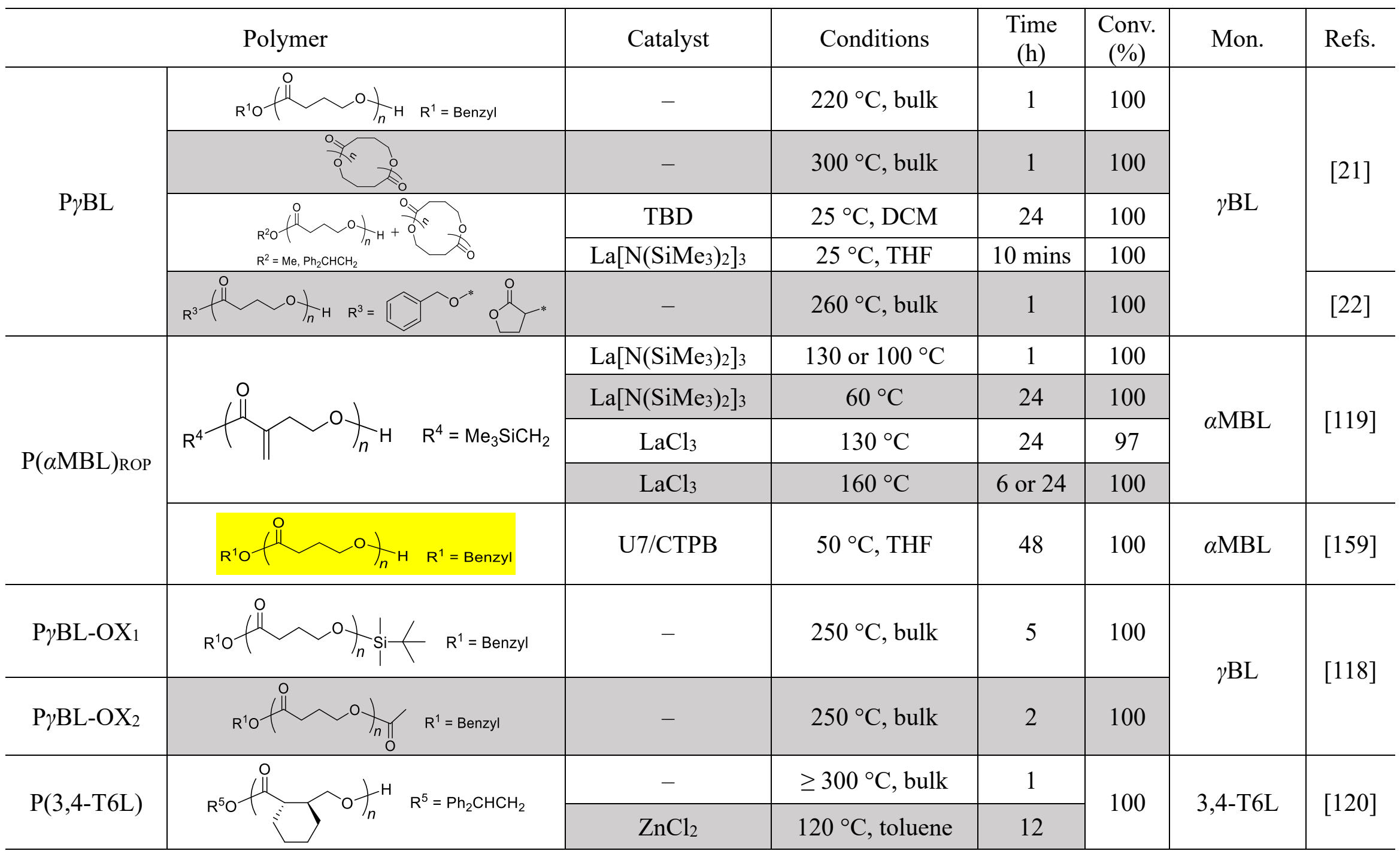




\begin{tabular}{|c|c|c|c|c|c|c|c|}
\hline & & - & $\geq 300^{\circ} \mathrm{C}$, bulk & 24 & & & \\
\hline & & $\mathrm{ZnCl}_{2}$ & $120^{\circ} \mathrm{C}$, toluene & 12 & & & \\
\hline \multirow{4}{*}{$\mathrm{P}(4,5-\mathrm{T} 6 \mathrm{~L})$} & $\mathrm{R}^{5} \mathrm{O}$ & - & $230^{\circ} \mathrm{C}$, bulk & 40 & 100 & $\begin{array}{c}4,5- \\
\text { T6L/4,5- } \\
\text { C6L } \\
(89 / 11)\end{array}$ & \multirow{3}{*}{ [123] } \\
\hline & & $\mathrm{La}\left[\mathrm{N}\left(\mathrm{SiMe}_{3}\right)_{2}\right]_{3}$ & $120^{\circ} \mathrm{C}$, toluene & 24 & \multirow{3}{*}{100} & \multirow{3}{*}{ 4,5-T6L } & \\
\hline & & $\mathrm{La}\left[\mathrm{N}\left(\mathrm{SiMe}_{3}\right)_{2}\right]_{3}$ & $120^{\circ} \mathrm{C}$, toluene & 24 & & & \\
\hline & $\mathrm{R}^{1}=$ Benzyl & TBD & $120^{\circ} \mathrm{C}$, toluene & 24 & & & [73] \\
\hline$i t$-PCBL & & \multirow{2}{*}{$\mathrm{ZnCl}_{2}$} & \multirow{2}{*}{$130{ }^{\circ} \mathrm{C}$, toluene } & \multirow{2}{*}{24} & \multirow{2}{*}{100} & \multirow{2}{*}{$r a c-\mathrm{CBL}$} & \multirow{2}{*}[122]{} \\
\hline & & & & & & & \\
\hline $\begin{array}{c}\text { Poly }(\gamma \mathrm{BL}-\mathrm{co-} \\
3,4-\mathrm{T} 6 \mathrm{~L})\end{array}$ & & $\mathrm{ZnCl}_{2}$ & $120^{\circ} \mathrm{C}$, toluene & 60 & 100 & $\begin{array}{c}\gamma \mathrm{BL}, 3,4- \\
\text { T6L }\end{array}$ & [143] \\
\hline $\begin{array}{c}\text { Poly(GA-co- } \\
\gamma \mathrm{BL})\end{array}$ & & $\begin{array}{l}1 \mathrm{M} \mathrm{NaOH} \text { and } \\
\text { subsequent } \\
\text { chemical steps }\end{array}$ & - & - & $\begin{array}{c}98 \\
94\end{array}$ & $\begin{array}{l}\text { Glycolic } \\
\text { acid, } \gamma \mathrm{BL}\end{array}$ & [63] \\
\hline
\end{tabular}




\section{Conclusion}

The ROP of $\gamma \mathrm{BL}$ under mild conditions was regarded as impossible or rarely possible for several decades. This review summarizes and comments on the development in polymerization of $\gamma \mathrm{BL}$, especially focusing on the recent advances, to synthesize $\mathrm{P} \gamma \mathrm{BL}$ with a high molar mass under moderate reaction conditions. Dual catalytic systems made of ureas and bases, that can be commercially available and inexpensive, are quite efficient. Anionic and coordination-insertion polymerizations, which were investigated more than cationic ones, showed better results. Low reaction temperatures (to keep $\Delta G_{\mathrm{p}}<0$ ) and high initial monomer concentrations are required for the homopolymerization of $\gamma \mathrm{BL}$. On the other hand, such success was also applied to the ROP of $\gamma \mathrm{BL}$ derivatives to deliver a broad diversity of polyesters. Through the prudent design of substitutes, some of them could even be polymerized at ambient temperature. Furthermore, the use of multifunctional $\gamma \mathrm{BL}$ derivatives provided an alternative to obtain functional polyesters. More significantly, several resultant polymers could be depolymerized to their corresponding monomer by thermal or chemical treatments.

The ROCP of $\gamma \mathrm{BL}$ or its derivatives with other cyclic monomers afforded an opportunity to circumvent the obstacles in their homopolymerization, which also enriched the variety of chain structures and properties of resultant polymers. In this case, the incorporation of $\gamma \mathrm{BL}$ or its derivatives could even be performed at mild temperatures. However, challenges still remain in this field, such as polymerization of $\gamma \mathrm{BL}$ at ambient temperature, enhancement of the selectivity of polymerization over side 
reactions (e.g., back-biting), and more precise control of the molar masses and thermal/mechanical properties of the resulting materials. Again, the dual catalytic approach seems to be a method to develop further if the polymerization control is expected.

\section{Acknowledgement}

Q. Song gratefully thanks the China Scholarship Council for offering the scholarship to work in LCPO, University of Bordeaux, France.

\section{References}

[1] Hillmyer MA, Tolman WB. Aliphatic polyester block polymers: Renewable, degradable, and sustainable. Acc Chem Res 2014;47:2390-6.

[2] Schneiderman DK, Hillmyer MA. Aliphatic polyester block polymer design. Macromolecules 2016;49:2419-28.

[3] Gonçalves FAMM, Fonseca AC, Domingos M, Gloria A, Serra AC, Coelho JFJ. The potential of unsaturated polyesters in biomedicine and tissue engineering: Synthesis, structure-properties relationships and additive manufacturing. Prog Polym Sci 2017;68:134.

[4] Kamber NE, Jeong W, Waymouth RM, Pratt RC, Lohmeijer BG, Hedrick JL. Organocatalytic ring-opening polymerization. Chem Rev 2007;107:5813-40.

[5] Penczek S, Cypryk M, Duda A, Kubisa P, Slomkowski S. Living ring-opening polymerizations of heterocyclic monomers. Prog Polym Sci 2007;32:247-82.

[6] Jerome C, Lecomte P. Recent advances in the synthesis of aliphatic polyesters by ringopening polymerization. Adv Drug Deliv Rev 2008;60:1056-76.

[7] Hu S, Zhao J, Zhang G, Schlaad H. Macromolecular architectures through organocatalysis. Prog Polym Sci 2017;74:34-77. 
[8] Bozell JJ, Petersen GR. Technology development for the production of biobased products from biorefinery carbohydrates - the US department of energy's "Top 10" revisited. Green Chem 2010;12:539-54.

[9] Bomgardner MM. Biobased polymers. Chem Eng News 2014. p. 10-4

[10] Moore T, Adhikari R, Gunatillake P. Chemosynthesis of bioresorbable poly $(\gamma$ butyrolactone) by ring-opening polymerisation: A review. Biomaterials 2005;26:3771-82.

[11] Saiyasombat W, Molloy R, Nicholson TM, Johnson AF, Ward IM, Poshyachinda S. Ring strain and polymerizability of cyclic esters. Polymer 1998;39:5581-5.

[12] Houk K, Jabbari A, Hall H, Alemán C. Why $\delta$-valerolactone polymerizes and $\gamma$ butyrolactone does not. J Org Chem 2008;73:2674-8.

[13] Aleman C, Betran O, Casanovas J, Houk KN, Hall HK, Jr. Thermodynamic control of the polymerizability of five-, six-, and seven-membered lactones. J Org Chem 2009;74:623744.

[14] Duda A, Kowalski A. Thermodynamics and kinetics of ring-opening polymerization. In: Philippe Dubois OC, Jean-Marie Raquez, editors. Handbook of ring-opening polymerization. Weinheim: Wiley-VCH Verlag GmbH \& Co KGaA, 2009. p. 1-51.

[15] Olsen P, Odelius K, Albertsson AC. Thermodynamic presynthetic considerations for ringopening polymerization. Biomacromolecules 2016;17:699-709.

[16] Carothers WH, Dorough GL, Natta FJv. Studies of polymerization and ring formation. X. The reversible polymerization of six-membered cyclic esters. J Am Chem Soc 1932;54:761-72.

[17] Hall HK, Schneider AK. Polymerization of cyclic esters, urethans, ureas and imides. J Am Chem Soc 1958;80:6409-12.

[18] Korte F, Glet W. Hochdruckreaktionen. II. Die polymerisation von $\gamma$-butyrolacton und $\delta$ valerolactam bei hohen drücken. J Polym Sci Part B Polym Lett 1966;4:685-9.

[19] Becker G, Wurm FR. Functional biodegradable polymers via ring-opening polymerization of monomers without protective groups. Chem Soc Rev. 2018;47:7739-82.

[20] Zhao W, He J, Zhang Y. Lewis pairs polymerization of polar vinyl monomers. Science Bulletin 2019;64:1830-40. 
[21] Hong M, Chen EY. Completely recyclable biopolymers with linear and cyclic topologies via ring-opening polymerization of $\gamma$-butyrolactone. Nat Chem 2016;8:42-9.

[22] Hong M, Chen EY. Towards truly sustainable polymers: A metal-free recyclable polyester from biorenewable non-strained $\gamma$-butyrolactone. Angew Chem Int Ed Engl 2016;55:418893.

[23] Zhao N, Ren C, Li H, Li Y, Liu S, Li Z. Selective ring-opening polymerization of nonstrained $\gamma$-butyrolactone catalyzed by a cyclic trimeric phosphazene base. Angew Chem Int Ed Engl 2017;56:12987-90.

[24] Walther P, Frey W, Naumann S. Polarized olefins as enabling (co)catalysts for the polymerization of $\gamma$-butyrolactone. Polym Chem 2018;9:3674-83.

[25] Zhang CJ, Hu LF, Wu HL, Cao XH, Zhang XH. Dual organocatalysts for highly active and selective synthesis of linear poly( $\gamma$-butyrolactone)s with high molecular weights. Macromolecules 2018;51:8705-11

[26] Lin L, Han D, Qin J, Wang S, Xiao M, Sun L, et al. Nonstrained $\gamma$-butyrolactone to highmolecular-weight poly $(\gamma$-butyrolactone): Facile bulk polymerization using economical ureas/alkoxides. Macromolecules 2018;51:9317-22.

[27] Gowda RR, Chen EYX. Sustainable polymers from biomass-derived $\alpha$-methylene- $\gamma$ butyrolactones. In Encyclopedia of polymer science and technology. Hoboken, NJ: John Wiley \& Sons, Inc. 2013 p. 1-37.

[28] Zhu Y, Romain C, Williams CK. Sustainable polymers from renewable resources. Nature 2016;540:354-62.

[29] Myers D, Cyriac A, Williams CK. Polymer synthesis: To react the impossible ring. Nat Chem 2016;8:3-4.

[30] Hong M, Chen EYX. Chemically recyclable polymers: A circular economy approach to sustainability. Green Chem 2017;19:3692-706.

[31] Zhang X, Fevre M, Jones GO, Waymouth RM. Catalysis as an enabling science for sustainable polymers. Chem Rev 2018;118:839-85.

[32] Mohanty AK, Vivekanandhan S, Pin JM, Misra M. Composites from renewable and sustainable resources: Challenges and innovations. Science 2018;362:536-42. 
[33] Tang H, Luan Y, Yang L, Sun H. A perspective on reversibility in controlled polymerization systems: Recent progress and new opportunities. Molecules 2018;23:2870/1-16.

[34] Hong M, Chen EYX. Future directions for sustainable polymers. Trends Chem 2019;1:14851.

[35] Tang X, Chen EYX. Toward infinitely recyclable plastics derived from renewable cyclic esters. Chem 2019;5:284-312.

[36] Coates GW, Getzler YDYL Chemical recycling to monomer for an ideal, circular polymer economy. Nat Rev Mater 2020;5:501-16.

[37] Danko M, Mosnacek J. Ring-opening polymerization of $\gamma$-butyrolactone and its derivatives: A review. Polimery 2017;62:272-82.

[38] Yuan PJ. Hong M. Ring-opening polymerizations of the "non-strained" $\gamma$-butyrolactone andits derivatives: An overview and outlook. Acta Polym Sin 2019;50:327-37.

[39] Kollar J, Danko M, Pippig F, Mosnacek J. Functional polymers and polymeric materials from renewable alpha-unsaturated gamma-butyrolactones. Front Chem 2019;7:845/1-8.

[40] Song Q, Zhao J, Zhang G, Peruch F, Carlotti S. Ring-opening (co)polymerization of $\gamma$ butyrolactone: A review. Polym J 2020;52:3-11.

[41] Sogah DY, Hertler WR, Webster OW, Cohen GM. Group transfer polymerization. polymerization of acrylic monomers. Macromolecules 1987;20:1473-88.

[42] Zhang Y, Miyake GM, John MG, Falivene L, Caporaso L, Cavallo L, Chen EY Lewis pair polymerization by classical and frustrated lewis pairs: Acid, base and monomer scope and polymerization mechanism. Dalton Trans 2012;41:9119-34.

[43] Chen EYX. Polymerization by classical and frustrated Lewis pairs. In: Erker G, Stephan DW, editors. Frustrated lewis pairs ii: Expanding the scope. Berlin, Heidelberg: Springer Berlin Heidelberg, 2013. p. 239-60.

[44] Overberger CG, Weise JK. Anionic ring-opening polymerization of thiolactones. J Am Chem Soc 1968;90:3533-7.

[45] Nishikubo T, Kameyama A, Kawakami S. A novel synthesis of poly(ester-alt-sulfide)s by the ring-opening alternating copolymerization of oxiranes with $\gamma$-thiobutyrolactone using quaternary onium salts or crown ether complexes as catalysts. Macromolecules 
1998;31:4746-52.

[46] Kikuchi H, Tsubokawa N, Endo T. First example of cationic ring-opening polymerization of $\gamma$-thionobutyrolactone. Chem Lett 2005;34:376-7.

[47] Zhang CJ, Cao XH, Zhang XH. Metal-free alternating copolymerization of nonstrained $\gamma$ selenobutyrolactone with epoxides for selenium-rich polyesters. Macromolecules 2019;53:203-11.

[48] Pan X, Driessen F, Zhu X, Du Prez FE. Selenolactone as a building block toward dynamic diselenide-containing polymer architectures with controllable topology. ACS Macro Lett 2017;6:89-92.

[49] Omoruyi U, Page S, Hallett J, Miller PW. Homogeneous catalyzed reactions of levulinic acid: To $\gamma$-valerolactone and beyond. ChemSusChem 2016;9:2037-47.

[50] Meerwein H. Uber oxoniumverbindungen des säure-ester und lactone. Angew Chem $1951 ; 63: 480-1$

[51] Marvel CS, Levesque CL. The structure of vinyl polymers. III. ${ }^{1}$ the polymer from $\alpha$ angelica lactone. J Am Chem Soc 1939;61:1682-4.

[52] Iwakura Y, Tamikado T, Fujimoto Y, Ikegami S, Maruyama M. The copolymerization of unsaturated lactones with acrylonitrile. Kobunshi Kagaku 1958;15:469-74.

[53] Yokoyama Y, Okada M, Sumitomo H. Cationic copolymerisation of 1,3-dioxolane with 5methyl-2,3-dihydro-2-furanone initiated with triethyloxonium tetrafluoroborate. Makromol Chem 1974;175:2525-38.

[54] Hirabayashi T, Yokota K. Copolymerization behavior of $\beta$-angelica lactone and styrene in the presence of organoaluminum chlorides. Polym J 1982;14:789-96.

[55] Deng X, Yao J, Yuan M. Polymerization of lactides and lactones 11. Ring-opening polymerization of $\alpha$-acetyl- $\gamma$-butyrolactone and copolymerization with $\beta$-butyrolactone. Eur Polym J 2000;36:2739-41.

[56] Bednarek M. Cationic oligomerization of $\alpha$-hydroxy- $\gamma$-butyrolactone. Polimery 2008;53:377-83.

[57] Tarabanko VE, Kaygorodov KL. New environmentally benign polymers produced by copolymerization with $\alpha$-angelicalactone. Macromol Symp 2015;354:367-73. 
[58] Tada K, Numata Y, Saegusa T, Furukawa J. Copolymerization of $\gamma$-butyrolactone and $\beta$ propiolactone. Makromol Chem 1964;77:220-8.

[59] Ito K, Inoue T, Yamashita Y. Copolymerizations of 3.3-bis(chloromethyl)oxacyclobutane with $\beta$-propiolactone and $\gamma$-butyrolactone by lewis acids: "Two-state" polymerization mechanism. Makromol Chem 1970;139:153-64.

[60] Fedtke M, Haufe J, Kahlert E, Müller G. Cationic copolymerization of phenyl glycidyl ether with lactones. Characterization of the reaction mixture with chromatographic methods. Angew Makromol Chem 1998;255:53-9.

[61] Chabanne P, Tighzert L, Pascault JP. Monoepoxy polymerization initiated by $\mathrm{BF}_{3}$-amine complexes in bulk. III. Influence of $\gamma$-butyrolactone on polymer formation. J Appl Polym Sci 1994;53:787-806.

[62] Kricheldorf HR, Mang T, Jonté JM. Polylactones, 2 copolymerization of glycolide with $\beta$ propiolactone, $\gamma$-butyrolactone or $\delta$-valerolactone. Makromol Chem 1985;186:955-76.

[63] Liu X, Hong M, Falivene L, Cavallo L, Chen EYX. Closed-loop polymer upcycling by installing property-enhancing comonomer sequences and recyclability. Macromolecules 2019;52:4570-8.

[64] Lee CW, Urakawa R, Kimura Y. Copolymerization of $\gamma$-butyrolactone and $\beta$-butyrolactone. Macromol Chem Phys 1997;198:1109-20.

[65] Lee CW, Urakawa R, Kimura Y. Copolymerization of $\gamma$-valerolactone and $\beta$-butyrolactone. Eur Polym J 1998;34:117-22.

[66] Nakayama A, Kawasaki N, Arvanitoyannis I, Aiba S, Yamamoto N. Synthesis and biodegradation of poly( $\gamma$-butyrolactone-co-L-lactide). J Environ Polym Degrad 1996;4:205-11.

[67] Nakayama A, Kawasaki N, Aiba S, Maeda Y, Arvanitoyannis I, Yamamoto N. Synthesis and biodegradability of novel copolyesters containg $\gamma$-butyrolactone units. Polymer 1998;39:1213-22.

[68] Kubisa P, Penczek S. Cationic activated monomer polymerization of heterocyclic monomers. Prog Polym Sci 1999;24:1409-37.

[69] Ottou WN, Sardon H, Mecerreyes D, Vignolle J, Taton D. Update and challenges in organo- 
mediated polymerization reactions. Prog Polym Sci 2016;56:64-115.

[70] Martin-Vaca B, Bourissou D. Ring-opening polymerization promoted by Brønsted acid catalysts. In: Andrew Dove HS, Stefan Naumann, editors. Organic catalysis for polymerisation. London: The Royal Society of Chemistry, 2018. p. 37-86.

[71] Yamashita K, Yamamoto K, Kadokawa Ji. Acid-catalyzed ring-opening polymerization of $\gamma$-butyrolactone under high-pressure conditions. Chem Lett 2014;43:213-5.

[72] Haba O, Itabashi H. Ring-opening polymerization of a five-membered lactone trans-fused to a cyclohexane ring. Polym J 2013;46:89-93.

[73] Cywar RM, Zhu JB, Chen EYX. Selective or living organopolymerization of a six-five bicyclic lactone to produce fully recyclable polyesters. Polym Chem 2019;10:3097-106.

[74] Lin WJ. Comparison of thermal characteristics and degradation properties of epsiloncaprolactone copolymers. J Biomed Mater Res 1999;47:420-3.

[75] Urbanek T, Trousil J, Rak D, Gunar K, Konefal R, Slouf M, Sedlak M, Sebestova Janouskova O, Hruby M. $\gamma$-butyrolactone copolymerization with the well-documented polymer drug carrier poly(ethylene oxide)-block-poly(epsilon-caprolactone) to fine-tune its biorelevant properties Macromol Biosci. 2020;20:1900408/1-15.

[76] Gao C, Tsou CH, Zeng CY, Yuan L, Peng R, Zhang XM. Organocatalyzed ring-opening copolymerization of $\alpha$-bromo- $\gamma$-butyrolactone with $\varepsilon$-caprolactone for the synthesis of functional aliphatic polyesters - pre-polymers for graft copolymerization Des Monomers Polym 2018;21:193-201.

[77] Undin J, Olsén P, Godfrey J, Odelius K, Albertsson AC. Controlled copolymerization of the functional 5-membered lactone monomer, $\alpha$-bromo- $\gamma$-butyrolactone, via selective organocatalysis. Polymer 2016;87:17-25.

[78] Danko M, Basko M, Duurkáčová S, Duda A, Mosnáček J. Functional polyesters with pendant double bonds prepared by coordination-insertion and cationic ring-opening copolymerizations of $\varepsilon$-caprolactone with renewable Tulipalin A. Macromolecules 2018;51:3582-96.

[79] Nederberg F, Connor EF, Moller M, Glauser T, Hedrick JL. New paradigms for organic catalysts: The first organocatalytic living polymerization. Angew Chem Int Ed Engl 
2001;40:2712-5.

[80] Carlotti S, Peruch F. Cyclic monomers: Epoxides, lactide, lactones, lactams, cyclic siliconcontaining monomers, cyclic carbonates, and others. In: Hadjichristidis N, Hirao A, editors. Anionic polymerization. Tokyo: Springer Japan, 2015. p. 191-305.

[81] Kiesewetter MK, Shin EJ, Hedrick JL, Waymouth RM. Organocatalysis: Opportunities and challenges for polymer synthesis. Macromolecules 2010;43:2093-107.

[82] Dove AP. Organic catalysis for ring-opening polymerization. ACS Macro Lett 2012;1:1409-12.

[83] Shanmugam S, Boyer C. Polymer synthesis. Organic photocatalysts for cleaner polymer synthesis. Science 2016;352:1053-4.

[84] Song QL, Hu SY, Zhao JP, Zhang GZ. Organocatalytic copolymerization of mixed type monomers. Chin J Polym Sci 2017;35:581-601.

[85] Xia Y, Zhao J. Macromolecular architectures based on organocatalytic ring-opening (co)polymerization of epoxides. Polymer 2018;143:343-61.

[86] Dove A, Sardon H, Naumann S, Editors. Organic catalysis for polymerisation. London: Royal Society of Chemistry, 2018. 648 pp.

[87] Jehanno C, Pérez-Madrigal MM, Demarteau J, Sardon H, Dove AP. Organocatalysis for depolymerisation. Polym Chem 2019;10:172-86.

[88] Bossion A, Heifferon KV, Meabe L, Zivic N, Taton D, Hedrick JL, et al. Opportunities for organocatalysis in polymer synthesis via step-growth methods. Prog Polym Sci 2019;90:164-210.

[89] Tang J, Chen EYX. Increasing complexity in organopolymerization of multifunctional $\gamma$ butyrolactones. Eur Polym J 2017;95:678-92.

[90] Tang J, Chen EYX. Organopolymerization of naturally occurring Tulipalin B: A hydroxylfunctionalized methylene butyrolactone. Org Chem Front. 2015;2:1625-31.

[91] Hong M, Tang X, Newell BS, Chen EYX. "Nonstrained" $\gamma$-butyrolactone-based copolyesters: Copolymerization characteristics and composition-dependent (thermal, eutectic, cocrystallization, and degradation) properties. Macromolecules 2017;50:8469-79.

[92] Shen Y, Zhang J, Zhao N, Liu F, Li Z. Preparation of biorenewable poly( $\gamma$-butyrolactone)- 
b-poly(L-lactide) diblock copolyesters via one-pot sequential metal-free ring-opening polymerization. Polym Chem 2018;9:2936-41.

[93] Zhao N, Ren C, Shen Y, Liu S, Li Z. Facile synthesis of aliphatic $\omega$-pentadecalactone containing diblock copolyesters via sequential ROP with 1-lactide, $\varepsilon$-caprolactone, and $\delta$ valerolactone catalyzed by cyclic trimeric phosphazene base with inherent tribasic characteristics. Macromolecules 2019;52:1083-91.

[94] Shen Y, Zhang J, Zhao Z, Zhao N, Liu F, Li Z. Preparation of amphiphilic poly(ethylene glycol)- b-poly( $\gamma$-butyrolactone) diblock copolymer via ring opening polymerization catalyzed by a cyclic trimeric phosphazene base or alkali alkoxide. Biomacromolecules 2019;20:141-8.

[95] Ohsawa S, Morino K, Sudo A, Endo T. Alternating copolymerization of bicyclic bis $(\gamma-$ butyrolactone) and epoxide through zwitterion process by phosphines. Macromolecules 2010;43:3585-8.

[96] Ohsawa S, Morino K, Sudo A, Endo T. Synthesis of a reactive polyester bearing $\alpha, \beta$ unsaturated ketone groups by anionic alternating copolymerization of epoxide and bicyclic bis( $\gamma$-butyrolactone) bearing isopropenyl group. Macromolecules 2011;44:1814-20.

[97] Ohsawa S, Morino K, Sudo A, Endo T. Synthesis of bicyclic bis( $\gamma$-butyrolactone) derivatives bearing sulfide moieties and their alternating copolymers with epoxide. J Polym Sci Part A Polym Chem 2012;50:4666-73.

[98] Tarabanko V, Kaygorodov K. New biodegradable polymers based on $\alpha$-angelicalactone. Chem Sustain Dev 2010;3:321-8.

[99] Tarabanko VE, Kaygorodov KL, Chernyak MY. Polyesterification of alphaangelicalactone. J Sib Fed Univ Chem 2008;2:118-23.

[100] Kaygorodov KL, Tarabanko VE, Tarabanko N, Foreman MRS. Thermodynamics of $\alpha-$ angelicalactone polymerization. Cogent Chem 2018;4:1443689/1-10.

[101] Tadokoro A, Takata T, Endo T. Efficient ring-opening polymerization of a $\gamma$-butyrolactone derivative. First anionic double ring-opening polymerization. Macromolecules $1993 ; 26: 2388-9$.

[102] Bhaw-Luximon A, Jhurry D, Motala-Timol S, Lochee Y. Polymerization of $\varepsilon$-caprolactone 
and its copolymerization with $\gamma$-butyrolactone using metal complexes. Macromol Symp $2005 ; 231: 60-8$

[103] Hall HK. Polymerization and ring strain in bridged bicyclic compounds. J Am Chem Soc $1958 ; 80: 6412-20$.

[104] Okada M, Sumitomo H. Stereochemical aspects of the cationic ring-opening polymerization of hetero bicyclic compounds. Makromol Chem 1985;14:29-43.

[105] Takata T, Tadokoro A, Endo T. Anionic ring-opening alternating copolymerization of a bicyclobis( $\gamma$-butyrolactone) with epoxide. Macromolecules 1992;25:2782-3.

[106] Tadokoro A, Takata T, Endo T. Anionic ring-opening alternating copolymerization of a bicyclic bis( $\gamma$-lactone $)$ with an epoxide: A novel ring-opening polymerization of a monomer containing a $\gamma$-lactone structure. Macromolecules 1993;26:4400-6.

[107] Chung K, Takata T, Endo T. Anionic copolymerization of bicyclic bis( $\gamma$-lactone)s with poly(glycidyl methacrylate) and volume change during the copolymerization. Macromolecules 1995;28:4044-6.

[108] Takata T, Tadokoro A, Chung K, Endo T. Anionic ring-opening alternating copolymerizations of bicyclic and spirocyclic bis( $\gamma$-lactone)s with epoxides via a tandem double ring-opening isomerization of the bislactones. Macromolecules 1995;28:1340-5.

[109] Zhang C, Ochiai B, Endo T. Matrix-assisted laser desorption/ionization time-of-flight mass spectrometry study on copolymers obtained by the alternating copolymerization of $\operatorname{bis}(\gamma-$ lactone) and epoxide with potassium tert-butoxide. J Polym Sci Part A Polym Chem $2005 ; 43: 2643-9$.

[110] Chung K, Takata T, Endo T. Anionic ring-opening copolymerization of bicyclic bis $(\gamma-$ lactone)s with mono- and bifunctional epoxides via double ring-opening isomerization of the $\operatorname{bis}(\gamma$-lactone)s and volume change during copolymerization. Macromolecules $1995 ; 28: 3048-54$.

[111] Chung K, Takata T, Endo T. Anionic cross-linking of polymers having an epoxy group in the side chain with bicyclic and spirocyclic bis( $\gamma$-lactone)s. Macromolecules $1997 ; 30: 2532-8$.

[112] Kuran W. Coordination polymerization of heterocyclic and heterounsaturated monomers. 
Prog Polym Sci 1998;23:919-92.

[113] Penczek S, Duda A, Kubisa P, Slomkowski S. Ionic and coordination ring-opening polymerization. In: Krzysztof Matyjaszewski YG, Ludwik Leibler, editors. Macromolecular engineering: Precise synthesis, materials properties, applications Weinheim: Wiley-VCH Verlag GmbH \& Co. KGaA 2011.p. 103-59.

[114] Ajellal N, Carpentier JF, Guillaume C, Guillaume SM, Helou M, Poirier V, Sarazin Y, Trifonov A. Metal-catalyzed immortal ring-opening polymerization of lactones, lactides and cyclic carbonates. Dalton Trans 2010;39:8363-76.

[115] Stirling E, Champouret Y, Visseaux M. Catalytic metal-based systems for controlled statistical copolymerisation of lactide with a lactone. Polym Chem 2018;9:2517-31.

[116] Li H, Shakaroun RM, Guillaume SM, Carpentier JF. Recent advances in metal-mediated stereoselective ring-opening polymerization of functional cyclic esters towards welldefined poly(hydroxy acid)s: From stereoselectivity to sequence-control. Chemistry 2020;26:128-38.

[117] Culkin DA, Jeong W, Csihony S, Gomez ED, Balsara NP, Hedrick JL, Waymouth RM. Zwitterionic polymerization of lactide to cyclic poly(lactide) by using n-heterocyclic carbene organocatalysts. Angew Chem Int Ed Engl 2007;46:2627-30.

[118] Tang J, Chen EYX. Effects of chain ends on thermal and mechanical properties and recyclability of poly( $\gamma$-butyrolactone). J Polym Sci Part A Polym Chem 2018;56:2271-9.

[119] Tang X, Hong M, Falivene L, Caporaso L, Cavallo L, Chen EY. The quest for converting biorenewable bifunctional $\alpha$-methylene- $\gamma$-butyrolactone into degradable and recyclable polyester: Controlling vinyl-addition/ring-opening/cross-linking pathways. J Am Chem Soc 2016;138:14326-37.

[120] Zhu JB, Watson EM, Tang J, Chen EY. A synthetic polymer system with repeatable chemical recyclability. Science 2018;360:398-403.

[121] Liu Y, Wu J, Liang H, Jin Z, Sheng L, Hu X, Zhu N, Guo K. Organomagnesium towards efficient synthesis of recyclable polymers. Eur Polym J 2020;130:109659/1-4

[122] Zhu JB, Chen EY. Catalyst-sidearm-induced stereoselectivity switching in polymerization of a racemic lactone for stereocomplexed crystalline polymer with a circular life cycle. 
Angew Chem Int Ed Engl 2019;58:1178-82.

[123] Zhu JB, Chen EY. Living coordination polymerization of a six-five bicyclic lactone to produce completely recyclable polyester. Angew Chem Int Ed Engl 2018;57:12558-62.

[124] Hori Y, Yamaguchi A, Hagiwara T. Chemical synthesis of high molecular weight poly(3hydroxybutyrate-co-4-hydroxybutyrate). Polymer 1995;36:4703-5.

[125] Duda A, Penczek S, Dubois P, Mecerreyes D, Jérôme R. Oligomerization and copolymerization of $\gamma$-butyrolactone - a monomer known as unable to homopolymerize, 1. Copolymerization with $\varepsilon$-caprolactone. Macromol Chem Phys 1996;197:1273-83.

[126] Duda A, Biela T, Libiszowski J, Penczek S, Dubois P, Mecerreyes D, et al. Block and random copolymers of $\varepsilon$-caprolactone. Polym Degrad Stab 1998;59:215-22.

[127] Nishiura M, Hou Z, Koizumi TA, Imamoto T, Wakatsuki Y. Ring-opening polymerization and copolymerization of lactones by samarium(II) aryloxide complexes. Macromolecules $1999 ; 32: 8245-51$.

[128] Duda A, Libiszowski J, Mosnáček J, Penczek S. Copolymerization of cyclic esters at the living polymer-monomer equilibrium. Macromol Symp 2005;226:109-20.

[129] Wei Z, Liu L, Qi M. Synthesis and characterization of homo- and co-polymers of $(\mathrm{r}, \mathrm{s})-\beta$ butyrolactone and $\gamma$-butyrolactone or $\beta$-valerolactone initiated with cyclic tin alkoxide. React Funct Polym 2006;66:1411-9.

[130] Qiu H, Shah MI, Bai T, Jiang L, Ling J. Zwitterionic copolymerization of $\gamma$-butyrolactone with 3,3-bis(chloromethyl) oxacyclobutane catalyzed by scandium triflates. Polym Chem 2020;11:1845-51.

[131] Ubaghs L, Waringo M, Helmut Keul A, Höcker H. Copolymers and terpolymers of tetramethylene urea, $\gamma$-butyrolactone, and ethylene carbonate or 1,2-propylene carbonate. Macromolecules 2004;37:6755-62.

[132] Lu L, Huang K. Synthesis and characteristics of a novel aliphatic polycarbonate, poly[(propylene oxide)-co-(carbon dioxide)-co-( $\gamma$-butyrolactone $)]$ Polym Int 2005;54:870-4.

[133] Lu L, Huang K. Preparation of poly(propylene-co- $\gamma$-butyrolactone carbonate) and release profiles of drug-loaded microcapsules. J Polym Sci Part A Polym Chem 2005;43:2468-75. 
[134] Gagliardi M, Di Michele F, Mazzolai B, Bifone AJJoPR. Chemical synthesis of a biodegradable pegylated copolymer from $\varepsilon$-caprolactone and $\gamma$-valerolactone: Evaluation of reaction and functional properties. J Polym Res 2015;22:17/1-12.

[135] Gagliardi M, Bifone AJPo. Ring-opening copolymerization thermodynamics and kinetics of $\gamma$-valerolactone/€-caprolactone. PLoS One 2018;13:e199231/1-15.

[135] Hong M, Chen EYX. Coordination ring-opening copolymerization of naturally renewable $\alpha$-methylene- $\gamma$-butyrolactone into unsaturated polyesters. Macromolecules 2014;47:361424.

[137] Zhou J, Schmidt AM, Ritter H. Bicomponent transparent polyester networks with shape memory effect. Macromolecules 2010;43:939-42.

[138] Chen T, Qin Z, Qi Y, Deng T, Ge X, Wang J, et al. Degradable polymers from ring-opening polymerization of $\alpha$-angelica lactone, a five-membered unsaturated lactone. Polym Chem 2011;2:1190-4.

[139] Gümüştaş S, Balcan M, Kınal A. Computational determination of ring opening polymerization reaction mechanism of $\alpha$-angelica lactone. Comput Theor Chem 2018;1142:1-8.

[140] Xi X, Jiang G, Wang X, Hu R, Wang R. Synthesis, characterization and degradation properties of poly( $\alpha$-angelica lactone-co- $\varepsilon$-caprolactone) copolymers. Polym Renew Resour 2013;4:49-60.

[141] Olsén P, Undin J, Odelius K, Albertsson AC. Establishing $\alpha$-bromo- $\gamma$-butyrolactone as a platform for synthesis of functional aliphatic polyesters - bridging the gap between rop and SET-LRP. Polym Chem 2014;5:3847-54.

[142] Sardon H, Dove AP. Plastics recycling with a difference. Science 2018;360:380-1.

[143] Sangroniz A, Zhu JB, Tang X, Etxeberria A, Chen EY, Sardon H. Packaging materials with desired mechanical and barrier properties and full chemical recyclability. Nat Commun 2019;10:3559/1-7.

[144] Hua G, Franzen J, Odelius K. One-pot inimer promoted ROCP synthesis of branched copolyesters using $\alpha$-hydroxy- $\gamma$-butyrolactone as the branching reagent. J Polym Sci Part A Polym Chem 2016;54:1908-18. 
[145] Hatamvand R, Shams A, Mohammadifar E, Yari A, Adeli M. Synthesis of boronic acidfunctionalized poly(glycerol-oligo $\gamma$-butyrolactone): Nano-networks for efficient electrochemical sensing of biosystems. J Polym Sci Part A Polym Chem 2019;57:1430-9.

[146] Piedra-Arroni E, Amgoune A, Bourissou D. Dual catalysis: New approaches for the polymerization of lactones and polar olefins. Dalton Trans 2013;42:9024-9.

[147] Winnacker M, Vagin S, Rieger B. Cooperative catalysis in polymerization reactions. In: Peters R, editor. Cooperative catalysis: Designing efficient catalysts for synthesis. Weinheim: Wiley-VCH Verlag GmbH \& Co. KGaA 2015. p. 373-416.

[148] Stephan DW. The broadening reach of frustrated Lewis pair chemistry. Science 2016;354:aaf7229/1-8.

[149] Hong M, Chen J, Chen EY. Polymerization of polar monomers mediated by main-group lewis acid-base pairs. Chem Rev 2018;118:10551-616.

[150] Li X, Chen C, Wu J. Lewis pair catalysts in the polymerization of lactide and related cyclic esters. Molecules 2018;23:189/1-13.

[150] Basterretxea A, Jehanno C, Mecerreyes D, Sardon H. Dual organocatalysts based on ionic mixtures of acids and bases: A step toward high temperature polymerizations. ACS Macro Lett 2019;8:1055-62.

[152] Pappuru S, Chakraborty D. Progress in metal-free cooperative catalysis for the ringopening copolymerization of cyclic anhydrides and epoxides. Eur Polym J 2019;121:109276/1-12.

[153] Thomas C, Bibal B. Hydrogen-bonding organocatalysts for ring-opening polymerization. Green Chem 2014;16:1687-99.

[154] Dharmaratne NU, Pothupitiya JU, Kiesewetter MK. The mechanistic duality of (thio)urea organocatalysts for ring-opening polymerization. Org Biomol Chem 2019;17:3305-13.

[155] Jain I, Malik P. Advances in urea and thiourea catalyzed ring opening polymerization: A brief overview. Eur Polym J 2020;133:109791/1-17.

[156] Xia Y, Chen Y, Song Q, Hu S, Zhao J, Zhang G. Base-to-base organocatalytic approach for one-pot construction of poly(ethylene oxide)-based macromolecular structures. Macromolecules 2016;49:6817-25. 
[157] Liu Y, Wang X, Li Z, Wei F, Zhu H, Dong H, et al. A switch from anionic to bifunctional H-bonding catalyzed ring-opening polymerizations towards polyether-polyester diblock copolymers. Polym Chem 2018;9:154-9.

[158].. Shen Y, Zhao Z, Li Y, Liu S, Liu F, Li Z. A facile method to prepare high molecular weight bio-renewable poly( $\gamma$-butyrolactone) using a strong base/urea binary synergistic catalytic system. Polym Chem 2019;10:1231-7.

[159] Shen Y, Xiong W, Li Y, Zhao Z, Lu H, Li Z. Chemoselective polymerization of fully biorenewable $\alpha$-methylene- $\gamma$-butyrolactone using organophosphazene/urea binary catalysts toward sustainable polyesters. CCS Chemistry. 2020;0:620-30.

[160] Zhao Z, Shen Y, Kou X, Shi J, Wang R, Liu F, Li Z. Organocatalytic ring-opening copolymerization of biorenewable $\alpha$-methylene- $\gamma$-butyrolactone toward functional copolyesters: Preparation and composition dependent thermal properties. Macromolecules 2020;53:3380-9.

[161] Walther P, Naumann S. N-heterocyclic olefin-based (co)polymerization of a challenging monomer: Homopolymerization of $\omega$-pentadecalactone and its copolymers with $\gamma$ butyrolactone, $\delta$-valerolactone, and $\varepsilon$-caprolactone. Macromolecules 2017;50:8406-16.

[162] Clayman NE, Morris LS, LaPointe AM, Keresztes I, Waymouth RM, Coates GW. Dual catalysis for the copolymerisation of epoxides and lactones. Chem Commun 2019;55:69147.

[163] Niu Y, Li H. Terpolymerization of carbon dioxide with propylene oxide and $\gamma$-butyrolactone catalyzed by salenco $^{\text {III }}$ (2,4-dinitrophenoxy) and lewis-basic cocatalyst. Adv Polym Tech 2018;37:230-4.

[164] Fukuzaki H, Aiba Y, Yoshida M, Asano M, Kumakura M. Direct copolymerization of Llactic acid with $\gamma$-butyrolactone in the absence of catalysts. Makromol Chem 1989;190:1553-9.

[165] Fukuzaki H, Yoshida M, Asano M, Aiba Y, Kumakura M. Direct copolymerization of glycolic acid with lactones in the absence of catalysts. Eur Polym J 1990;26:457-61.

[166] Fukuzaki H, Yoshida M, Asano M, Kumakura M, Mashimo T, Yuasa H, et al. A new biodegradable copolymer of glycolic acid and lactones with relatively low molecular 
weight prepared by direct copolycondensation in the absence of catalysts. J Biomed Mater Res 1991;25:315-28.

[167] Matsumura S. Enzymatic synthesis of polyesters via ring-opening polymerization. In: Kobayashi S, Ritter H, Kaplan D, editors. Enzyme-catalyzed synthesis of polymers. Berlin, Heidelberg: Springer Berlin Heidelberg, 2005. p. 95-132.

[168] Champagne E, Strandman S, Zhu XX. Recent developments and optimization of lipasecatalyzed lactone formation and ring-opening polymerization. Macromol Rapid Commun 2016;37:1986-2004.

[169] Yang J, Liu Y, Liang X, Yang Y, Li Q. Enantio-, regio-, and chemoselective lipase-catalyzed polymer synthesis. Macromol Biosci 2018;18:1800131/1-9.

[170] Engel J, Cordellier A, Huang L, Kara S. Enzymatic ring-opening polymerization of lactones: Traditional approaches and alternative strategies. ChemCatChem 2019;11:498397.

[171] Nobes GAR, Kazlauskas RJ, Marchessault RH. Lipase-catalyzed ring-opening polymerization of lactones: A novel route to poly(hydroxyalkanoate)s. Macromolecules 1996;29:4829-33.

[172] Dong H, Wang H, Cao SG, Shen JC Lipase-catalyzed polymerization of lactones and linear hydroxyesters. Biotechnol Lett 1998;20:905-8.

[173] Gorke JT, Okrasa K, Louwagie A, Kazlauskas RJ, Srienc F. Enzymatic synthesis of poly(hydroxyalkanoates) in ionic liquids. J Biotechnol 2007;132:306-13.

[174] Kadokawa J, Iwasaki Y, Tagaya H. Ring-opening polymerization of lactones catalyzed by ion-exchanged clay montmorillonite. Green Chem 2002;4:14-6.

[175] Miura H, Tajima T, Nagata M, Royama T, Saito K, Hasegawa M. Synthesis of poly(ester ether)s by the reaction of $\gamma$-butyrolactone with diols and their application to polyurthaues. Kobunshi Ronbunshu 1999;56:291-7.

[176] Arasa M, Ramis X, Maria?? Salla J, Mantecón A, Serra A. FTIR/ATR study of the copolymerization of diglycidyl ether of bisphenol a with methyl-substituted $\gamma$-lactones catalyzed by rare earth triflate initiators. J Polym Sci Part A Polym Chem 2007;45:212941. 
[177] Arasa M, Ramis X, Salla JM, Mantecón A, Serra A. Kinetic study by FTIR and DSC on the cationic curing of a DGEBA $/ \gamma$-valerolactone mixture with ytterbium triflate as an initiator. Thermochim Acta 2008;479:37-44.

[178] Arasa M, Ramis X, Salla JM, Ferrando F, Serra A, Mantecón A. Study on the effect of rare earth metal triflates as initiators in the cationic curing of DGEBA $/ \gamma$-valerolactone mixtures and characterization of the thermosets obtained. Eur Polym J 2009;45:1282-92.

[179] Spegazzini N, Ruisánchez I, Larrechi MS, Serra A, Mantecón A. Two-dimensional Fourier transform infrared correlation spectroscopy and evolving factor analysis in the study of cationic curing of DGEBA and $\gamma$-valerolactone mixtures. J Polym Sci Part A Polym Chem 2008;46:3886-99.

[180] Arasa M, Ramis X, Salla JM, Mantecón A, Serra A. A study of the degradation of estermodified epoxy resins obtained by cationic copolymerization of DGEBA with $\gamma$-lactones initiated by rare earth triflates. Polym Degrad Stab 2007;92:2214-22.

[181] Arasa M, Ramis X, Salla JM, Mantecón A, Serra A. Anionic copolymerization of DGEBA with two bicyclic bis( $\gamma$-lactone) derivatives using tertiary amines as initiators. Polymer 2009;50:2228-36.

[182] Ohsawa S, Barkakaty B, Sudo A, Endo T. Acid-promoted double ring-opening reaction of bicyclobis ( $\gamma$-butyrolactone) with alcohol and its application to polyester synthesis. J Polym Sci Part A Polym Chem 2012;50:1281-9.

[183] Moins S, Loyer P, Odent J, Coulembier O. Preparation of a mimetic and degradable poly(ethylene glycol) by a non-eutectic mixture of organocatalysts (NEMO) via a one-pot two-step process. RSC Adv 2019;9:40013-6.

[184] Hu S, Zhao J, Zhang G. Noncopolymerization approach to copolymers via concurrent transesterification and ring-opening reactions. ACS Macro Lett 2015;5:40-4.

[185] Liu X, Hong M. Transesterification by air/moisture-tolerant bifunctional organocatalyst to produce 'nonstrained' $\gamma$-butyrolactone-based aliphatic copolyesters: Turning a bane into a boon. Eur Polym J 2019;121:109277/1-10. 